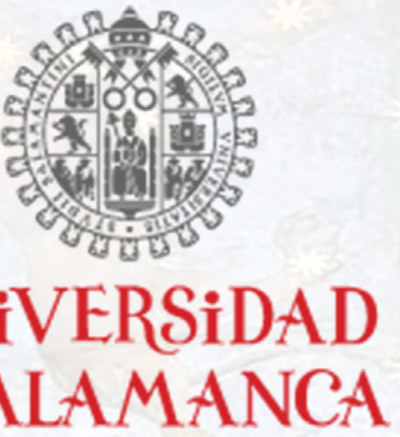

CAMPUS DE EXCELENCIA INTERNACIONAL

VNIVERSiDAD BSALAMANCA

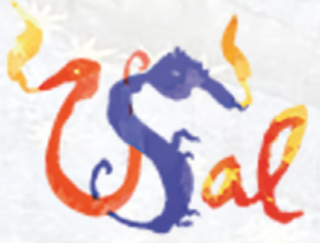

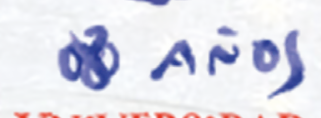

VNIVERSIDAD BSALAMANCA

$1218-2018$
BIOCIENCIAS:

BIOLOGÍA Y CLÍNICA DEL CÁNCER Y MEDICINA TRASLACIONAL. ANÁLISIS CLÍNICO DE TUMORES SÓLIDOS Y CÁNCER

\title{
ANÁLISIS EN UNA SERIE DE VIGILANCIA ACTIVA. FACTORES RELACIONADOS CON LA EVOLUCIÓN, LA CALIDAD DE VIDA Y LA ANSIEDAD
}

\section{D̃̃a. SARA MARCOS ASENSIO}

TESIS DOCTORAL ABRIL 2021

DIRECTORES

DR. FRANCISCO A. GÓMEZ VEIGA DR. ÁLVARO J. VIRSEDA RODRÍGUEZ 
"Lo importante no es lo que nos hace el destino, sino lo que nosotros le hacemos a él."

- In memorian, Florence Nightingale (1820-1910). 


\section{AGRADECIMIENTOS}

A todas las personas que a lo largo de este camino me ayudaron y apoyaron para que hoy esta tesis sea una realidad.

A mis directores de tesis, Dr. Francisco A. Gómez Veiga y Dr. Álvaro J. Virseda Rodríguez. Por enseñarme el valor del rigor científico, la mirada crítica y la metodología de investigación, por creer en mi y en el valor de la enfermera gestora de casos. Sin vuestra guía y vuestro apoyo no hubiera conseguido realizar uno de los mayores retos de mi vida profesional.

A mis pacientes. Por enseñarme realmente lo que significa ser enfermera.

A mis padres. Por ser mi modelo a seguir, creer en mis sueños y animarme a perseguirlos, por estar a mi lado en cada bache enseñándome levantarme de las caídas.

A mi hermano Luis. Por sacarme siempre una sonrisa sincera.

A mis abuelos, Cesar y Pepa, que desde las estrellas hoy estarán orgullosos.

A mis compañeros del grupo GITUR-IBSAL. Trabajando a vuestro lado, he crecido como profesional, pero también como persona.

A mis amigos, Sara H. y Álvaro V. Bendita "Vigilancia Activada" que un día unió nuestros caminos. Gracias por no dejar que me rindiera, por ser cobijo pero también alas en este proceso. No hubiera sido posible llegar al final sin teneros cerca. 


\section{ÍNDICE}

Relación de abreviaturas por orden de aparición.

Relación de imágenes, tablas y gráficos por orden de aparición.

\section{INTRODUCCIÓN}

1.1. La próstata.

1.1.1. Anatomía de la próstata.

1.1.2. Fisiología de la próstata.

1.2. El Cáncer de próstata.

1.2.1. Epidemiología.

1.2.2. Etiología.

1.2.3. Diagnóstico.

1.2.3.1. Cribado y diagnóstico precoz.

1.2.3.2. Diagnóstico clínico.

1.2.4. Anatomía Patológica.

1.2.4.1. Clasificación Grado Gleason.

1.2.4.2. Clasificación "The International Society of Urological Pathology".

1.2.5. Estadiaje.

1.2.5.1. TNM.

1.2.5.2. Asociación Europea de Urología.

1.2.5.3. National Comprehensive Cancer Network.

1.2.6. Tratamiento.

1.3. La Vigilancia Activa.

1.3.1. Qué es y uso como tratamiento del Cáncer de Próstata.

1.3.2. Historia.

1.3.3. Criterios de inclusión y seguimiento.

1.3.4. Dificultades y controversias.

1.4. Calidad de vida y ansiedad en los pacientes en Vigilancia Activa. Enfermera gestora de casos: su papel en el manejo de la ansiedad y la calidad de vida.

1.4.1. Calidad de vida y ansiedad en pacientes en Vigilancia Activa.

1.4.2. Evaluación de la calidad de vida y la ansiedad: cuestionarios.

1.4.3. Enfermera gestora de casos y su papel en el programa de Vigilancia Activa.

\section{HIPÓTESIS Y OBJETIVOS DEL ESTUDIO.}

2.1. Hipótesis.

2.2. Objetivos.

\section{MATERIAL Y MÉTODOS.}

3.1. Generalidades.

3.2. Método.

3.2.1. Selección muestral.

3.2.2. Diseño y Consentimiento informado.

3.3. Análisis estadísticos.

3.4. Conflicto de intereses.

\section{RESULTADOS.}

4.1. Análisis del Cáncer de Próstata en Salamanca: 2014-2020.

4.2. Análisis descriptivo de los pacientes en Vigilancia Activa en Salamanca: 2014-2020.

4.3. Análisis de la adherencia al protocolo de Vigilancia Activa en Salamanca: 2014-2020.

4.4. Análisis de la salida del protocolo, motivos salida, progresión y estatus de los pacientes.

4.5. Análisis de la calidad de vida y los niveles de ansiedad de los pacientes en el protocolo de VA.

\section{DISCUSIÓN.}

6. LIMITACIONES DEL ESTUDIO.

7. CONCLUSIONES.

8. BIBLIOGRAFÍA.

9. ANEXOS. 
RELACION ABREVIATURAS SEGÚN ORDEN DE APARICIÓN.

\begin{tabular}{|c|c|}
\hline HBP & Hiperplasia Benigna de Próstata \\
\hline DHT & Dihidrotestosterona \\
\hline $\mathrm{CP}$ & Cáncer de Próstata \\
\hline PSA & Antígeno Prostático Específico \\
\hline REDECAM & Red Española de Registros de Cáncer \\
\hline SEOM & Sociedad Española de Oncología Médica \\
\hline $\mathrm{CV}$ & Calidad de vida \\
\hline AVAC & Años de vida ajustados por calidad \\
\hline USPSTF & US Preventive Services Task Force \\
\hline EUA & Asociación Europea de Urología \\
\hline TR & Tacto rectal \\
\hline SV & Sonda Vesical \\
\hline RMN & Resonancia Nuclear Magnética \\
\hline VA & Vigilancia Activa \\
\hline GG & Grado de Gleason \\
\hline ISUP & The International Society of Urological Pathology \\
\hline AJCC & The American Joint Committee on Cancer \\
\hline TAC & Tomografía Axial Computarizada \\
\hline GGO & Gammagrafía Ósea \\
\hline PET & Tomografía por Emisión de Positrones \\
\hline LBR & Localizado Bajo Riesgo \\
\hline LRI & Localizado Riesgo Intermedio \\
\hline LAR & Localizado Alto Riesgo \\
\hline $\mathrm{NCCN}$ & National Comprehensive Cancer Network \\
\hline LMBR & Localizado Muy Bajo Riesgo \\
\hline FRI & Factores de Riesgo intermedio \\
\hline LRIF & Localizado Riesgo Intermedio Favorable \\
\hline LRID & Localizado Riesgo Intermedio Desfavorable \\
\hline LMAR & Localizado Muy Alto Riesgo \\
\hline PR & Prostatectomía radical \\
\hline RT & Radioterapia \\
\hline IMRT & Radioterapia de intensidad modulada \\
\hline SBRT & Radioterapia estereostática extracraneal \\
\hline
\end{tabular}

Braquiterapia

Hormonoterapia

Hormona liberadora de hormona luteinizante

Cancer de próstata resistente a castración

Quimioterapia

Estrategia diferida

Superantiandrógenos

Esperar y ver

Prostate Cancer Research International Active Surveillance

Asociación Española de Urología

National Prostate Cancer Register of Sweden

Complejo Asistencial Universitario de Salamanca

National Institute for Health and Care Excellence

Organización Mundial de la Salud

CVRS Calidad de Vida Relacionada con la Salud

CAVIPRES Cuestionario Español de Calidad de Vida en Pacientes con Cáncer de próstata

QLQ-C3O European Organization Research and Treatment of Cancer. Quality of Life QUESTIONNAIRE Core 30

QLQ-PR-25 European Organization Research and Treatment of Cancer. Quality of Life QUESTIONNAIRE for prostate cancer patients

SF-12 12-items short form health survey

SF-36 36-items short form health survey

UCLA-PCI University of California-Los Angeles Prostate Cancer Index

WHOQOL World Health Organization Quality of Life

EPIC Expanded Prostate INDEX Composite

FACT-P Functional Assessment of Cancer THERAPY- Prostate

NHS National Health Service

HTA Hipertensión arterial

DM Diabetes Mellitus

DL Dislipemia

CEIM Comité de Ética de Investigación con Medicamentos

RTU-P Resección Transuretral Prostática

SMD Síndrome Mielodisplásico

EVA $\quad$ Escala Visual Analógica

AECC Asociación Española Contra el Cáncer

SCE Supervivencia Cáncer Específica 


\section{RELACIÓN ABREVIATURAS SEGÚN ORDEN DE APARICIÓN.}

\section{RELACIÓN DE IMÁGENES}

Imagen 1. Corte transversal de la próstata

Imagen 2. Topografía prostática

Imagen 3. Tacto rectal

Imagen 4. Biopsia prostática transrectal

\section{RELACION DE TABLAS}

Tabla 1. Grados de Gleason

Tabla 2. Relación ISUP vs Grados Gleason

Tabla 3. Clasificación TNM Cáncer de Próstata

Tabla 4. Grupos de riesgo de recaída bioquímica EAU

Tabla 5. Clasificación NCCN para Cáncer de Próstata

Tabla 6. Criterios de inclusión en VA de las principales series

Tabla 7. Cuestionarios más utilizados para la valoración de la $\mathrm{CV}$ en pacientes con CP

Tabla 8. Evolución de la VA a lo largo de los años de estudio

Tabla 9. Puntuaciones globales CAVIPRES en relación con el estado civil, tratamiento urológico y tiempo en VA

Tabla 10. Puntuaciones apartado psicológico CAVIPRES en relación con el estado civil, tratamiento urológico y tiempo en VA

Tabla 11. Puntuaciones apartado futuro CAVIPRES en relación con el estado civil, tratamiento urológico y tiempo en VA

Tabla 12. Puntuaciones apartado vida sexual CAVIPRES en relación con el estado civil, tratamiento urológico y tiempo en VA

Tabla 13. Puntuaciones apartado apoyo CAVIPRES en relación con el estado civil, tratamiento urológico y tiempo en VA

Tabla 14. Relación ansiedad - momento de recogida datos

Tabla 15. Relación ansiedad-CVRS

Tabla 16. Relación ansiedad-apartado psicosocial CAVIPRES

Tabla 17. Relación ansiedad con la edad de los pacientes

\section{RELACIÓN DE GRÁFICOS}

Gráfico 1. Estimación de tumores en los varones españoles en el año 2020

Gráfico 2. Estimación de la mortalidad según los distintos tipos de tumores en el año 2018 en el mundo Gráfico 3. Tratamiento CP en función del grupo de riesgo NCCN

Gráfico 4. Tratamientos más utilizados según los grupos de riesgo de la EUA

Gráfico 5. Evolución de la VA a lo largo de los años de estudio

Gráfico 6. Comorbilidades pacientes VA

Gráfico 7. Motivos de no realización de RMN

Gráfico 8. Motivos de no realización de re-biopsia

Gráfico 9. Motivos clínicos salida VA

Gráfico 10. Tratamiento realizado tras la salida de VA según el motivo de la salida Gráfico 11. CVRS por apartados 
1. INTRODUCCIÓN 


\section{INTRODUCCIÓN.}

\subsection{LA PRÓSTATA.}

\subsubsection{ANATOMÍA DE LA PRÓSTATA.}

La próstata es la glándula accesoria más grande del aparato genital masculino. Es una glándula unitaria que se encuentra situada en la pelvis menor rodeando a la uretra prostática, inmediatamente inferior a la vejiga. [1]

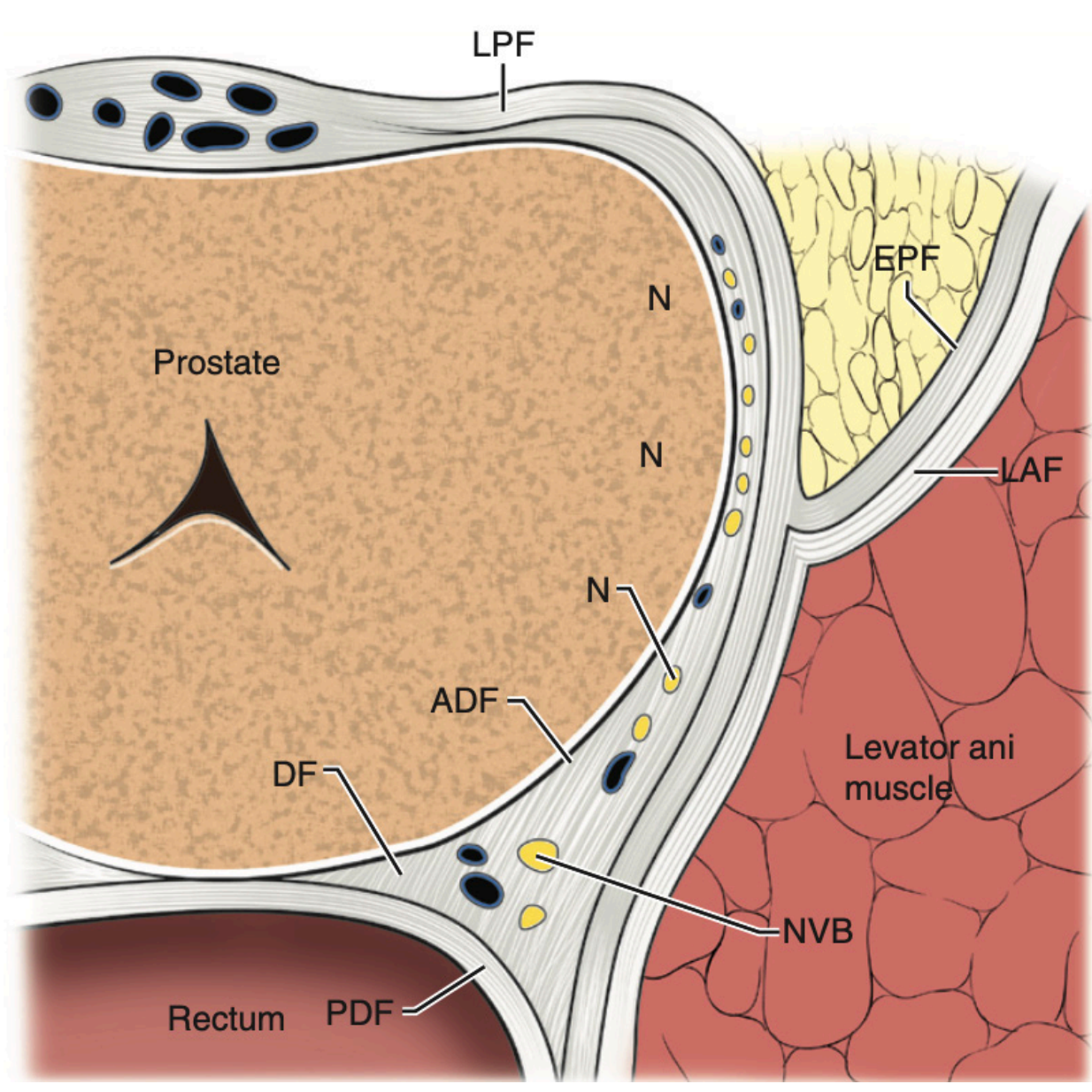

Imagen 1. Corte transversal de la próstata [2]

La próstata se describe como un órgano con forma cónica y aplastada de delante a atrás, la cual alcanza su máximo desarrollo en la etapa adulta. Alcanzado un tamaño de 28-30 $\mathrm{mm}$ de altura por $40 \mathrm{~mm}$ de anchura y 25 $\mathrm{mm}$ de espesor, y un peso aproximado de 20-25 gramos. Estas medidas varían entre individuos y a lo largo de la vida de los varones, puesto que el crecimiento de la misma es hormonodependiente. Llega a su punto máximo hacia los 25 años, momento en el cual sufrirá un estancamiento hasta la cuarta década de la vida, en la cual se podrán producir marcados crecimientos debido a la aparición de procesos adenomatosos, lo que es conocido como Hiperplasia Benigna de Próstata (HBP)
Embriológicamente, la próstata tiene su origen al finalizar el tercer mes de gestación en el epitelio endodérmico correspondiente a la uretra prostática primitiva. De esta, comienzan a proliferar unas yemas, las cuales se rodearán de tejido mesodérmicos, el cual en el varón tiene como resultado la próstata y en la mujer las glándulas uretrales y parauretrales. [4]

Histológicamente, la próstata está formada tenido glandular (70\%) y tejido fibromuscular (30\%). [4]

Para describir anatómicamente la próstata, la primera clasificación descrita fue la clasificación de Lowsley, la cual divide la glándula prostática en 5 lóbulos: anterior, posterior, medio, lateral derecho y lateral izquierdo [5]. Más tarde, en 1980, McNeal divide la glándula prostática en 5 partes: periférica, central, transicional y fibromuscular anterior, zona de las glándulas periuretrales [6]. Este modelo es el aceptado en la actualidad para describir la anatomía de la próstata.
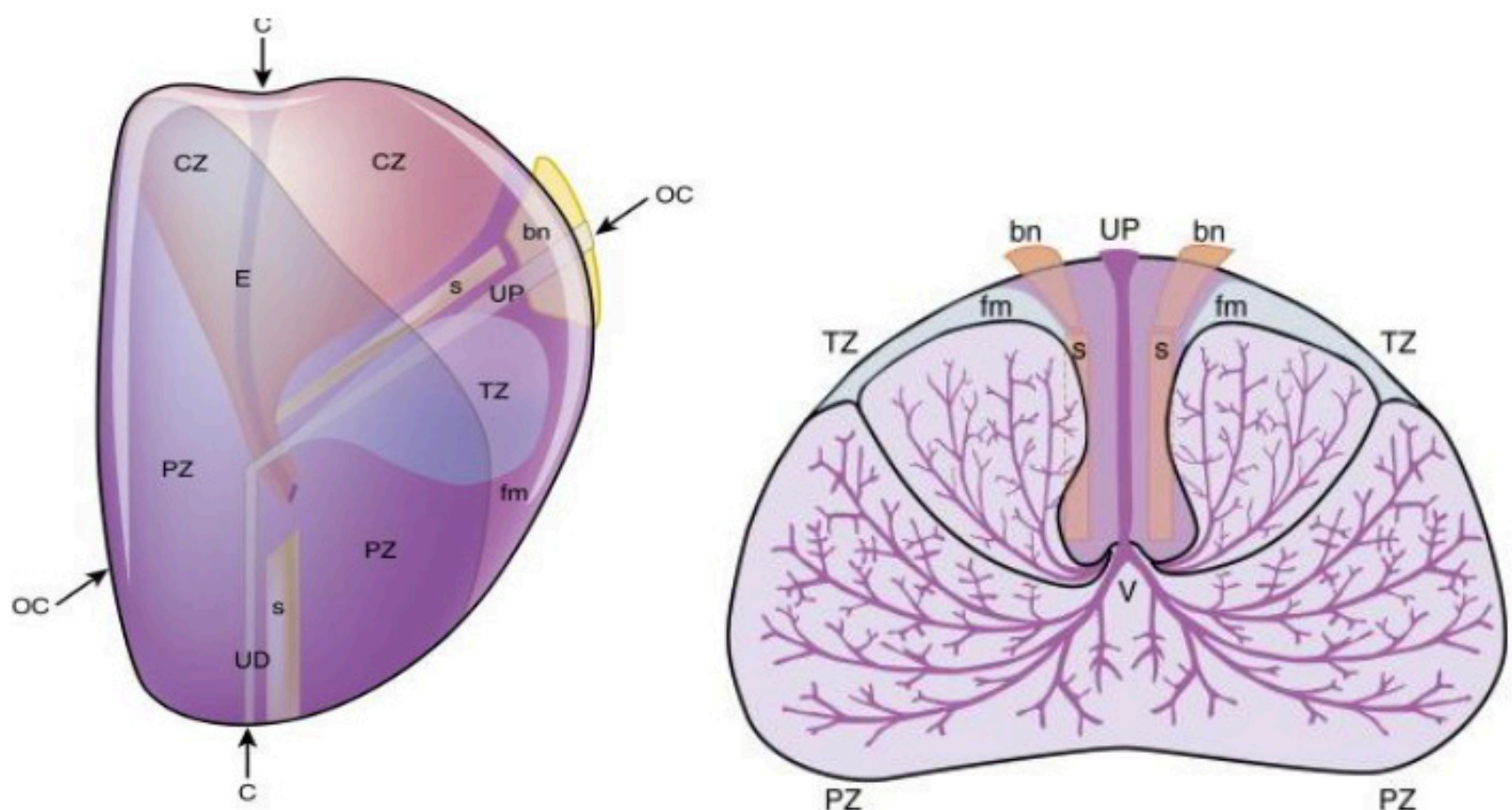

Imagen 2. Topografía prostática

1. Corte sagital.

Corte transversal.

La próstata se encuentra alrededor de la uretra y los conductos eyaculadores en la llamada encrucijada urogenital. Debajo de la vejiga, encima de la aponeurosis perineal media, limitada entre la sínfisis púbica por delante y el recto por detrás. La uretra prostática atraviesa la próstata desde la base al ápex describiendo una trayectoria oblicua que cruza el eje mayor de la próstata de adelante hacia atrás, en su región media se encuentra el verumontanum, en cuyos surcos laterales desembocarán los conductos excretores de las glándulas prostáticas de la región central y periférica. En la región medial de la zona caudal del verumontanum desembocará el utrículo prostático, rudimento que se dirige hacia atrás dividiendo la región periférica de la glándula en lóbulo derecho e izquierdo así como los conductos eyaculadores, que bordearán por fuera la región transicional continuándose con las vesículas seminales que se encontrarán inmersas en la zona central de la glándula. Las relaciones extrínsecas de la próstata estarán delimitadas por el llamado compartimento prostático o zona de Retzius, cápsula formada por la condensación del tejido celular pélvico periprostático que contiene la glándula prostática rodeada de una serie plexos venosos donde irán a parar las venas prostáticas y la mayoría de las venas vesicales. $[8,9]$ 
En cuanto a la vascularización prostática, las arterias que la irrigan son ramas de la arteria hemorroidal media y de la arteria pudenda interna, así como una rama de la arteria hipogástrica. Las venas emergen del espesor de la glándula y tienen especial relevancia las de la región anterior donde se forma el plexo de Santorini y en las regiones laterales donde al confluir las venas vesicales se forma la vena genitovesical de Farabeuf. [10]

La inervación prostática es realizada por el ganglio hipogástrico, el cual da ganglios sensitivos y secretorios encargados de la función puramente glandular, y otros motores los cuales están destinados a las fibras musculares de estroma y a los vasos. [10]

\subsubsection{FISIOLOGÍA DE LA PROSTATA.}

Para entender la fisiología prostática, lo primero que debemos tener en cuenta, es, como hemos dicho anteriormente, que la próstata es una glándula hormonodependiente. A continuación vamos a ver cuales son las hormonas más importantes implicadas en el funcionamiento de la próstata.

En primer lugar, tenemos la testosterona, que es una hormona masculina que ejerce su acción por un mecanismo de difusión por la membrana. Actúa sin canales específicos sobre el receptor androgénico a través de su metabolito activo, la dihidrotestosterona (DHT) [11,12]. Para la conversión de testosterona en DHT es necesaria la 5-alfa reductasa. Esta es una isoenzima que se produce mayoritariamente en el estroma prostático y en menor cantidad en las células basales del epitelio [13]

En segundo lugar, tenemos los estrógenos. Los estrógenos pueden ser aromatizados a andrógenos en un reacción metabólica irreversible. Estas reacciones son parte del origen de la HBP, pero también lo seráń de Cancer de Próstata (CP). [13]

\section{En la próstata tenemos los tipos de receptores estrogénicos: [11]}

- Receptores alfa: únicamente presentes en el estroma

Receptores beta: en las células secretoras luminales del epitelio.

En tercer lugar, nos encontramos con los factores de crecimiento, los cuales necesitan receptores específicos Estos factores intervienen en el efecto mitogénico que tienen los andrógenos en el crecimiento prostático. [11,12]

Finalmente, la próstata, también secreta varias proteínas como pueden ser: fosfatasa ácida, seminina, activado de plasminógeno y antígeno prostático específico (PSA) [1,13]. El PSA es una serin-proteasa, cuya función fisiológica es disolver el semen coagulado, que se forma por acción de las proteínas de las vesículas seminales, a los pocos minutos de la eyaculación. Un aumento de su cantidad en la sangre acompaña frecuentemente a u crecimiento anormal de la glándula, por lo cual el PSA es el marcador más importante, hasta la fecha, para la detección del cáncer de próstata, si bien no es un marcador específico de enfermedad tumoral, sino de crecimiento prostático. $[1,13]$ El PSA también existe en el suero en forma libre (PSA libre) o unido a inhibidores de proteasas (principalmente $\alpha-1$ antiquimiotripsina) $[2,13,14]$

\subsection{EL CÁNCER DE PRÓSTATA.}

\subsubsection{EPIDEMIOLOGÍA}

El Cáncer de Próstata (CP) es el tumor más prevalente en el varón adulto en el mundo [15]. Según datos de la American Cancer Society, en el año 2019 en Estados Unidos se diagnosticaron 174.650 tumores de próstata de novo, lo cual supone que más de 3,6 millones de varones estadounidenses han sido diagnosticados de CP. [16]

En España, la Red Española de Registros de Cáncer (REDECAM) estima que en el año 2020 se diagnosticarán 35.126 tumores de próstata, siendo dicho tumor el de mayor número de diagnósticos en el varón, seguido del cáncer colorrectal y pulmonar respectivamente. [17] A mayores de lo reportado por la REDECAM, en España existen registros específicos para informar de la incidencia y prevalencia del CP, como son el Registro Nacional de Cáncer de Próstata y el Registro de Castilla y León de Cáncer de Próstata (CAPCYL) $[18,19]$

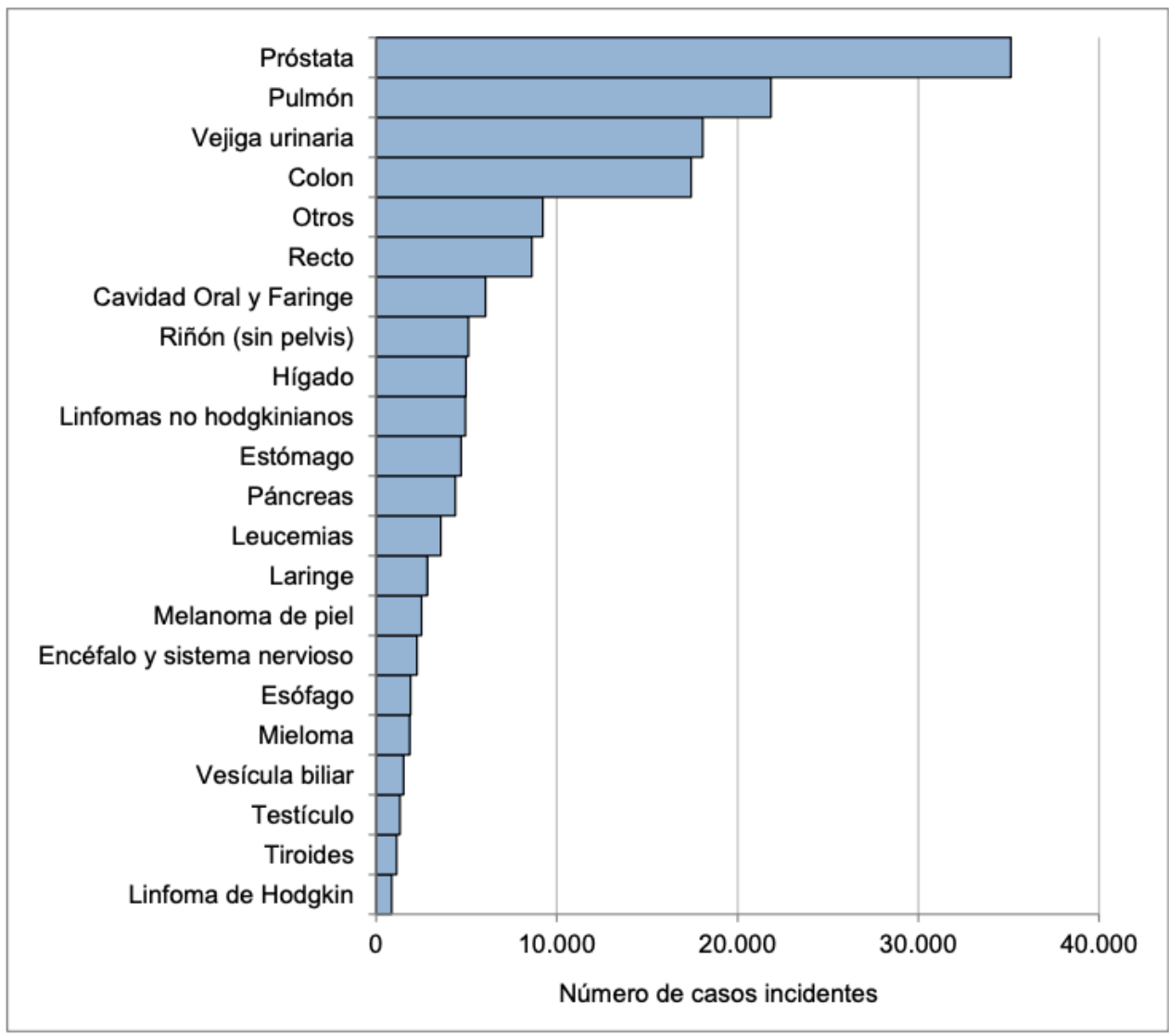

Fuente: Red Española de Registros de Cáncer

Gráfico 1. Estimación de tumores en los varones españoles en el año 2020. Fuente REDECAM. [17]

Sin embargo, contrariamente a lo esperado debido a su alta prevalencia, la mortalidad del CP es mucho más baja. Según datos comunicados por la American Cancer Society y la Sociedad Española de Oncología Medica (SEOM) solamente el 3,8\% de los pacientes con CP en el mundo, en el año 2018, falleció a causa de dicho tumor, frente al 18,4\% de los pacientes que padecían un tumor pulmonar. [20] En España, la REDECAM recoge una supervivencia neta a 5 años del $89,8 \%$ de los pacientes con CP. [20] 


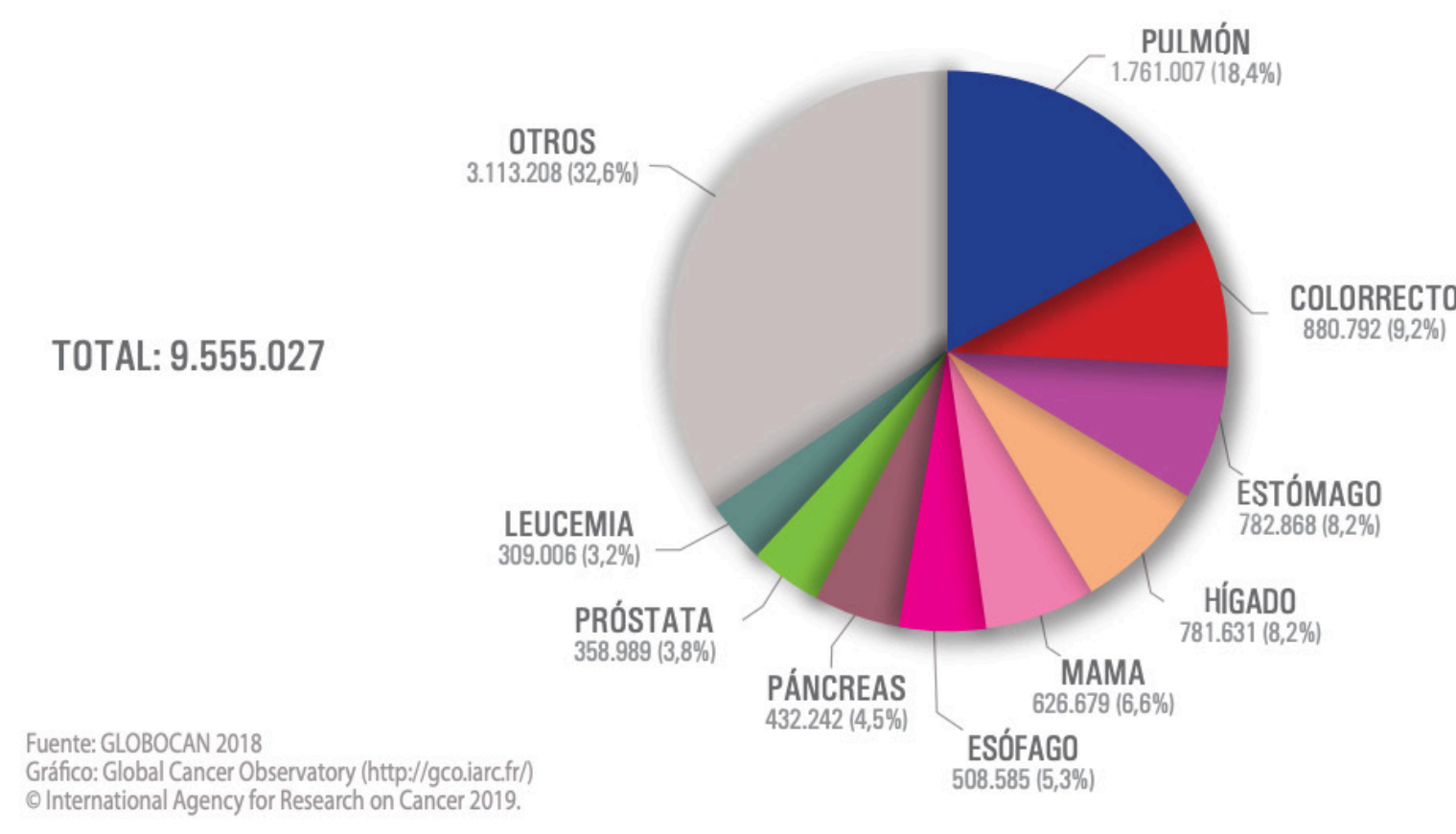

Gráfico 2. Estimación de mortalidad según los distintos tipos de tumores en el año 2018 en el mundo. Fuente SEOM [20]

\subsubsection{ETIOLOGÍA.}

Actualmente, seguimos sin conocer las causas directas responsables del CP. Sin embargo, si que se conoce que existen diversos factores que aumentan el riesgo de aparición de la enfermedad.

\section{Edad}

La edad se ha identificado como uno de los factores principales para la aparición del CP. La prevalencia del CP aumenta en relación directamente proporcional con la edad, de forma más rápida que pueda ocurrir en cualquier otro tipo de cáncer.

Menos de un 1\% de los casos de cáncer de próstata se diagnostican antes de los 40 años [21]. Datos derivados de estudios de autopsia muestran que, entre el $30 \%$ y el $40 \%$ de los hombres mayores de 50 años presentan evidencia histológica de la enfermedad y aproximadamente el $70 \%$ de los hombres mayores de 70 años [6, 22]

\section{Etnia y herencia genética}

La historia familiar y la etnia son dos factores asociados al aumento de la incidencia del CP, por lo que se sugiere que existe una predisposición genética a padecer $\mathrm{CP}$, aunque solamente una pequeña parte (alrededor del $9 \%$ ) de los diagnósticos de $\mathrm{CP}$ tienen una verdadera condición hereditaria. [23, 24]

En el caso de los CP hereditarios se asocia con un inicio más temprano de la enfermedad, pero no cambios en la agresividad ni en el curso clínico de la misma. [24,25] Los varones con un familiar de primer grado con diagnóstico de $\mathrm{CP}$ tienen mayor riesgo de padecer $\mathrm{CP}$, y este riesgo aumenta si los familiares son el padre y un hermano y aún más si son dos hermanos. [26]
Aún se está estudiando los determinantes subyacentes de la diversidad genómica y de los mecanismos entre los factores genéticos y ambientales, pero está aceptado que los varones de ascendencia africana muestran mayor incidencia de CP y con una agresividad mayor que los varones de ascendencia caucásica. [27]

Actualmente se está estudiando la incidencia de las mutaciones de la línea germinal de algunos genes en el desarrollo del CP. Las mutaciones en los genes BRCA 1, BRCA 2 y HOXB13 se han asociado con un mayor riesgo de $\mathrm{CP}$, por lo que un análisis genómico dirigido a estos genes podría ayudar a identificar familiar de alto riesgo de padecer CP. [28,29]

\section{Otros factores de riesgo}

A lo largo de la historia, se ha debatido ampliamente la existencia de factores exógenos asociados al desarrollo de $\mathrm{CP}$ o cuya etiología impacte en la progresión del CP latente a CP clínico. [30]

Algunos de estos factores de riesgo son:

- Síndrome metabólico

- El uso de metformina como tratamiento de la diabetes mellitus

- El uso de estatinas

- La obesidad

- Factores asociados a la dieta

\subsubsection{DIAGNÓSTICO.}

1.2.3.1. CRIBADO Y DIAGNÓSTICO PRECOZ.

El cribado se define como "examen sistemático de los varones asintomáticos de riesgo, iniciado por parte de las autoridades sanitarias”. El objetivo del cribado es reducir la mortalidad por CP y aumentar la calidad de vida (CV) expresada como años de vida ajustados por calidad (AVAC). [31]

Actualmente, el cribado poblacional del CP continúa siendo uno de los temas más controvertidos en los foros urológicos internacionales [32] Esto se debe a que un cribado masivo, puede dar lugar a un sobrediagnóstico y por tanto un sobretratamiento mayor, que la realización de un cribado oportunista. [33]

En el año 2017, The US Preventive Services Task Force (USPSTF), publicó un informe en el cual los varones de entre 55-69 debían ser informados sobre los perjuicios y beneficios de una determinación sistemática de PSA, puesto que el beneficio en supervivencia era bajo. Esto supuso un cambio de paradigma, al desestimarse un cribado masivo con PSA, y recomendarse un cribado individualizado basado en las características personales de los pacientes. [34]

Las recomendaciones de la Asociación Europea de Urología (EUA), en la última actualización de sus guías clínicas, sobre el diagnóstico precoz del CP son: [31]

- No someter a los hombres a la una determinación de PSA sin asesorarlos sobre los posibles riesgos y beneficios. - Ofrecer una estrategia individualizada y adaptada al riesgo para la detección temprana a un hombre bien informado y una esperanza de vida de al menos 10 a 15 años.

- Ofrecer pruebas de PSA tempranas a hombres bien informados con riesgo elevado de tener CP: 
- Varones > 50 años;

-Varones > 45 años y antecedentes familiares de $\mathrm{CP}$

-Varones afrodescendientes $>45$ años;

-Varones portadores de mutaciones BRCA2> 40 años.

- Ofrecer una estrategia adaptada al riesgo (basada en el nivel de PSA inicial), con intervalos de seguimiento de 2 años para los que inicialmente están en riesgo:

- Varones con un nivel de PSA> $1 \mathrm{ng} / \mathrm{mL}$ a los 40 años;

- Varones con un nivel de PSA> 2 ng / mL a los 60 años;

- Aplazar el seguimiento hasta 8 años en aquellos que no están en riesgo.

- Detener el diagnóstico temprano de CP en función de la esperanza de vida y el estado funcional; es poco probable que se beneficien los hombres que tienen una esperanza de vida $<15$ años.

\subsubsection{DIAGNÓSTICO CLÍNICO.}

Para el diagnóstico clínico del CP debemos tener en cuanta principalmente 3 parámetros: los niveles de PSA, el tacto rectal (TR) y la biopsia prostática.

\section{Niveles de PSA.}

Como decíamos anteriormente, el PSA es una serin-proteasa secretada por la próstata. Su descubrimiento en el año 1971 supuso una revolución en el diagnóstico del CP. [35,36] El PSA no es un marcador tumoral, sino un marcador de la glándula, por lo que las elevaciones del mismo pueden deberse a causa tumoral o no. [37] De manera general, se considera normal unos niveles de PSA entre o-4 ng/mL, si bien no existen unos valores de referencia aceptados de manera internacional [38].

Debemos tener en cuenta que la realización de procedimientos invasivos (colonoscopia, TR, cistoscopia...) práctica de deportes de impacto, las infecciones de orina, las sondas vesicales (SV) o las relaciones sexuales, en los días previos a la toma de muestra para la determinación del PSA pueden alterar los valores de la misma. [39]

\section{Tacto rectal.}

El TR continúa siendo, junto con la determinación de PSA, la primera prueba en el diagnóstico del CP. Es una prueba poco sensible y con grandes limitaciones, puesto que está altamente influido por la experiencia de la persona que lo realiza. [40]

La mayoría de los CP se localizan en la zona periférica de la glándula prostática, por lo que si tienen un volumen mayor de 0,2 mL podrán localizarse mediante palpación a la hora de realizarse el TR. [41]

Siempre que sospechemos de un TR anormal se deberá indicar al paciente la realización de una biopsia, puesto que se asociada con un mayor riesgo de $\mathrm{CP}$ de alto grado. $[42,43]$

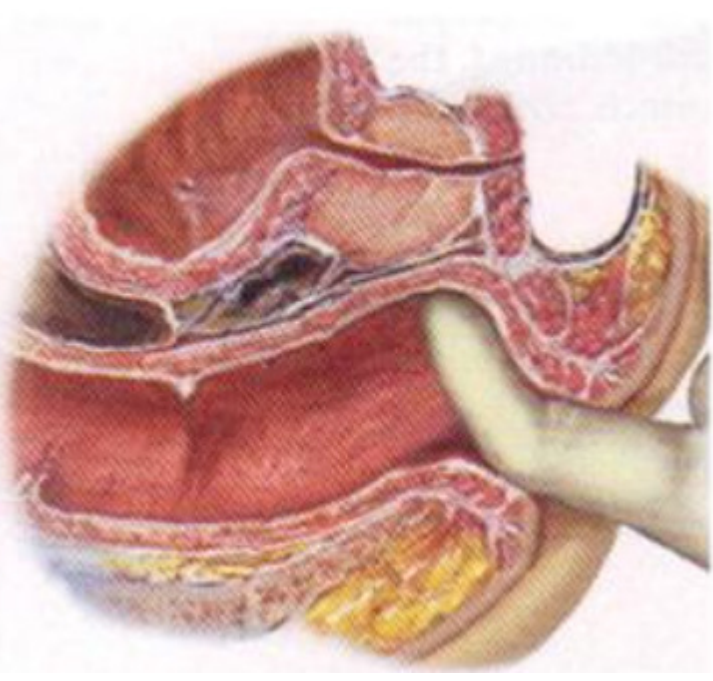

Imagen 3. Tacto rectal [44]

\section{Biopsia prostática}

La biopsia prostática consiste en la toma de tejido prostático para su análisis anatomopatológico. Está indicada en los pacientes con varias elevaciones de PSA por encima del límite considerado normal y/o tacto rectal patológico. Hay que tener en cuenta la edad, las comorbilidades y las posibilidades terapéuticas que el paciente va a tener tras la realización de la biopsia. [45].

La forma más frecuente de realización de esta biopsia es guiada mediante una ecografía por abordaje transrectal, aunque también es posible hacerlo mediante abordaje transperineal. [46]

Los avances en las técnicas diagnósticas, y sobre todo en las pruebas de imagen, cambiaron el paradigma del diagnóstico del $\mathrm{CP}$, con la introducción de la Resonancia Magnética Nuclear (RMN) [47] Actualmente, la RMN está indicada en los pacientes con biopsias previas negativas para guiar las biopsias sucesivas, pudiéndose realizar mediante técnica de fusión cognitiva o fusión softwares, dependiendo de los medios de los que dispongamos en nuestro centro de trabajo. De la misma manera, la RMN está indicada en los protocolos de Vigilancia Activa (VA) previamente a la realización de las rebiopsias tras el diagnóstico, como veremos más adelante.

La biopsia prostática es una técnica invasiva que no está exenta de complicaciones. La complicación más frecuente, es la infección urinaria posterior a la misma. Las guías de la EAU recomiendan el uso de antibiótico oral o intravenoso previo a la realización de la biopsia [31]. Otras complicaciones son la hematuria y la hemospermia en los días posteriores a la realización de la técnica.

\subsubsection{ANATOMÍA PATOLÓGICA.}

1.2.4.1. CLASIFICACIÓN GRADO GLEASON

\begin{tabular}{|cc|}
\hline Grado de Gleason (GG) & Patrón \\
\hline GG 6 & $3+3$ \\
\hline GG 7 & $3+4$ \\
\hline & $4+3$ \\
\hline GG 8 & $4+4$ \\
\hline GG 9 & $4+5$ \\
\hline & $5+4$ \\
GG 10 & $5^{+5}$ \\
\hline
\end{tabular}

Tabla 1. Grados de Gleason [48]

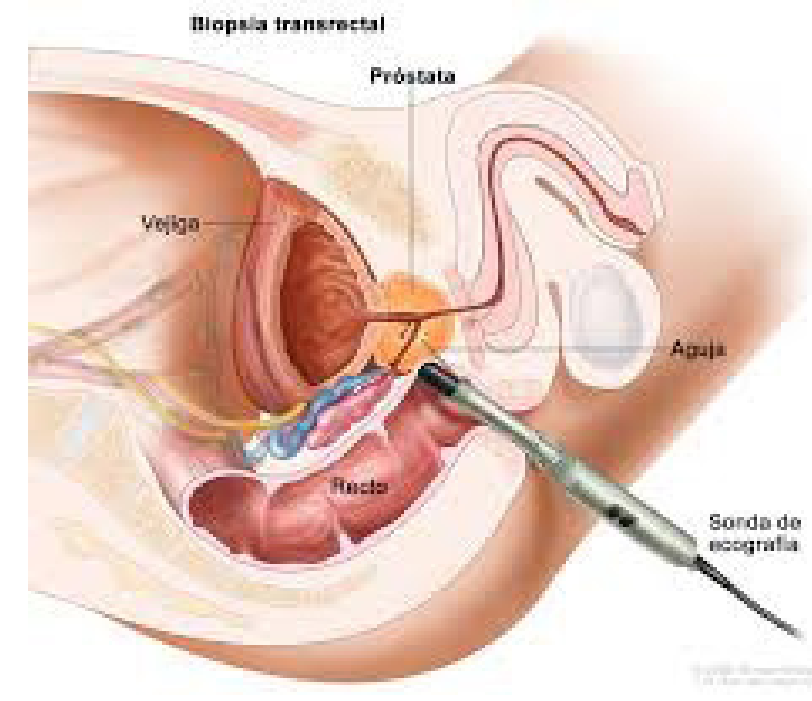

Imagen 4. Biopsia prostática transrectal. Fuente: Internet 
1.2.4.2. CLASIFICACIÓN "THE INTERNATIONAL SOCIETY OF UROLOGICAL PATHOLOGY" (ISUP).

Tal y como se comenta en el apartado anterior, la clasificación del Grado Gleason lleva siendo utilizada por la comunidad urológica internacional desde hace más de 40 años para clasificar los tumores prostáticos, pero en el año 2005, The International Society of Urological Pathology (ISUP), publicó por consenso, una nueva clasificación anatomopatológica del CP basada en los grados Gleason. [50] Esta clasificación se basa en 5 grupos fundamentados en la puntuación Gleason [50].

\begin{tabular}{cc} 
ISUP & Gleason \\
\hline ISUP 1 & $3+3$ \\
\hline ISUP 2 & $3+4$ \\
\hline ISUP 3 & $4+3$ \\
\hline ISUP 4 & $4+4$ \\
ISUP 5 & $4+5$ y $5+5$
\end{tabular}

Tabla 2.

Relación ISUP vs Grado Gleason [48,50]
Esta clasificación fue revisada por la propia ISUP en 2014, en la cual, se desarrolló de manera más clara la clasificación propuesta en el año 2005 y se clarificaron los criterios morfológicos, actualizándose la definición anatomopatológica del Gleason patrón 4. [51]

Y nuevamente en el año 2019, la ISUP volvió a revisar su clasificación, puesto que los avances diagnósticos en el campo del CP hacían necesaria una nueva modificación sobre la clasificación inicial propuesta en el año 2005. [52] Las modificaciones aprobadas por la ISUP en el 2019 no suponen un cambio sustancial en la clasificación ISUP sino en la manera de realizar los informes de anatomía patológica y la importancia de reseñar en los mismo el patrón anatomopatológico de los cilindros de la biopsia que se toman guiados por la RMN [52].

\subsubsection{ESTADIAJE.}

Los sistemas de clasificación de tumores se utilizan en la práctica clínica con el objetivo de poder agrupar pacientes con características clínicas similares y así poder diseñar ensayos clínicos en poblaciones homogéneas para poder comparar los datos clínicos y patológicos para desarrollar recomendaciones de tratamiento para los distintos grupos.

\subsubsection{TNM}

El Sistema TNM para la clasificación de los tumores fue desarrollado por The American Joint Committee on Cancer (AJCC) cuya primera edición fue publicada en 1977. La última actualización de dicha clasificación es la octava edición que entró en vigor el 1 de enero de 2018. [53]

Esta clasificación se elabora para todos los tipos de tumores y es realizada teniendo en cuenta 3 parámetros: [54]

- T: tumor. Hace referencia al tamaño de tumor primario y a su extensión contigua. El rol de la T está definido específicamente para cada tipo de tumor.

- N: nódulos. El rol de la $\mathrm{N}$ se define con la presencia o ausencia de ganglios en la zona regional.

- M: metástasis. Se catalogan las metástasis a distancia respecto al tumor primario.
En el caso del CP, la categorización de T puede realizarse de manera clínica (cT), que sería la información obtenida de los estudios de imagen así como del tacto rectal realizado por el urólogo. O de manera anatomopatológica, cuando se realiza una prostatectomía radical y se analiza la pieza completa (pT). [53]

La categorización $\mathrm{N}$ se obtiene por estudios de imagen, tanto Tomografía Axial Computarizada (TAC) como RMN y se consideran aquellos nódulos de la región pélvica, hasta la bifurcación de las arterias iliacas comunes. [53]

La categorización M se obtiene también por estudios de imagen, tanto TAC, RMN como estudios de medicina nuclear como la Gammagrafía Ósea (GGO) o la Tomografía por Emisión de Positrones (PET); considerando diseminación a distancia todo aquello que se encuentre fuera de la región pélvica, bien sea a nivel ganglionar, visceral u óseo. Los lugares más frecuentes para la aparición de metástasis no ganglionares del CP son las lesiones óseas, seguidas las metástasis a nivel pulmonar y hepático. [53].

La clasificación TNM para el CP aparece recogida en la siguiente tabla.

\begin{tabular}{|cc|}
\hline Categoría & Criterio \\
\hline cT & No se puede evaluar el tumor primario \\
\hline cTx & No evidencia de tumor primario \\
\hline cTo & Tumor clínicamente inaparente que no es palpable \\
\hline cT1 & Tumor incidental en $5 \%$ o menor el tejido resecado \\
\hline cT1a & Tumor incidental en más del $5 \%$ del tejido resecado \\
\hline cT1b & Tumor identificado por biopsia pero no palpable \\
\hline cT1c & Tumor palpable y confinado en la próstata \\
\hline cT2 & Tumor que abarca la mitad o menos de un lóbulo \\
\hline cT2a & Tumor que abarca más de la mitad de un único lóbulo \\
\hline cT2b & Tumor que abarca ambos lóbulos \\
\hline cT2c & Tumor extraprostático que no se fija o no invade la \\
\hline estructura adyacente \\
\hline cT3 & Extensión extraprostática (unilateral o bilateral) \\
\hline cT3b & Tumor invade vesículas seminales \\
\hline cT4 & Tumor se fija o invade estructuras adyacente distintas \\
a las vesículas seminales
\end{tabular}




\begin{tabular}{|c|c|}
\hline Nx \\
\hline No \\
\hline N1 \\
\hline M \\
\hline Mx \\
\hline Mo \\
\hline M1 \\
\hline M1a \\
\hline M1b \\
\hline M1c \\
\hline
\end{tabular}

Nódulos regionales no evaluados
No nódulos regionales positivos
Metástasis en nódulos regionales
Metástasis a distancia no evaluadas
No metástasis a distancia
Metástasis a distancia
Metástasis a distancia en nódulo no regionales
Metástasis en hueso
Metástasis en otras localizaciones

Tabla 3. Clasificación TNM Cáncer de Próstata [52]

\subsubsection{ASOCIACIÓN EUROPEA DE UROLOGÍA.}

La EAU se funda en los años 70’ pero no es hasta el año 2000 cuando se publican las primeras guías clínicas de la EAU con el objetivo de ayudar en la toma de decisiones compartidas a los urólogos europeos. [55]

En estas guías clínicas, el comité científico de la EAU propone una clasificación del CP en función del riesgo de recaída bioquímica. [31] Estos grupos de riesgo combinan varios factores que afectan a la aparición de una posible recaída bioquímica del $\mathrm{CP}$ tras el tratamiento primario. Estos factores son:

- Grado de Gleason

- Valor de PSA

- Estadiaje cT

Los grupos de riesgo de recaída bioquímica de la EAU quedan reflejado en la siguiente tabla.

\begin{tabular}{|c|c|}
\hline Grupo de riesgo & Características \\
\hline $\begin{array}{l}\text { Localizado bajo riesgo } \\
\text { (LBR) }\end{array}$ & $\begin{array}{c}\text { Cumple TODAS las siguientes características: } \\
- \text { PSA }<10 \text { ng/mL } \\
\text { - Gleason }<\text { 7a (ISUP } 2) \\
\text { - cT1-2a }\end{array}$ \\
\hline $\begin{array}{l}\text { Localizado riesgo intermedio } \\
\text { (LRI) }\end{array}$ & $\begin{array}{c}\text { Cumple alguna de las siguientes características: } \\
\text { - PSA 10-20 ng/mL } \\
\text { - Gleason } 7 \text { (ISUP } 2 \text { y 3) } \\
\text { - cT2b }\end{array}$ \\
\hline $\begin{array}{l}\text { Localizado alto riesgo } \\
\text { (LAR) }\end{array}$ & $\begin{array}{c}\text { Cumple alguna de las siguientes características: } \\
\text { - PSA }>20 \mathrm{ng} / \mathrm{mL} \\
\text { - Gleason }>7 \text { (ISUP 4 y 5) } \\
\text { - cT2c }\end{array}$ \\
\hline Localmente Avanzado & $\begin{array}{c}\text { Cumple alguna de las siguientes características: } \\
\text { - Cualquier PSA } \\
\text { - Cualquier Gleason } \\
\text { - cT3-4 y/o N1 }\end{array}$ \\
\hline
\end{tabular}

Tabla 4. Grupos de riesgo de recaída bioquímica EAU [31]

1.2.5.4. NATIONAL COMPREHENSIVE CANCER NETWORK.

La National Comprehensive Cancer Network (NCCN) es una alianza entre los centros oncológicos líderes investigación y atención a la paciente fundada con el objetivo de mejorar y facilitar una atención oncológica de calidad, eficaz, eficiente y accesible para que los pacientes puedan vivir una vida mejor. [56]

La NCCN propone una clasificación de los tumores prostáticos basada en criterios anatomopatológicos, y clínicos que se refleja en la siguiente tabla. [57]

Grupo de riesgo

Localizado muy bajo riesgo (LMBR)

\section{Localizado bajo riesgo} (LBR)

\section{Localizado riesgo intermedio (LRI) \\ Factores riesgo intermedio (FRI) - cT2b-2c \\ - PSA 10-20}

Localizado alto riesgo (LAR)

\section{Localizado muy alto riesgo
(LMAR)}

\section{Localmente avanzado}

Metastásico
Características

Cumple TODAS las siguientes características: - cT1c
- ISUP 1

$-\mathrm{PSA}<10 \mathrm{ng} / \mathrm{mL}$

- Menos de 3 cores positivos, $\leq 50 \%$ afectación tumoral en cada core - Densidad de PSA (DPSA) <0,15 ng/mL/g

Cumple TODAS las siguientes características pero no está clasificado como muy bajo riesgo:

$$
\begin{aligned}
& \text { - cT1-2a } \\
& \text { - ISUP } 1
\end{aligned}
$$$$
\mathrm{PSA}<10 \mathrm{ng} / \mathrm{mL}
$$

Localizado riesgo intermedio favorable (LRIF)

Cumple TODAS las siguientes características:

$$
\text { - } 1 \text { FRI }
$$

$<50 \%$ cores positivos

Localizado riesgo intermedio desfavorable (LRID)

Cumple una o más las siguientes características:

$$
\begin{aligned}
& -2 \text { o } 3 \text { FRI } \\
& \text { - ISUP } 3
\end{aligned}
$$

$-\leq 50 \%$ cores positivo

Cumple alguno de las siguientes características:

$$
\begin{gathered}
\text { - cT3a } \\
\text { - ISUP } 4 \text { o } 5 \\
\text { - PSA > } 20 \mathrm{ng} / \mathrm{mL}
\end{gathered}
$$

Cumple al menos una de las siguientes características: - cT3b-4

- Patrón primario de Gleason 5 203 características de alto riesso - > 4 cores con ISUP 4-5

Cumple las siguientes características: - Cualquier estadio $\mathrm{T}$

$$
\begin{aligned}
& -\mathrm{N} 1 \\
& -\mathrm{Mo}
\end{aligned}
$$

Cumple las siguientes características: - Cualquier estadio T

$$
\text { - M1 }
$$

Tabla 5. Clasificación NCCN para CP [57] 


\subsection{TRATAMIENTO.}

Los distintos tipos de tratamientos para el CP son:

1. Vigilancia Activa (VA): es un tratamiento que consiste en la monitorización estrecha de los pacientes mediante controles analíticos, radiológicos y anatomopatológicos. [58]. Este tratamiento se desarrollará en profundidad en los siguientes apartados de dicha tesis.

2. Prostatectomía Radical (PR): consiste en la extirpación quirúrgica de la próstata completa junto con las vesículas seminales. Esta cirugía se puede realizar por distintas vías de abordaje de la piel (abierta, laparoscópica y asistida por robot). Esta cirugía mayor puede ir acompañada de la extirpación de las cadenas ganglionares próximas a la próstata (linfadenectomía), en función del riesgo del tumor primario diagnosticado en la biopsia. [59]

Los principales efectos secundarios de la cirugía son la incontinencia urinaria y la disfunción eréctil [31]. La incontinencia urinaria se recupera en un plazo de 1 a 2 años en la mayoría de los pacientes gracias a la rehabilitación del suelo pélvico. Mientras que la disfunción eréctil se puede intentar prevenir en aquellos pacientes en los que se realiza preservación neurovascular, la cual no siempre se puede realizar dependiendo de las características tumorales, y se puede tratar con medicación o con prótesis de pene, una vez pasado un tiempo después de la intervención quirúrgica.

3. Radioterapia (RT) externa: es una modalidad de tratamiento en la cual la radiación es administrada a paciente desde el exterior mediante un acelerador lineal. Este tratamiento de puede realizar de diversas maneras: RT conformada o tridimensional (RTC-3D), RT de intensidad modulada (IMRT) o Radioterapia estereostática extracraneal (SBRT). [6o]

4. Braquiterapia (BT) o RT interna: consiste en la colocación de isótopos radiactivos en la próstata enferma para el tratamiento del tumor.

5. Terapia hormonal (HT): este tratamiento consiste en la administración de medicación hormonal que inhibe la liberación de la hormona liberadora de hormona luteinizante (LHRH) en el eje hipotálamo-hipófisis, produciéndose así una disminución de los niveles de testosterona en sangre.

En el campo dela terapia hormonal para el CP hahabido grandes avances en los últimos años con el descubrimiento de nuevos fármacos como la Abiraterona, la Enzalutamida, la Darolutamida, la Apalutamida... Los cuales abren nuevos abanicos terapéuticos en los pacientes con tumores de próstata de alto riesgo y/o metastásicos, así como en las segundas líneas de tratamientos de los pacientes que se convierten en resistentes al tratamiento hormonal (CPRC).

6. Quimioterapia (QT): tratamiento sistémico del cáncer de próstata mediante fármacos quimioterápicos. En el caso del CP el fármaco de elección en primera línea si no existen otras contraindicaciones es el Docetaxel

Como hemos visto, existen distintos tipos de tratamiento para el CP, en función de la agresividad del tumor diagnosticado en la biopsia, para lo cual nos basamos en la clasificación de los grupos de riesgo de la EUA. En el siguiente gráfico, vemos reflejado que tipo de tratamiento está indicado en función del grupo de riego diagnosticado.
Menos de 70 años

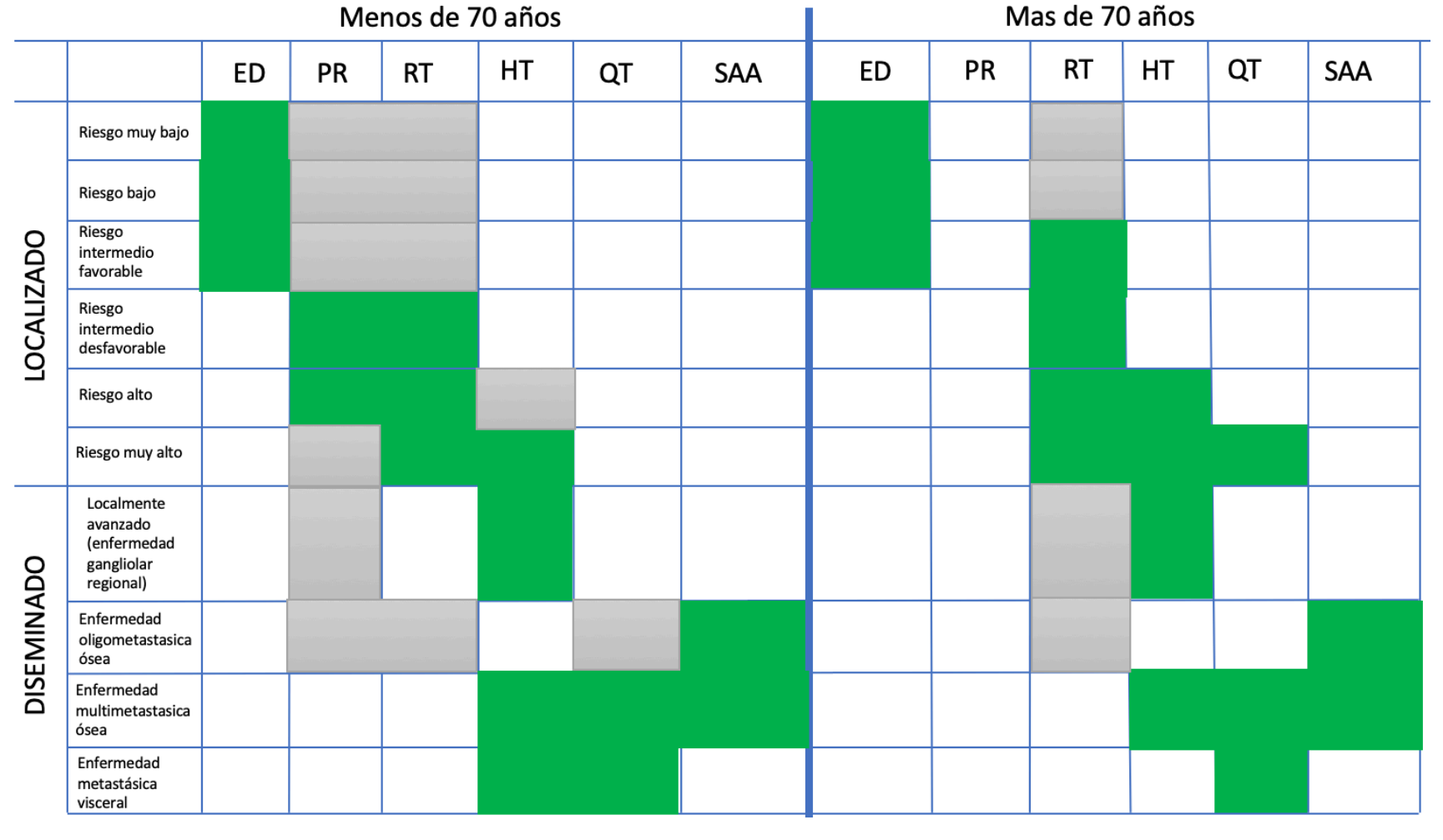

Gráfico 3. Tratamiento CP en función del grupo de riesgo NCCN

$$
\text { Leyenda: }
$$

\section{VERDE: tratamiento de elección.}

GRIS: tratamiento posible. ED=estrategia diferida, $P R=$ prostatectomía radical $R T=$ radioterapia $H T=$ hormonoterapia $Q T=q u i m i o t e r a p i a ~ S A A=$ superantiandrógenos

Debemos tener en cuenta, que en los últimos años, la edad ha perdido relevancia como elemento decisivo para tomar decisiones terapéuticas. Si bien estos límites han sido, conceptual y arbitrariamente utilizados en el pasado, están siendo sustituidos en la actualidad por diferentes herramientas. Fundamentalmente provenientes de la investigación básica y de esta integrada junto a análisis del estatus funcional y comorbilidad general. Estas herramientas, combinadas, son de mayor utilidad para optar por un tipo de tratamiento u otro. Además hay que tener en cuenta, que la elección de un tratamiento u otro debe ser una decisión compartida entre el onco-urólogo y el paciente y su familia. [61] 


\subsection{LA VIGILANCIA ACTIVA.}

1.3.1. QUÉ ES Y SU USO COMO TRATAMIENTO DEL CÁNCER DE PRÓSTATA.

La VA es una modalidad de tratamiento del CP para los pacientes de muy bajo riesgo, bajo riesgo y riesgo intermedio favorable, que consiste en la monitorización estrecha de estos tumores, mediante control de los valores de PSA, pruebas de imagen (RMN) y re- confirmación anatomopatológica.

El objetivo es reducir la morbilidad de los pacientes provocada por tratamientos más agresivos, pero sin impactar en su supervivencia a largo plazo [58].

Según las guías clínicas de la EUA y la NCCN en sus actualizaciones del año 2020 [31, 57], la VA debería ser el tratamiento de elección en los pacientes de bajo riesgo (EAU) y muy bajo riesgo y bajo riesgo (NCCN).

Tenemos que diferenciar la VA de la otra estrategia de tratamiento diferido existente, denominada Esperar y Ver (WW).

Mientras que la VA es una estrategia de tratamiento con intención curativa enfocada a pacientes más jóvenes con una monitorización muy estrecha. Cuyo fin es abordar la enfermedad en el primer momento que se produzca una reclasificación del tumor a uno más agresivo que el diagnosticado inicialmente, lo cual comprometa la supervivencia del paciente.

El WW es una estrategia de tratamiento enfocada a pacientes mayores y con pluripatología con el objetivo de hacer un tratamiento paliativo del cáncer; en esta estrategia solo se tratarían a los pacientes en el caso de que el tumor le produjera clínica que empeorara su calidad de vida. [62]

\subsubsection{HISTORIA.}

La VA aparece a mediados de los años noventa. Las primeras universidades que propusieron sus criterios de inclusión y seguimiento para pacientes en VA fueron la Universidad de Toronto [63] y la Universidad John Hopkins [64], después de ellas, muchos otros grupos de investigación propusieron sus propios criterios de inclusión y seguimiento, lo que supone que actualmente tengamos más de 17 protocolos de VA diferentes.

Al mismo tiempo que se estaban desarrollando estos protocolos de VA, en Estado Unidos y en Inglaterra se llevaban a cabo dos ensayos clínicos para comparar la eficacia de la observación frente a los tratamientos activos.

Por un lado, nos encontramos con el estudio PIVOT, el cual entre noviembre de 1994 y enero de 2002 reclutó 731 pacientes con tumor prostático localizado a los que se trató mediante PR o mediante observación [65]. Este estudio concluyó, tras 10 años de seguimiento, que no había diferencias significativas en cuanto a mortalidad en las dos ramas del estudio (PR y observación), no obstante, los pacientes en la rama de observación tenían más progresión de la enfermedad, aunque esto no impactara en su supervivencia. Sin embargo, este estudio fue criticado, puesto que, por una parte, no se reclutó al número de pacientes que se había estimado inicialmente, y, por otra, los criterios para incluir a los pacientes en la rama de observación no se adaptan a los criterios actuales de VA; estas controversias dificultan la extrapolación de los resultados a nuestras poblaciones actuales. [66]
Por otro lado, tenemos el estudio ProtecT, el cual, reclutó entre 1999 y 2009, 1643 pacientes con diagnóstico de CP localizado, que fueron randomizados en tres ramas: PR, RT y VA [67]. Este estudio, tras 10 años de seguimiento de los pacientes, concluyó que no había diferencias significativas entre los tratamientos, aunque los tratamientos activos como la RT y PR tenían una incidencia menor en la aparición de progresión y metástasis, respecto a la VA, si bien no había impacto en la supervivencia de estos pacientes.

Estos estudios, pusieron de manifiesto qué, en un grupo de pacientes bien seleccionados, el uso de la VA conlleva menos impacto en su calidad de vida y menor morbimortalidad y desarrollo de efectos secundarios que los tratamientos tradicionales de PR y RT; todo ello sin impactar en su supervivencia a largo plazo.

\subsubsection{CRITERIOS DE INCLUSIÓN Y SEGUIMIENTO.}

Actualmente existen más de 17 programas de VA en el mundo, cada uno de ellos con sus propios criterios de inclusión y seguimiento de los pacientes.

De manera general, la VA se contempla como opción de tratamiento para pacientes que cumplan las siguientes características:

- Grado de Gleason menor o igual a 3+3

- PSA hasta $10 \mathrm{ng} / \mathrm{mL}$

- Tacto rectal hasta cT2a

- Máximo de 3 cores positivos.

Sin embargo, estos criterios difieren dependiendo de los distintos protocolos. Existen criterios más restrictivos como los propuestos por Tosoian [64] o Becker [68], los cuales exigen un TR normal (cT1c) para la inclusión en el programa de VA. Mientras que otros programas tienen criterios más amplios, como los propuestos por el Royal Marsden Hospital [69] que permiten la inclusión de pacientes con hasta el 50\% de los cilindros afectados y la posibilidad de incluir pacientes con GG 3+4. O el protocolo Prostate Cancer Research International Active Surveillance (PRIAS) [70], el cual también permite incluir pacientes con GG hasta 3+4 pero con PSA hasta 10 ng/mL. En esa misma línea también nos encontramos con los criterios propuestos por el grupo de Klotz en la Universidad de Toronto [63] o los propuestos por la Asociación Española de Urología (AEU) en su estudio AEUPIEM/2014/o01 [71] los cuales permiten incluir pacientes con PSA hasta 15 ng/mL.

En este sentido, en el Servicio de Urología del Complejo Asistencial Universitario de Salamanca (CAUSA), los pacientes que se incluyen en el protocolo de VA se dividen en dos grandes grupos, debiendo cumplir los siguientes criterios que están basados en los propuestos en el protocolo PRIAS [70, 74]:

- VA pura: cumple todos: GG 3+3 (ISUP 1), PSA $\leq 10$, tacto cT1c, máximo 2 cores positivos y suma de diámetros máx. $\leq 10 \mathrm{~mm}$

- VA expandida: cumple alguno (máximo dos) de los siguientes criterios: GG hasta 3+4 (ISUP 2), PSA entre 10-20, tacto hasta cT2b, 3 cores afectos, afectación bilateral de la próstata, suma de diámetros máximos mayor de $10 \mathrm{~mm}$.

Al igual que ocurre con los criterios de inclusión en VA, a la hora de realizar los seguimientos de estos pacientes también existen multitud de criterios, tantos como programas deVA existen. Pero todos ellos coinciden que durante el seguimiento de estos pacientes se deben realizar determinaciones de PSA, TR, nueva biopsia de confirmación, y actualmente RMN, sin embargo, las variaciones entre los distintos criterios de seguimiento se encuentran en el momento en el que se deben realizar dichas pruebas. 


\begin{tabular}{|c|c|c|c|c|c|}
\hline Institución & $\begin{array}{l}\text { Estadio } \\
\text { clínico }\end{array}$ & $\begin{array}{c}\text { PSA } \\
\text { (ng/mL) }\end{array}$ & $\begin{array}{c}\text { DPSA } \\
\text { (ng/mL/cc) }\end{array}$ & GG & $\begin{array}{c}\text { \% cores } \\
\text { positivos }\end{array}$ \\
\hline $\begin{array}{l}\text { Universidad de } \\
\text { Toronto (Klotz } \\
\text { 2015) [63] }\end{array}$ & & $\begin{array}{l}\frac{\text { Si menor } 70 \text { años: }}{-\leq 10 \mathrm{ng} / \mathrm{mL}} \\
\frac{\text { Si mayor/igual } 70}{\text { años: }} \\
-\leq 15 \mathrm{ng} / \mathrm{mL}\end{array}$ & & $\begin{array}{c}\frac{\text { Si menor } 70 \text { años: }}{-\leq 3+3} \\
\frac{\text { Si mayor/igual } 70}{\text { años: }} \\
-\leq 3^{+4}\end{array}$ & \\
\hline $\begin{array}{c}\text { Universidad } \\
\text { Johns Hopkins } \\
\text { (Tosoian 2011) } \\
\text { [64] }\end{array}$ & cTic & & $\begin{array}{c}\mathrm{0}, 15 \mathrm{ng} / \mathrm{mL} / \\
\mathrm{cc}\end{array}$ & $\leq 3+3$ & $\leq 2$ cores \\
\hline $\begin{array}{c}\text { PRIAS (Bul } \\
\text { 2013) [7o] }\end{array}$ & cT1c-cT2 & $\leq 10 \mathrm{ng} / \mathrm{mL}$ & $\leq \mathrm{o}, 2 \mathrm{ng} / \mathrm{mL} / \mathrm{cc}$ & $\leq 3+3$ & $\leq 3$ cores \\
\hline $\begin{array}{c}\text { Memorial } \\
\text { Sloan Kettering } \\
\text { Cancer Center } \\
\text { (Adamy 2011) } \\
\text { [72] }\end{array}$ & cT1-cT2a & $\leq 10 \mathrm{ng} / \mathrm{mL}$ & & $\leq 3+3$ & $\leq 2$ cores \\
\hline $\begin{array}{c}\text { Royal Marsden } \\
\text { Hospital } \\
\text { (Selvadurai } \\
\text { 2013) [69] }\end{array}$ & cT1-cT2 & $\leq 15 \mathrm{ng} / \mathrm{mL}$ & & $\begin{array}{c}\frac{\text { Si menor } 65 \text { años: }}{-\leq 3+3} \\
\frac{\text { Si mayor/igual } 65}{\text { años: }} \\
-\leq 3^{+4}\end{array}$ & $\leq 50 \%$ \\
\hline $\begin{array}{c}\text { National } \\
\text { Prostate } \\
\text { Cancer Register } \\
\text { (NPCR) of } \\
\text { Sweden (Loeb } \\
\text { 2016) [73] }\end{array}$ & cT1-cT2 & $\leq 20 \mathrm{ng} / \mathrm{mL}$ & & $\leq 3+4$ & \\
\hline
\end{tabular}

Tabla 6. Criterios de inclusión en VA de las principales series.

En este sentido, la EAU en el año 2018, publicó un consenso y su posicionamiento respecto a los criterios de seguimiento de la VA [75], consistente en:

\section{- TR 1 vez al año.}

- Determinación de PSA cada 6 meses.

- RMN en los 12 meses posteriores a la inclusión.

- Biopsia confirmatoria entre los 3-5 años posteriores a la inclusión.

En el CAUSA, los pacientes que se encuentran en VA se adquiere al posicionamiento de la EAU.

La adherencia a los protocolos de seguimiento en las grandes series mundiales, según la revisión realizada por algunos autores [76], disminuye cuanto más tiempo de seguimiento tienen los pacientes, si bien es verdad, que en el primer año desde la inclusión todas las pruebas se realizan en los plazos establecidos. Cuando los pacientes ya llevan más de 12 meses de seguimiento, esta adherencia disminuye, sobre todo en el apartado de realización de las biopsias de confirmación, las cuales dependiendo del protocolo se deben de realizar de manera anual o más espaciadas en el tiempo. [77,78]
El papel de la RMN aún no está completamente definido [79], puesto que su inclusión en el seguimiento de estos pacientes es muy reciente. Las guías del National Institute for Health and Care Excellence (NICE) introducen su posible uso en el año 2014 [80], y la EAU lo sugiere en su posicionamiento del año 2018 [77], siendo incorporado en la guía de práctica clínica de la EAU en marzo de 2019 [31]. Las guías clínicas de la NCCN [57], también recogen en su última actualización el uso de la RMN para realizar el seguimiento de los pacientes en VA.

En esta línea, el estudio ASIST [81] pone de manifiesto que en el manejo de pacientes en VA, el uso de biopsia estándar más biopsia dirigida a las zonas indicadas por la RMN, aumenta el valor de la RMN en estos pacientes. Sí bien es cierto, que se requiere una buena curva de aprendizaje tanto en la realización de la RMN por radiólogos expertos como en la realización de las biopsias dirigidas. Por otro lado, debemos tener en cuenta que la RMN es una técnica costosa y observador-dependiente y que no está disponible en todos los hospitales. Por lo que la disponibilidad (o ausencia) de esta es uno de los principales problemas que nos encontramos en su uso para el seguimiento de los pacientes en VA. [82]

\subsubsection{DIFICULTADES Y CONTROVERSIAS.}

En primer lugar, uno de los principales problemas que existente a la hora de tratar a los pacientes mediante VA es identificar correctamente el riesgo individual de sufrir una reclasificación a un tumor agresivo de manera temprana. Esta es una de las principales controversias actuales sobre el uso de la VA, sobre todo, en los pacientes más jóvenes, en los cuales la reclasificación a un tumor agresivo puede tener más impacto en su supervivencia, así como en su calidad de vida. [83]

En segundo lugar, como hemos visto existen multitud de criterios de seguimiento, lo cual dificulta la extrapolación de los resultados y comparación de estos entre las distintas series de paciente en VA.

En tercer lugar, algunos de los pacientes incluidos en el protocolo de VA sufren ansiedad debido a que saben que tienen un tumor y que no están recibiendo un tratamiento agresivo contra el mismo, lo cual impacta de manera muy negativa en su calidad de vida, y es uno de los motivos de abandono del programa. Estos pacientes pese a cumplir características clínicas compatibles con la permanencia en VA, no son capaces de continuar debido a los efectos secundarios en la esfera psicológica, optando por tratamientos más radicales pese a sus efectos secundarios. [84]

Por estos motivos, es muy importante la individualización y la toma de decisiones consensuadas (Shared Decisión Making) en estos pacientes, así como el contar con equipos multidisciplinares formados por urólogos especializados en uro-oncología, enfermeras especializadas en uro-oncología, radioterapeutas, oncólogos, psicooncólogos para realizar el seguimiento y control de estos pacientes. [85] 


\subsection{CALIDAD DE VIDA Y ANSIEDAD EN LOS PACIENTES EN VIGILANCIA ACTIVA. ENFERMERA GESTORA DE CASOS: SU PAPEL EN EL MANEJO DE LA ANSIEDAD Y LA CALIDAD DE VIDA.}

\author{
1.4.1. CALIDAD DE VIDA Y ANSIEDAD EN PACIENTES EN \\ VIGILANCIA ACTIVA.
}

La CV es la percepción de los individuos acerca de su posición en la vida, enmarcada en su contexto cultural y en relación con metas, expectativas, normas e intereses. Es decir, la CV corresponde al nivel de bienestar que se deriva de la evaluación que hacen los individuos sobre las diversas áreas de su vida. [86] Este concepto fue desarrollado por la Organización Mundial de la Salud (OMS) en el año 1995.

La calidad de vida relacionada con la salud (CVRS) se define como el aspecto de la CV referido específicamente a la salud del individuo, el cual se usa para designar los resultados concretos de la evaluación clínica y de la toma de decisiones terapéuticas. [87]

Según Manual de diagnóstico y estadístico de los trastornos mentales de la Asociación Americana de Psiquiatría; la ansiedad es un estado emocional estresante y displacentero que provoca un sentimiento de nerviosismo y desasosiego [88]. Un cierto grado de ansiedad es adaptativo a las distintas situaciones que se presentan en el transcurso de la vida, sin embargo, cuando va a más, y provoca disfunciones, se considera un trastorno y es necesario el tratamiento por especialistas.

El impacto que el cáncer y sus tratamientos, algunos muy agresivos, producen en la CV y en la CVRS de los pacientes está ampliamente recogido en la literatura, y es función de los equipos multidisciplinares la promoción y mantenimiento de una adecuada CV en estos pacientes, siempre teniendo en cuenta que lo más importante es mantener la salud. [89]

En el campo de la uro-oncología, y en concreto en el CP, el impacto en la CV de los pacientes está, por un lado, influenciado por el tipo de tumor que tienen nuestros pacientes; los tumores localmente avanzados o metastásicos tendrán mayor impacto en la CV que los tumores localizados de bajo riesgo. Y, por otro lado, relacionado con el tipo de tratamiento realizado para la curación o control del tumor. [90,91]

Para analizar el impacto en la CV de los pacientes con CP, debemos analizar la influencia que los distintos tratamientos tienen sobre las siguientes esferas de la vida del paciente:

\section{Sexual}

Continencia

Tránsito intestinal

Esfera mental y psicológica

Puesto que estas son, en las que la elección de un tratamiento u otro afectará a la CV de los pacientes.

A la hora de valorar estas esferas mediante los distintos cuestionarios, a parte de tener en cuenta el tipo de tumor y el tratamiento realizado, se debe tener en cuenta, el estado basal a nivel urológico de los pacientes. Para lo cual se deberá interrogar a los pacientes sobre sus hábitos miccionales y sexuales previos al diagnóstico, recoger el tratamiento farmacológico empleado, y si es posible, realizar pruebas objetivas, como la flujometría y el estudio urodinámico, para la valoración del estatus miccional basal de los pacientes. Así como su estatus civil, puesto algunos estudios refieren que existe una relación entre la situación civil de los pacientes y CV. [84,92]

Con la llegada de la VA al tratamiento de los pacientes con CP localizados de bajo riesgo, el análisis de la CV de los pacientes cobró una gran relevancia, desarrollándose en las últimas décadas diversos estudios comparativos entre la VA y los distintos tratamientos activos, y la afectación que estos tienen sobre las distintas esferas de la CV y de la CVRS. Ya que, a igualdad de efectividad en términos oncológicos, la afectación funcional y de la CV tienen más importancia, sobre todo en los pacientes más jóvenes.

Van Stam MA et al [93], en su estudio realizado a los pacientes con CP localizado, pusieron de manifiesto la importancia de valorar la CV y la CVRS de los pacientes a la hora de proponerles un tratamiento u otro, puesto que, a igual eficacia en términos de oncológicos, la CVRS cobra mayor relevancia. Este grupo reporta, que sus pacientes en VA tuvieron mejor puntuación en relación con los tratamientos activos (PR, RT) en los campos de continencia urinaria, clínica obstructiva, clínica intestinal, disfunción eréctil y fatiga; y que los niveles de ansiedad relacionados con la enfermedad experimentados por los tres grupos de pacientes eran similares.

En esta misma línea comunican sus resultados otros grupos, Sebakk K S et al,[94] en su revisión sobre la CVRS comparando pacientes sometidos a VA y a PR, aunque estadísticamente no obtiene diferencias significativas entre los tratamientos, los pacientes tratados con PR presentan mayores problemas de incontinencia urinaria y disfunción eréctil que los tratados con VA. Este autor destaca el valor del tratamiento de estos pacientes en equipos multidisciplinares y la importancia de contar con enfermeras especialistas en uro-oncología para el manejo de estos pacientes.

\subsubsection{EVALUACIÓN DE LA CALIDAD DE VIDA Y LA ANSIEDAD: CUESTIONARIOS.}

La evaluación de la CV y de los niveles de ansiedad de los pacientes se lleva a cabo mediante cuestionarios. Estos cuestionarios suelen ser auto administrados, es decir, es el propio paciente el que contesta a las preguntas directamente sin que el profesional sanitario se las vaya formulando.

Existen multitud de cuestionarios para valorar la CV y la ansiedad dependiendo del ámbito de atención en el que estos se realicen. En el aspecto de la oncología y en concreto de la uro-oncología, la tabla 7 recoge los más relevantes.

\begin{tabular}{|ccc}
\hline Nombre completo del cuestionario & Abreviatura & $\begin{array}{c}\text { Año de } \\
\text { validación }\end{array}$ \\
\hline $\begin{array}{c}\text { CUESTIONARIO ESPAÑOL DE CALIDAD DE VIDA EN } \\
\text { PACIENTES CON CÁNCER DE PRÓSTATA }\end{array}$ & CAVIPRES & 2009 [95] \\
\hline $\begin{array}{c}\text { EUROPEAN ORGANIZATION RESEARCH AND TREATMENT OF } \\
\text { CANCER. QUALITY OF LIFE QUESTIONNAIRE CORE 3O }\end{array}$ & QLQ-C3O & 1993 [96] \\
\hline $\begin{array}{c}\text { EUROPEAN ORGANIZATION RESEARCH AND TREATMENT OF } \\
\text { CANCER. QUALITY OF LIFE QUESTIONNAIRE FOR PROSTATE } \\
\text { CANCER PATIENTS }\end{array}$ & QLQ-PR 25 & 2008 [97] \\
\hline $\begin{array}{c}\text { 12-ITEMS SHORT FORM HEALTH SURVEY } \\
\text { 36-ITEMS SHORT FORM HEALTH SURVEY }\end{array}$ & SF-12 & 1996 [98] \\
\hline
\end{tabular}




\begin{tabular}{ccc}
\hline UNIVERSITY OF CALIFORNIA-LOS ANGELES PROSTATE & UCLA-PCI & 1998 [100] \\
CANCER INDEX & WHOQOL & $2000[101]$ \\
WORLD HEALTH ORGANIZATION QUALITY OF LIFE & EPIC & $2000[102]$ \\
EXPANDED PROSTATE INDEX COMPOSITE & FACT-P & $1997[103]$ \\
\hline FUNCTIONAL ASSESSMENT OF CANCER THERAPY- & & \\
PROSTATE & &
\end{tabular}

Tabla 7. Cuestionarios más utilizados para la valoración de la CV en pacientes con CP.

\subsubsection{ENFERMERA GESTORA DE CASOS Y SU PAPEL EN EL PROGRAMA DE VIGILANCIA ACTIVA.}

La gestión de casos se define como "la práctica avanzada de cuidados mediante la cual se desarrolla un proceso de colaboración para satisfacer las necesidades de salud de personas con elevada complejidad clínica y/o necesidades de cuidados, así como de su entorno cuidador". [104]

Este modelo de atención sanitaria apareció en Estados Unidos en la década de los 80-90 debido a los cambios que se habían producido en la atención sanitaria, con el aumento de la esperanza de vida y de las patologías crónicas [105] y después se extendió al resto de los países.

El papel de la gestión de casos puede ser llevado a cabo por distintos profesionales de la salud, pero fundamentalmente es llevado a cabo por las enfermeras. [106]

Los objetivos fundamentales de la enfermera gestora de casos son los siguientes:

Identificar a la población con mayor riesgo de complejidad y mayor necesidad de cuidados.

Asegurar la continuidad de los cuidados y la coordinación entre los distintos ámbitos de atención sanitaria.

Mejorar la homogenización de la práctica asistencial entre los distintos niveles sanitarios.

Mantener y mejorar la calidad de vida de los pacientes y sus familias.

Fomentar el autocuidado, la autogestión y la autonomía.

Participar en la planificación de los cuidados de la población diana

Asegurar intervenciones que reduzcan la hiperfrecuentación y los reingresos

Contribuir a la sostenibilidad del sistema fomentando el uso eficiente de los recursos

Las funciones llevadas a cabo por las enfermeras gestoras de caso se pueden resumir en:

Información y movilización de los recursos disponibles.

Comunicación y coordinación entre los distintos profesionales sanitarios

Velar por los derechos de los pacientes

Creación y coordinación de un plan de atención único e integrado

Seguimiento de los pacientes.

Garantizar la continuidad de los cuidados entre los distintos niveles asistenciales.

Existen diversos modelos de enfermeras gestoras de casos, dependiendo del tipo de pacientes al que vaya dirigido En el caso de los pacientes oncológicos, uno de los modelos más utilizados es el modelo Patient Navigator; el cual, las enfermeras gestoras de casos ofrecen asistencia individualizada a pacientes, familias y cuidadores para ayudar a superar las barreras del sistema de salud y facilitar el acceso oportuno a atención médica y psicosocial de calidad durante todo su proceso oncológico [107]

Una revisión realizada por Joo JY et al, se refleja que la figura de la enfermera gestora de caso en el manejo de lo pacientes oncológicos tiene como resultado un aumento de la $\mathrm{CV}$ de estos pacientes, y una disminución del número de reingresos hospitalarios, y por tanto de los costes asociados. [108] Por ese motivo, es importante el seguimiento por parte de enfermería de los pacientes oncológicos, y la puesta en marcha de la figura de la enfermera gestora de casos en todos los hospitales con pacientes oncológicos

El rol de la enfermera gestora de casos en el CP es muy reciente. Entre los primeros sistemas sanitarios en implantar este rol, se encuentra el National Health Service (NHS) en Inglaterra. En el NHS, el papel de la enfermera gestora de casos en el CP está perfectamente definido, habiéndose creado 3 maneras de seguimiento del CP en función del tipo y del tratamiento realizado, llevándose a cabo en todo momento todos los procedimientos dentro de un equipo multidisciplinar. [109] Esta forma de seguimiento de los pacientes a demostrado un aumento de la satisfacción de los pacientes y del equipo sanitario.

Cobra especial relevancia el papel de la enfermera gestora de casos en el caso de los pacientes cuyo tratamiento para el CP es la VA, puesto que como hemos dicho anteriormente, en estos pacientes, la esfera psicológica y mental a veces se encuentra más afectada que en los pacientes que reciben tratamiento activo [93], y el apoyo de la enfermera gestora de casos durante el proceso, supone una disminución de la ansiedad ocasionada por el proceso oncológico. [110]

En España, uno de los primeros hospitales en implantar la figura de la enfermera gestora de casos en los pacientes con tumores genitourinarios fue el Hospital Clinic de Barcelona, la cual tuvo como consecuencia la mejora en las condiciones de atención y seguimiento de dichos pacientes. [111] 


\section{HIPÓTESIS Y OBJETIVOS \\ DEL ESTUDIO}




\section{HIPÓTESIS Y OBJETIVOS DEL ESTUDIO.}

2.1. HIPÓTESIS.

Ho: La VA no es una alternativa segura para el tratamiento del Cáncer de Próstata de muy bajo y bajo riesgo localizado, e impacta negativamente en la calidad de vida de estos pacientes.

H1: La VA puede ser una alternativa segura y con buen impacto en la calidad de vida de los pacientes con Cáncer de Próstata localizado de muy bajo y bajo riesgo

\subsection{OBJETIVOS.}

\section{Los objetivos de la presente tesis son:}

1. Análisis y factores relacionados con la población incluida en el protocolo de VA y sus motivos de salida del mismo.

2. Conocer el nivel de ansiedad y calidad de vida de los pacientes incluidos en el protocolo de Va mediante la revisión de los cuestionarios incluidos en la Historia Clínica, realizados a los pacientes en distintos momentos de su paso por el protocolo de VA.

3. Análisis de la adherencia al protocolo de seguimiento de VA durante el primer año desde su inclusión.

4. Impacto del Cáncer de Próstata en la provincia de Salamanca y criterios de inclusión en VA.

\section{MATERIAL Y MÉTODOS}




\section{MATERIAL Y MÉTODOS.}

\subsection{GENERALIDADES}

Se realiza una revisión retrospectiva de los pacientes en VA en el CAUSA. Se revisaron las historias clínicas de los 276 pacientes incluidos en el protocolo de VA en el CAUSA desde el 1 de enero de 2014 al 30 de septiembre de 2020.

El estudio fue presentado ante el Comité de Ética del CAUSA y aprobado por el mismo con el siguiente código de proyecto: PI 202004476

Todos los pacientes fueron diagnosticados y tratados en el CAUSA y a través de la revisión de las historias clínicas se elaboró el cuaderno de recogida de datos electrónico en el que constaban los siguientes datos de los pacientes:

Edad al diagnóstico

Comorbilidades: hipertensión arterial (HTA), diabetes mellitus (DM), dislipemia (DL), antecedentes oncológicos.

Fecha de biopsia

Fecha de inclusión en VA

Biopsias previas al diagnóstico

Tacto rectal

Estadio cT

Analítica al diagnóstico: hemoglobina, neutrófilos, linfocitos, PSA

Volumen prostático

Número de cilindros totales, positivos derechos y positivos izquierdos

Milímetros de tumor

Grado de Gleason/ISUP

Grupo de riesgo según la EAU y la NCCN

Fecha de la primera revisión con PSA

Realización de RMN y fecha de la misma

Realización de la re-biopsia y fecha de la misma y anatomía patológica

Salida del protocolo de VA, fecha de la salida y motivo de salida

Estatus del paciente (vivo o muerto) y fecha de exitus

Puntuación CAVIPRES, puntuación escala de ansiedad, momento de realización de los cuestionarios.

Se elaboró un documento en formato EXCEL para la recogida de todos estos datos, que, posteriormente fueron analizados con el programa estadísticos SPSS v.26

\subsection{MÉTODO}

\subsubsection{SELECCIÓN MUESTRAL}

La selección muestral se obtiene de los pacientes incluidos en el protocolo de VA del CAUSA entre enero de 2014 y septiembre de 2020, de manera retrospectiva.

\subsection{DISENO Y CONSENTIMIENTO INFORMADO}

Se trata de un estudio retrospectivo observacional. Los pacientes diagnosticados de Cáncer de Próstata son informados del carácter maligno de este y sus posibilidades de manejo así como las distintas modalidades de tratamiento posibles. El consentimiento informado previo a la realización de la biopsia diagnóstica, así como el de la inclusión en el protocolo de VA del CAUSA recogen la posibilidad de usar los datos clínicos para los estudios de los grupos de investigación del CAUSA. En estos consentimientos se les explica que los datos serán manejados cumpliendo con las leyes vigentes: "Ley Orgánica de Protección de Datos 3/2018 del 5 de diciembre". Todos los pacientes firman previos a su inclusión, dichos consentimientos informados.

De igual manera, en el servicio de urología del CAUSA se cuenta con la aprobación del Comité de Ética de Investigación con medicamentos (CEIm) del CAUSA para la realización de un registro de los tumores urológicos diagnosticados en Salamanca: "REGTUMUROL-2019-01. PI 201907 345"; la presente tesis doctoral cuenta con la aprobación del CEIm: PI 202004476

\subsection{ANÁLISIS ESTADÍSTICO}

El análisis estadístico de esta Tesis Doctoral contó con el asesoramiento estadístico del Departamento de Estadística/Unidad de Bioestadística de la Universidad de Salamanca.

Se realiza estadística descriptiva de las características de la población seleccionada aportando para las variables cuantitativas media y desviación típica si la distribución es normal o mediana y rango intercuartílico si no se cumple esta condición. En el caso de variables categóricas los resultados se presentan en frecuencias y porcentajes.

Se realizan análisis de t de Student, Chi Cuadrado, según corresponda, así como análisis de la varianza de ANOVA cuando se considera necesario.

Se construyen gráficos con los datos más relevantes y Kaplan Meir para el análisis del seguimiento de los pacientes .

Estos análisis son realizados con el paquete estadístico SPSS v.26

\subsection{CONFLICTO DE INTERESES.}

El estudio se lleva a cabo sin presentar conflicto de intereses. Ni los investigadores ni los pacientes fueron ncentivados. No se realizaron tratamientos adicionales, pruebas o gastos adicionales a los ordinarios del proceso presentado por los pacientes según los estándares de Guías de Buena Practica Clínica y Guía de la Asociación Europea de Urología. 
4. RESULTADOS 


\section{RESULTADOS}

\subsection{ANÁLISIS DEL CÁNCER DE PRÓSTATA EN SALAMANCA:} 2014-2020

Entre el 1 de enero de 2014 y el 30 de septiembre de 2020, se diagnosticaron en Salamanca, 1776 pacientes de Cáncer de Próstata (CP).

La edad media de estos pacientes es de 70,6 años (min 39 máx 91). Si agrupamos estos pacientes por grupos de edad, 844 (47,5\%) eran menores de 70 años, frente a 932 (52,5\%) que eran mayores de 70 años.

Estos pacientes presentaron una mediana de PSA de 7,59 ng/mL. La media era de $24,74 \mathrm{ng} / \mathrm{mL}$. Hay que tener en cuenta que la media está muy influida por los valores extremos que presentan, sobre todo, los pacientes metastásicos, estos, tienen elevados niveles de PSA al diagnóstico. Si agrupamos los valores de PSA, la mayoría de los pacientes presentaban un PSA entre 4-10 ng/mL (1095 pacientes 61,7\%), seguidos de los que presentaban un PSA entre 10-20 ng/mL (345 pacientes, 19,6\%). El resto de los pacientes presentaron un PSA menor de $4 \mathrm{ng} / \mathrm{mL}$ (82 pacientes 4,6\%) o un PSA mayor de $20 \mathrm{ng} / \mathrm{mL}$ (235 pacientes $13,2 \%$ ).

Dentro de estos 1776 pacientes, $1607(90,4 \%)$ fueron tumores localizados, mientras que $154(8,7 \%)$ fueron tumores localmente avanzados y/o metastásicos. Existe una pérdida de 15 pacientes $(0,9 \%)$ de los cuales desconocemos su grupo de riesgo, puesto que a fecha de la realización de la revisión de los mismos continuaba pendiente el estudio de extensión (12 pacientes: 0,7\%) o no disponemos de Grado de Gleason en la anatomía patológica (3 pacientes: $0,2 \%$ ).

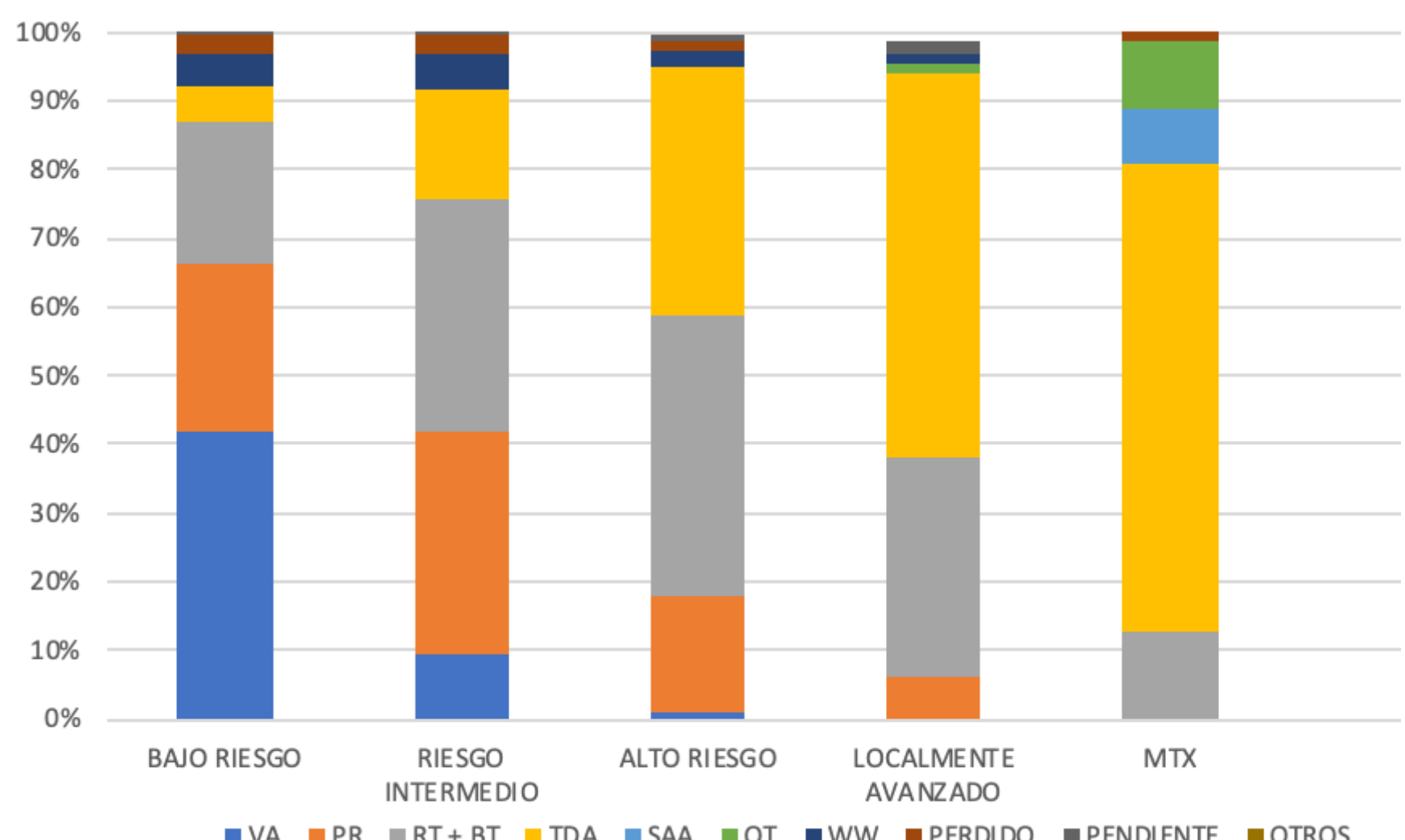

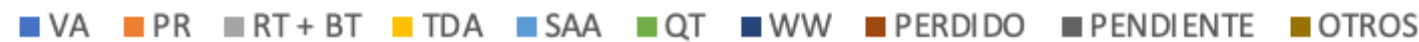

Si analizamos los tratamientos utilizados para toda esta población de pacientes, los 5 tratamientos más usados fueron: en primer lugar la RT que fue el tratamiento de elección en 450 pacientes $(25,3 \%)$, seguido de la PR en 413 pacientes $(23,3 \%)$, después la HT, que fue utilizada como tratamiento inicial en 397 pacientes $(22,4 \%)$. En cuarto lugar, nos encontramos las estrategias diferidas (ED): VA y WW, que fueron el tratamiento de elección para 338 de los 1176 pacientes $(17,8 \%)$ y en quinto lugar, 95 pacientes $(9,5 \%)$, fueron tratados con BT.

Si analizamos solo los pacientes de los grupos de bajo riesgo y riesgo intermedio de la EUA (1139 pacientes: 64,13\%), y/o grupos muy bajo riesgo, bajo riesgo y riesgo intermedio favorable según la NCCN (1149 pacientes: $64,69 \%$ ), que son los pacientes potencialmente tributarios a ser tratados mediante VA encontramos como, en ambos casos, el tratamiento de elección es la PR (328 pacientes: $28,9 \% / 330$ pacientes: $28,7 \%$ ), seguido muy de cerca de las ED (322 pacientes: $28,2 \% / 324$ pacientes $28,2 \%$ ).

La tabla 8 refleja como ha ido cobrando mayor relevancia el uso de la VA como tratamiento de elección en los pacientes de bajo riesgo y riesgo intermedio (según la EAU) y muy bajo riesgo, bajo riesgo, riesgo intermedio favorable (según la NCCN) a lo largo de los 5 años de estudio.

\begin{tabular}{|ccc|ccc|}
\hline \multicolumn{3}{c|}{ EAU } & \multicolumn{3}{c|}{ NCCN } \\
\hline $\mathbf{2 0 1 4}$ & LBR & LRI & LMBR & LBR & LRIF \\
\hline $\mathbf{2 0 1 5}$ & $2(5 \%)$ & $2(2,3 \%)$ & $2(8 \%)$ & 0 & $2(4,7 \%)$ \\
\hline $\mathbf{2 0 1 6}$ & $16(32 \%)$ & $5(5,5 \%)$ & $16(55,2 \%)$ & $3(8,8 \%)$ & $2(4,4 \%)$ \\
$\mathbf{2 0 1 7}$ & $24(25 \%)$ & $9(8,2 \%)$ & $15(34,1 \%)$ & $4(9,3 \%)$ & $6(10,7 \%)$ \\
$\mathbf{2 0 1 8}$ & $47(59,5 \%)$ & $18(17 \%)$ & $21(45,7 \%)$ & $10(27,8 \%)$ & $11(20 \%)$ \\
\hline $\mathbf{2 0 1 9}$ & $67(54,5 \%)$ & $7(7 \%)$ & $51(73,9 \%)$ & $16(29,6 \%)$ & $7(17,1 \%)$ \\
\hline $\mathbf{2 0 2 0}(*)$ & $33(50 \%)$ & $3(8,6 \%)$ & $26(76,5 \%)$ & $7(21,9 \%)$ & $2(12,5 \%)$ \\
\hline
\end{tabular}

Tabla 8. Evolución de la VA a lo largo de los años de estudio.

(Número total de paciente tratados con VA dentro de cada grupo por año y porcentaje de pacientes tratados con VA dentro del total de pacientes de ese grupo en ese año) *Solo se analiza de enero-septiembre de 2020

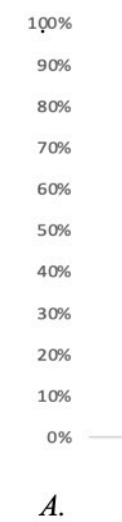

Gráfico 4. Tratamientos más utilizados según los Grupos de Riesgo de la EAU.

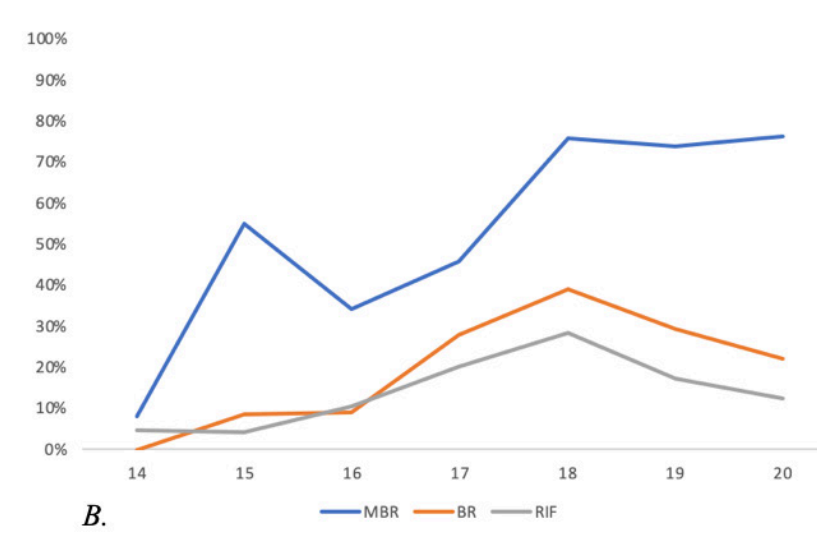

Gráfico 5. Evolución de la VA a lo largo de los años de estudio. A. Según la EAU. B. Según la NCCN 


\subsection{ANÁLISIS DESCRIPTIVO DE LOS PACIENTES EN VIGILANCIA ACTIVA EN SALAMANCA: 2014-2020}

A fecha de la revisión de los datos de dicha tesis doctoral, en el protocolo de VA del CAUSA había 276 pacientes, de los cuales 272 fueron diagnosticados mediante biopsia transrectal ecodirigida en el CAUSA, 3 pacientes fueron diagnósticos incidentales (resección trasuretral prostática (RTU-P) o cistoprostatectomía) en el CAUSA, y 1 de los pacientes fue diagnosticado mediante biopsia transrectal fuera del CAUSA pero su seguimiento se hace en el mismo.

Como decíamos anteriormente, en el CAUSA los pacientes que entran en el protocolo de VA pueden hacerlo mediante dos esquemas de seguimiento: VA pura o VA expandida. El 59,4\% de los pacientes incluidos en e protocolo lo hicieron mediante el esquema de VA pura, mientras que el 40,6\% restante cumplía criterios de VA expandida.

La edad media al diagnóstico de estos pacientes era de 68,35 años (min 46 máx 78). Si agrupamos los pacientes por franjas de edad, 159 pacientes (57,6\%) eran menores de 70 años, mientras que 117 pacientes (42,4\%) tenían más de 70 años.

Se analizaron las comorbilidades: HTA, DM, DL y antecedentes oncológicos que presentaban estos pacientes, las cuales quedan reflejadas en el gráfico 6

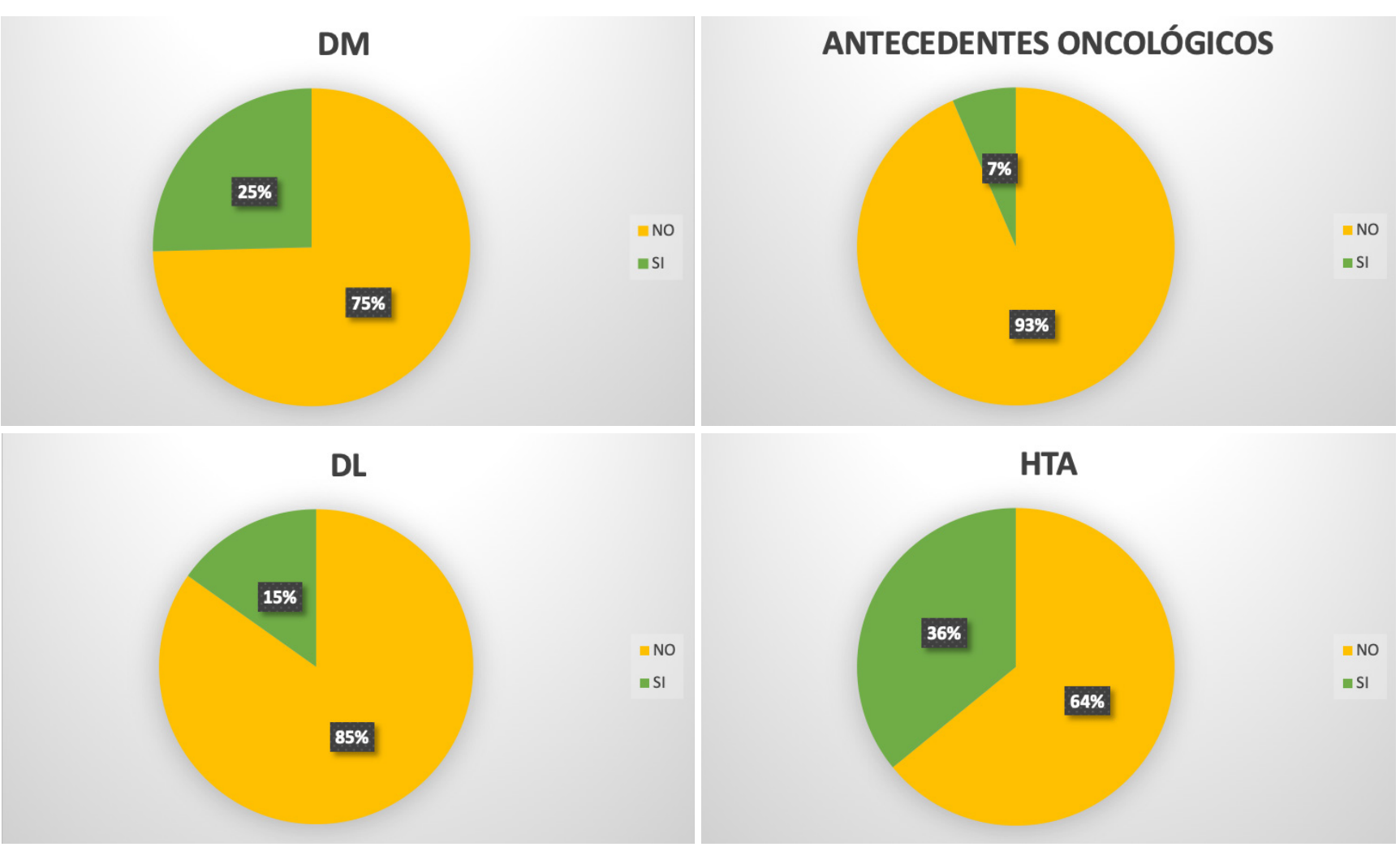

Gráfico 6. Comorbilidades de los pacientes en VA en el CAUSA.

$$
\text { Leyenda: }
$$

Amarillo: no comorbilidad. Verde: si comorbilidad. $D M=$ diabetes mellitus $D L=$ dislipemia $H T A=$ hipertensión arterial
Dentro de los antecedentes oncológicos, los más prevalentes eran los tumores digestivos (7 pacientes 38,9\%) y los tumores de vejiga (4 pacientes $22,2 \%$ ).

Los pacientes incluidos en VA presentaban una media de PSA de 7,10 ng/mL, mediana 6,33 ng/mL (min 1,08 máx 33,29). Si agrupamos los pacientes por franjas de PSA, la mayoría de los pacientes presentaron un PSA entre $4-10 \mathrm{ng} / \mathrm{mL}$ (224 pacientes $81,2 \%)$.

Durante la realización de la biopsia transrectal ecodirigida, se extrajeron de media 10,89 cilindros (min 9, máx 29), de los cuales la media de cilindros positivos para tumor fue de 1,61 (min 1 máx 6). Con una mediana de longitud de 1,95 $\mathrm{mm}$ de tumor (min 0,12mm, máx 60mm). La mayoría de los tumores diagnosticados fueron en un solo lóbulo prostático (unilaterales), $243(88 \%)$, frente a $30(10,9 \%)$ pacientes, que tenían tumor en ambos lóbulos prostáticos.

Si analizamos la anatomía patológica de los tumores de los pacientes en VA, el 97,1\% (268 pacientes) presentaron un tumor ISUP 1/GG 3+3 y el 2,9\% (8 pacientes) un tumor ISUP 2/GG 3+4.

Considerando los grupos de riesgo de recaída bioquímica de la EAU, el 77,3\% de los pacientes en VA pertenecen al grupo de localizado bajo riesgo, el 21,7\% al localizado riesgo intermedio y el 1,1\% al localizado alto riesgo. Este $1,1 \%$ corresponde a 3 pacientes con PSA por encima de $20 \mathrm{ng} / \mathrm{mL}$, motivo por el cual son considerados pacientes de alto riesgo, pero que tienen realizada RMN y biopsia de confirmación con resultado de HBP, por lo cual se consensuó con el comité de uro-oncología del CAUSA y con los propios pacientes su permanencia en el programa de VA con un seguimiento más estrecho de lo habitual, decidiendo los pacientes permanecer en el mismo.

Si tenemos en cuenta los grupos de riesgo de la NCCN, el 61,2\% de los pacientes eran pacientes localizados de muy bajo riesgo, el 21,4\% localizados de bajo riesgo, el 15,9\% localizados de riesgo intermedio favorable, el o,7\% localizado de riesgo intermedio desfavorable y el o,7\% localizados de alto riesgo.

\subsection{ANÁLISIS DE LA ADHERENCIA AL PROTOCOLO DE VIGILANCIA ACTIVA EN SALAMANCA: 2014-2020}

Para evaluar la adherencia al protocolo de VA se han seleccionado aquellos pacientes que a fecha de revisión de los datos, habían pasado al menos 12 meses desde que se les había propuesto entrar en el programa de VA, realizando así el análisis sobre los 218 pacientes que cumplen esta condición $(78,9 \%)$

En primer lugar, se analizó el tiempo que transcurre desde la realización de la biopsia prostática, hasta que el paciente es informado del resultado de la anatomía patológica y se decide realizar tratamiento con VA y es, por tanto, incluido en dicho protocolo. La mediana fue de 29 días (min 10 máx 211).

En segundo lugar, el protocolo de VA estipula que los pacientes deben realizar una primera revisión con PSA ranscurridos un máximo de 6 meses tras el diagnóstico. En el CAUSA, esta primera revisión fue realizada por el servicio de Urología en el 99,5\% (217 pacientes) de los pacientes. El paciente que no realizó la revisión es un paciente diagnosticado de un cáncer de laringe sincrónico en control por el servicio de oncología radioterápica el cual le realiza simultáneamente el seguimiento de ambos tumores. Esta revisión se realizó de media a los 4,61 meses; mediana de 4 meses (min o máx 19). 
En tercer lugar, como se comentó anteriormente, uno de los requisitos del protocolo de VA es la realización de una RMN previamente a la realización de la biopsia de confirmación. De media, la RMN se realiza a los 8,97 meses desde la inclusión, mediana de 7 meses (min o máx 36). El 72,5\% de los pacientes (158) había realizado dicha RMN, mientras que el 27,5\% (6o) no llegaron a realizar la RMN. Los motivos de no realización se desglosan en el gráfico 7. El principal factor es un fallo en el protocolo, es decir, la RMN se solicita pero debido a problemas en la gestión hospitalaria esta no se puede realizar antes de la biopsia de confirmación, esto ocurre en 22 pacientes (36,7\% de los pacientes que no realizan la RMN); seguido muy de cerca por la decisión del paciente de no realizarse la prueba, bien, porque deciden abandonar el protocolo de VA previamente a que les corresponda la realización de la prueba, o porque pese a estar citados para la misma no se presentan a la prueba, lo cual ocurre en 18 pacientes (30\% de los pacientes que no realizan la RMN).

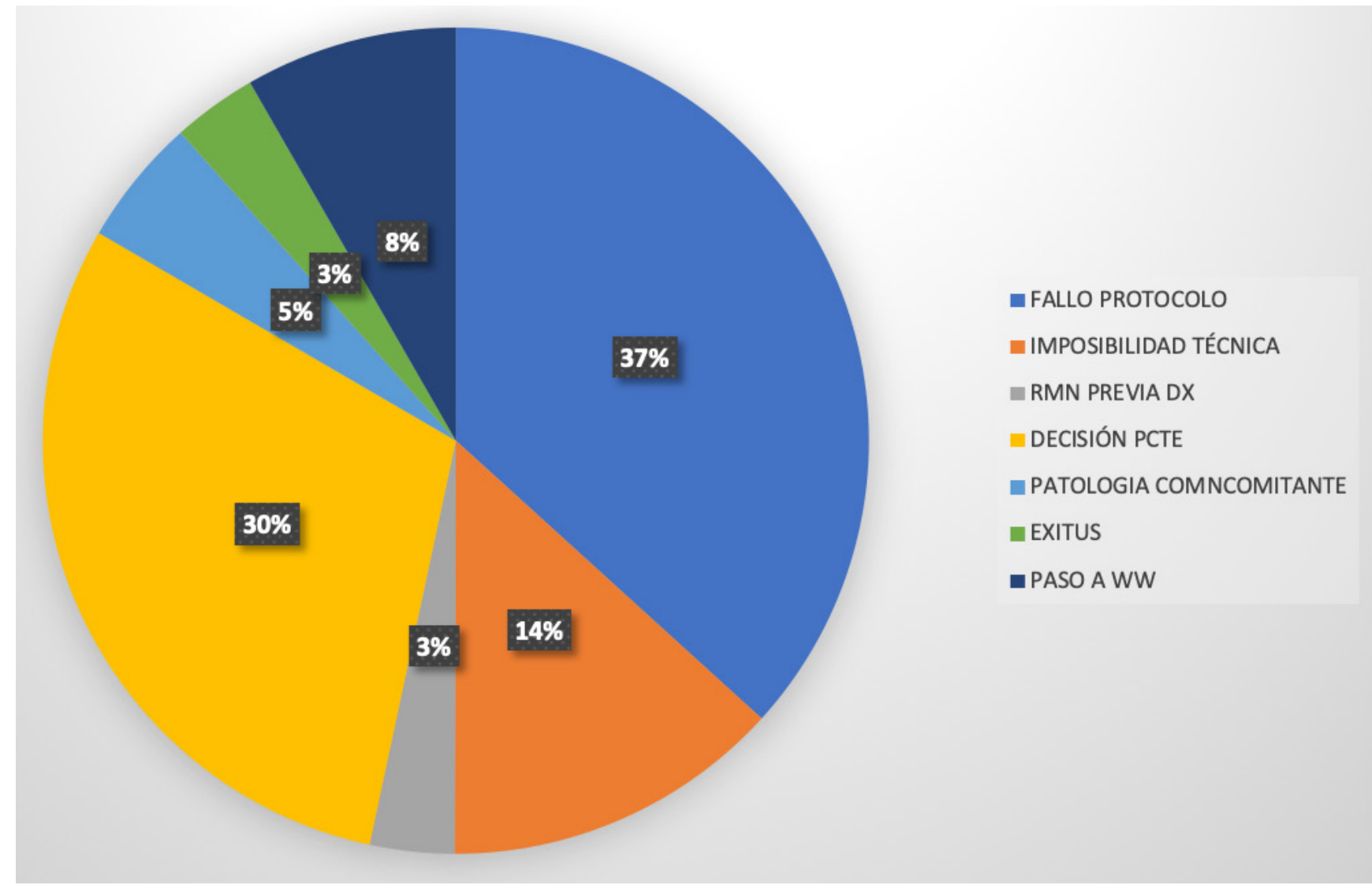

Gráfico 7. Motivos de no realización de la RMN (\% referidos dentro del total de RMN no realizadas)

Finalmente, dentro del primer año de seguimiento de los pacientes en VA, los protocolos estipulan que se debe de realizar una nueva biopsia de confirmación. En el CAUSA, esta re-biopsia se realiza de media a los 14,81 meses, mediana de 13,50 meses (min 2 máx 39). De los 218 pacientes con al menos un año de seguimiento, a la fecha de dicha revisión, el 60,6\% de los pacientes (132) había realizado la biopsia en tiempo y forma correcta. El 39,4\% de los pacientes (86) pese a estar indicada dicha re-biopsia no puedo ser realizada por diversos motivos, el principal motivo fue la decisión del paciente de salir de protocolo previo al año de seguimiento (26 pacientes de 86: 30\%). Los demás motivos de no realización de la re-biopsia se detallan en el gráfico 8. Hay que tener en cuenta, que la pandemia COVID-19, con las limitaciones de acceso a quirófano en algunos momentos, también puede haber influido en estos datos

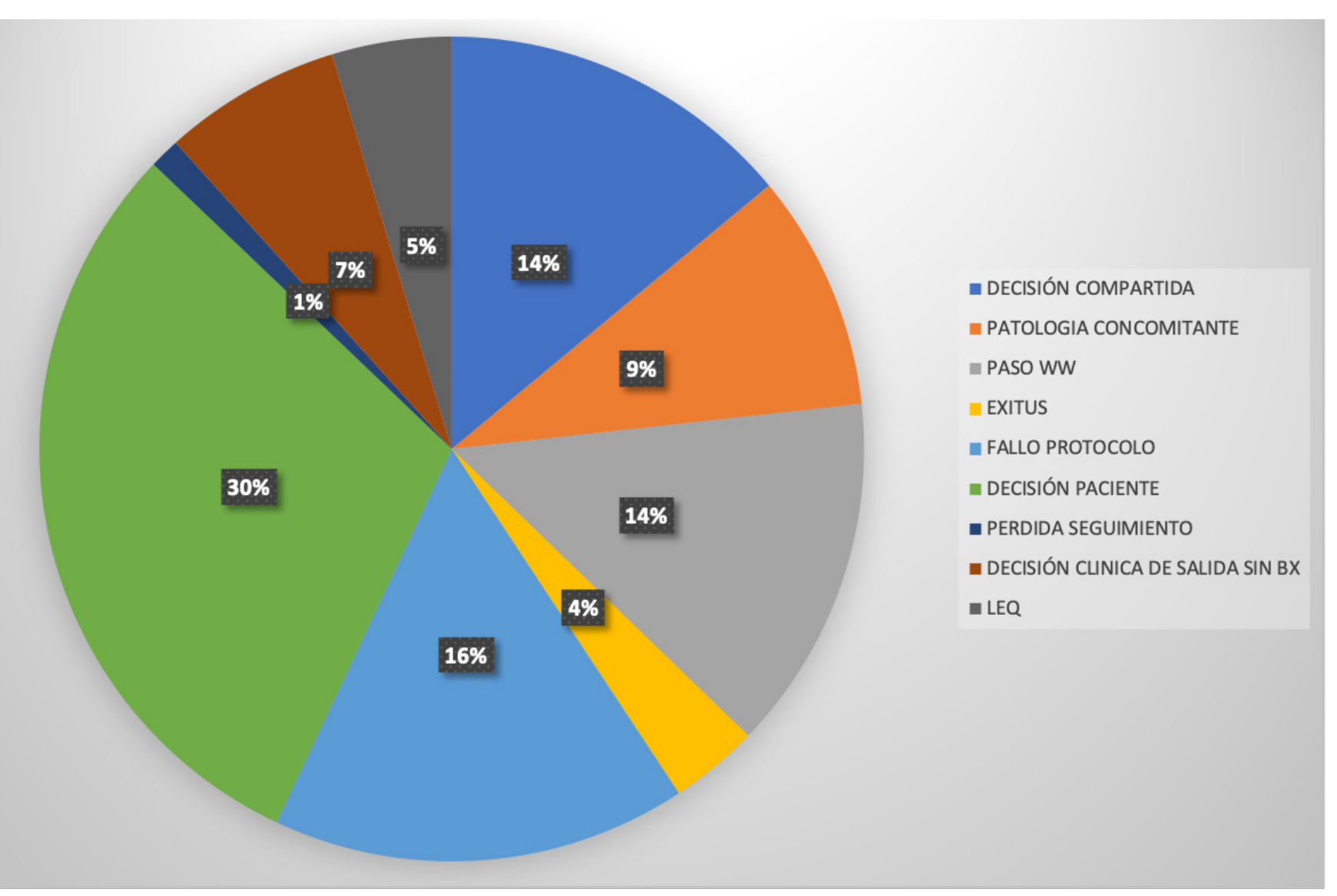

Gráfico 8. Motivos de no realización de re-biopsia. (\% referidos dentro del total de re-biopsias no realizadas)

\subsection{ANÁLISIS DE LA SALIDA DEL PROTOCOLO, MOTIVOS SALIDA, PROGRESIÓN Y ESTATUS DE LOS PACIENTES}

Para evaluar la salida del protocolo y sus motivos, así como la progresión de la enfermedad y el estatus de los pacientes, se han seleccionado aquellos pacientes que a fecha de revisión de los datos, había pasado al menos 12 meses que se les había propuesto entrar en el programa de VA, realizando así el análisis sobre los 218 pacientes que cumplen esta condición $(78,9 \%)$

En primer lugar analizamos la salida de manera global del protocolo. De los 218 pacientes analizados, 122 (56\%) continúan dentro del protocolo, habiendo salido del programa 96 pacientes (44\%).

En segundo lugar, se analizan los motivos de salida del programa de VA: motivo clínico (47 pacientes, 21,6\% del total de pacientes analizados), decisión personal del paciente (32 pacientes, 14,7\% del total de pacientes analizados), paso a WW debido a la edad del paciente (14 pacientes, $6,4 \%$ del total de pacientes analizados) y exitus ( 3 pacientes, $1,4 \%$ del total de pacientes analizados).

Los motivos clínicos se analizan en el gráfico 9. El principal de estos motivos es el aumento del GG, ocurriendo el 57,4\% de los pacientes que salen por causa clínica ( 27 de 47 pacientes); lo que suponen únicamente el 12,3\% de los pacientes analizados. 


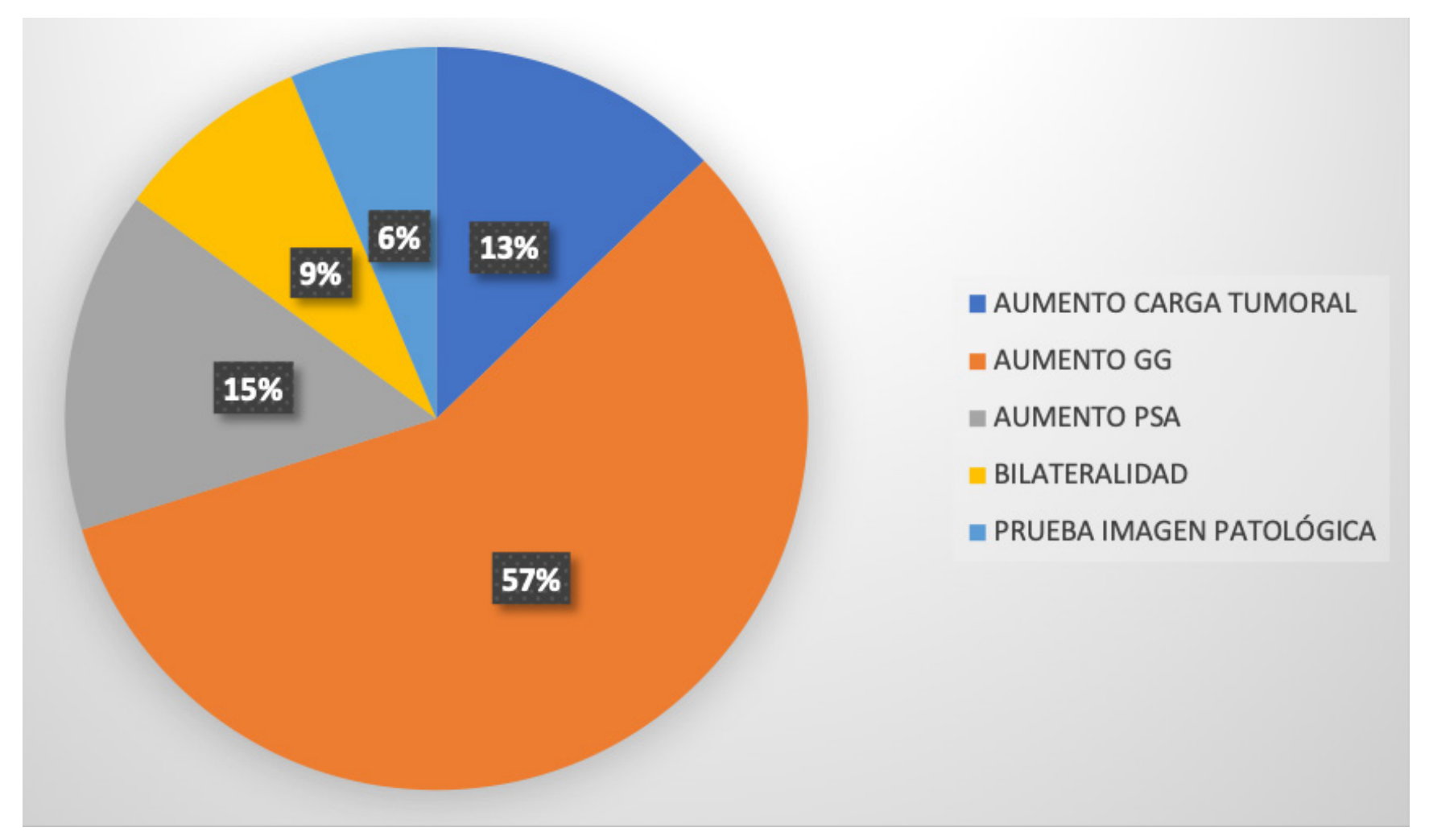

Gráfico 9. Motivos clínicos de salida de VA

(\% referidos dentro del total de pacientes que salen por motivo clínico)

La siguiente causa principal para el abandono del programa de VA, es la decisión del paciente de no continuar en el protocolo pese a cumplir criterios clínicos para su permanencia. Esto ocurre en el 33,3\% (32 pacientes de 96) de los pacientes que abandonan nuestro programa. La principal causa que manifiestan los pacientes para dejar el protocolo de VA, pese a la indicación del equipo multidisciplinar de que pueden continuar en él es la ansiedad que les produce saber que tienen una enfermedad tumoral que no está recibiendo un tratamiento radical.

Esta ansiedad es producida debido al miedo a que el tumor progrese y después no se les pueda realizar un tratamiento con intención radical y eso impacte en su supervivencia. Si bien es verdad, que en nuestro programa de VA ese motivo ha ido disminuyendo a lo largo de los años, debido al empleo de las decisiones consensuadas con el propio paciente implantadas en el protocolo.

Tras la salida del protocolo de VA, independientemente del motivo de la misma, el 34,4\% de los pacientes (33 pacientes de 96) reciben RT externa como tratamiento de su tumor, seguido del 20,8\% de los pacientes (20 paciente de 96) que son tratados mediante PR.

Si analizamos los tratamientos realizados tras la salida de VA, en función del motivo de salida, nos encontramos que el tratamiento de elección en el caso de los pacientes que salen por decisión clínica es la RT (23 pacientes de 47: $48,9 \%)$.

En el caso de los pacientes que salen por decisión propia, el tratamiento elegido es la BT (12 pacientes de 32: $37,5 \%)$

La media de seguimiento los 218 pacientes analizados es de 22,76 meses, con una mediana de 19 meses (min o máx 72)

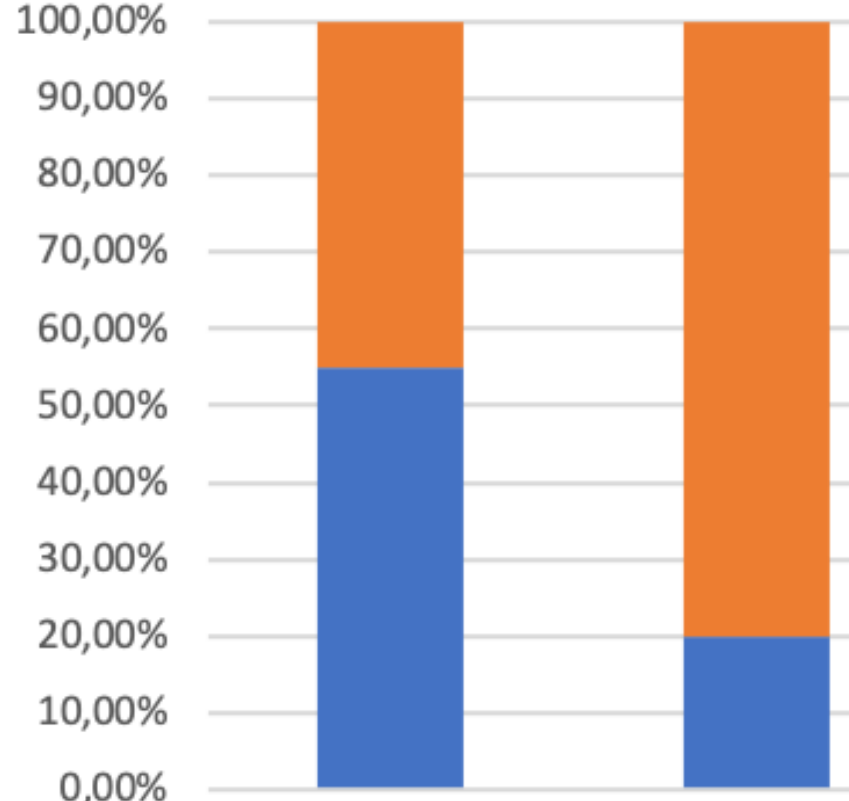

PR

BT

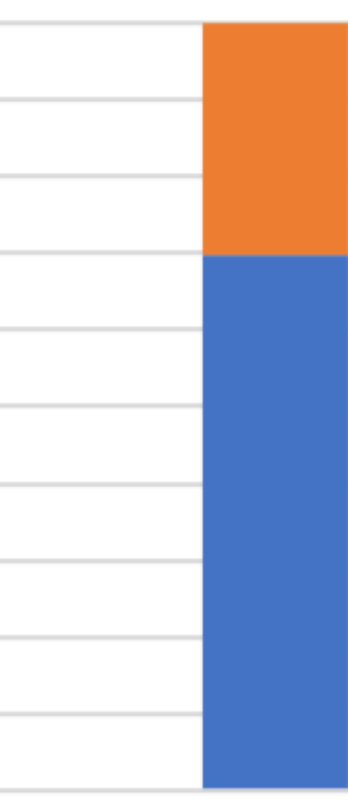

RT

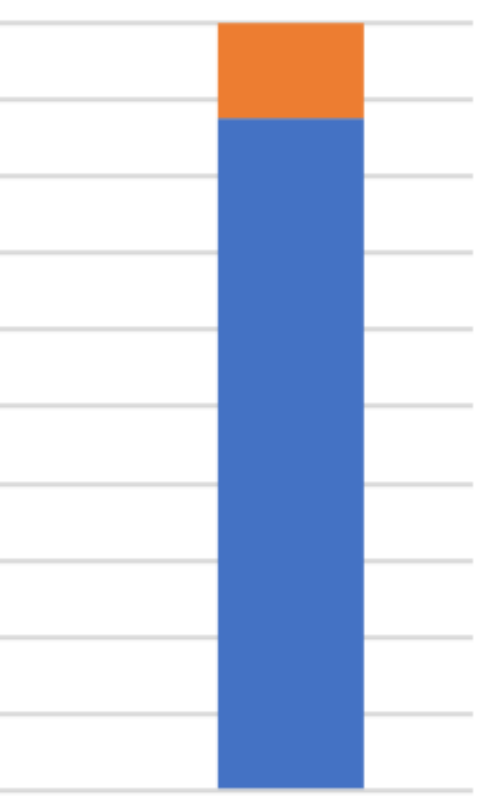

TDA
- MOTIVO CLINICO MOTIVO PACIENTE

De los 218 pacientes analizados, 3 de ellos habían fallecido a fecha de revisión de los datos, pero ninguno por causas relacionadas con su tumor prostático: uno falleció por neumonía bilateral por SARS-COV-2, otro por una complicación de su Síndrome Mielodisplásico (SMD) concomitante, y el tercer por un traumatismo craneoencefálico tras una caída accidental.

\subsection{ANÁLISIS DE LA CALIDAD DE VIDA Y NIVELES DE ANSIEDAD DE LOS PACIENTES EN EL PROTOCOLO DE VA.}

De los 276 pacientes incluidos en el programa VA en el momento de nuestra revisión, sobre 77 de ellos se ha contado con datos objetivos (medidos mediante cuestionarios y escalas visuales) sobre su percepción de su CVRS y sus niveles de ansiedad relacionado con la enfermedad.

La CVRS fue evaluada mediante el cuestionario CAVIPRES [95] (ANEXO 1) y los niveles de ansiedad mediante una escala visual analógica (EVA) en la que el menor nivel de ansiedad era el o y el máximo el 10. (ANEXO 1). Así mismo se evaluó el estado civil de los pacientes y el tratamiento farmacológico urológico concomitante; así como el tiempo que llevaban en el protocolo de VA los pacientes.

De los 77 pacientes de los que se disponían datos sobre la CVRS, 72 de ellos eran válidos para el análisis; de los 5 restantes, los cuestionarios estaban incompletos por lo que no fue posible su correcta valoración.

La media de puntuación total del CAVIPRES es de 79,17 puntos (min 53 máx 124). Gómez Veiga et al, [95] cuando procedieron a la validación del cuestionario CAVIPRES, establecieron que las puntuaciones entre 30-54 
puntos correspondían a una muy mala CVRS, que en esta muestra supone el 2,8\% de los pacientes (2 pacientes de 72), entre 55-78 puntos mala CVRS; en nuestros pacientes supone el 45,8\% de ellos (33 pacientes de 72); entre 79-102 puntos regular CVRS, 47,2\% de la muestra (34 pacientes de 72); entre 103-126 puntos buena CVRS, 4,2\% de los pacientes cuestionados (3 pacientes de 72) y entre 127-150 puntos muy buena CVRS.

El cuestionario CAVIPRES está dividido en 5 apartados: aspectos psicológicos, esperanza y futuro, vida sexual, apoyo social y pareja, otros:

1. Aspecto psicológico; cuanto mayor es la puntuación, mejor en la CVRS de ese paciente en ese apartado. En nuestro caso tenemos una media de 27,88 puntos (min 11 máx 40). El 55,6\% de los pacientes (40 de 72 pacientes) demostraban tener una buena CVRS si analizáramos solamente este aspecto del cuestionario.

2. Esperanza y el futuro, cuando menor es la puntuación obtenida en ese apartado, mejor es la CVRS del paciente En los datos analizados se obtiene una media de 6,82 puntos (min 4 máx 20). El 80,5\% de los pacientes (62 de 72 pacientes) decían tener una buena CVRS en ese subapartado.

3. Vida sexual, a mayor puntuación mayor CVRS. En los datos analizados se obtiene una media de 19,71 punto (min 6 máx 30). El 34,7\% de los pacientes (25 de 72 pacientes) presenta una muy buena CVRS en este apartado.

4. Apoyo social y pareja; a menor puntuación, mayor es la percepción del apoyo familiar y de la pareja, y por tanto mejor es la CVRS. Obtenemos una puntuación media de 9,99 puntos (min 6 máx 28). El 80,6\% de los pacientes (58 de 72 pacientes) refieren un buen apoyo familiar y/o de pareja.

Los datos anteriores se reflejan en el gráfico 11.

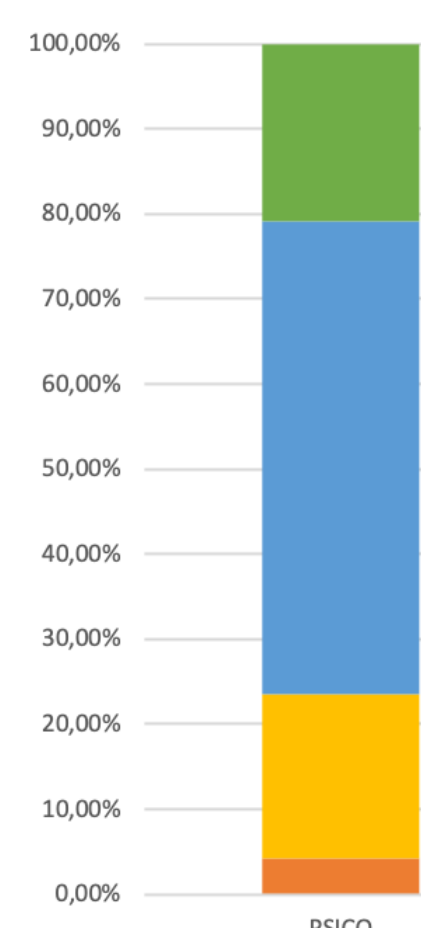

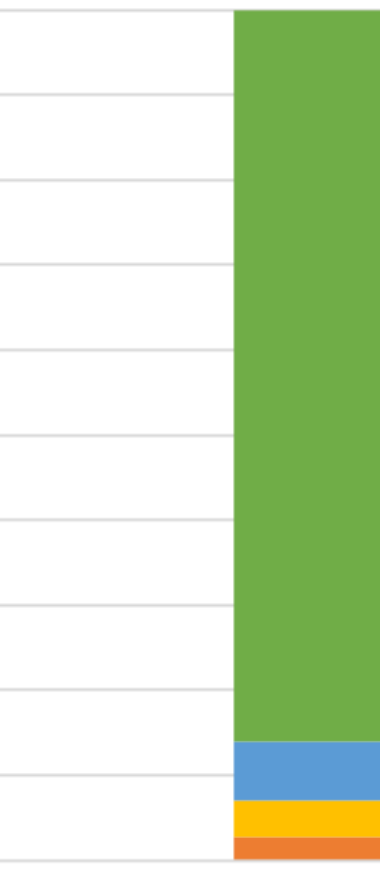

FUTURO

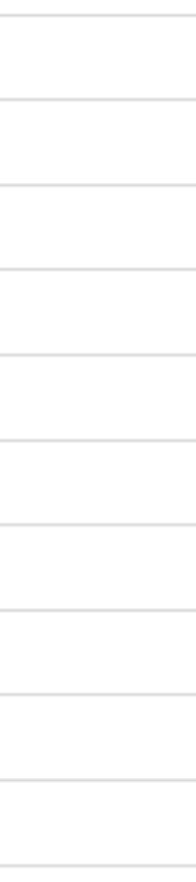

I BUENA CYRS SEXUS

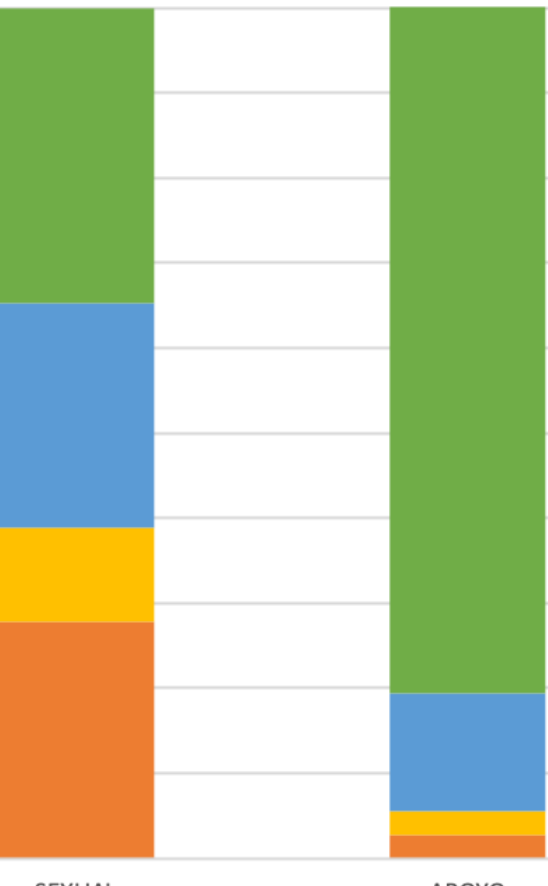

Gráfico 11. CVRS por apartados.
Tras analizar las puntuaciones obtenidas en el cuestionario de manera global, se procede al análisis de la relación entre la puntuación en el mismo con el estado civil, el tratamiento farmacológico urológico concomitante y el tiempo transcurrido desde la inclusión en VA, quedando reflejado en las tablas 9, 10, 11, 12 y 13

\begin{tabular}{|c|c|c|c|c|c|c|c|c|}
\hline & \multicolumn{2}{|c|}{ Pareja } & \multicolumn{2}{|c|}{$\begin{array}{c}\text { Tratamiento } \\
\text { farmacologico }\end{array}$} & \multicolumn{4}{|c|}{ Tiempo en VA } \\
\hline & No & SI & NO & SI & Basal & $\begin{array}{c}\text { 6-12 } \\
\text { meses }\end{array}$ & $\begin{array}{l}12-18 \\
\text { meses }\end{array}$ & $\begin{array}{c}\text { Más } \\
\text { de } 18 \\
\text { meses }\end{array}$ \\
\hline $\begin{array}{l}\text { Muy } \\
\text { mala } \\
\text { CVRS }\end{array}$ & $\begin{array}{c}1 \\
(50 \% / \\
4,3 \%)\end{array}$ & $\begin{array}{c}1 \\
(50 \% / \\
2 \%)\end{array}$ & 0 & $\begin{array}{c}2 \\
(100 \% / \\
5,7 \%)\end{array}$ & 0 & $\begin{array}{c}1 \\
(50 \% / \\
7,7 \%)\end{array}$ & 0 & $\begin{array}{c}1 \\
(50 \% / \\
4,5 \%)\end{array}$ \\
\hline $\begin{array}{l}\text { Mala } \\
\text { CVRS }\end{array}$ & $\begin{array}{c}8 \\
(24,2 \% / \\
34,8 \%)\end{array}$ & $\begin{array}{c}25 \\
(75,8 \% / \\
51 \%)\end{array}$ & $\begin{array}{c}19 \\
(57,6 \% / \\
51,4 \%)\end{array}$ & $\begin{array}{c}14 \\
(42,4 \% / \\
40 \%)\end{array}$ & $\begin{array}{c}13 \\
(39,4 \% / \\
54,2 \%)\end{array}$ & $\begin{array}{c}6 \\
(18,2 \% / \\
46,2 \%)\end{array}$ & $\begin{array}{c}6 \\
(18,2 \% / \\
46,2 \%)\end{array}$ & $\begin{array}{c}8 \\
(24,2 \% / \\
36,4 \%)\end{array}$ \\
\hline $\begin{array}{l}\text { Regular } \\
\text { CVRS }\end{array}$ & $\begin{array}{c}14 \\
(41,2 \% / \\
60,9 \%)\end{array}$ & $\begin{array}{c}20 \\
(58,8 \% / \\
40,8 \%)\end{array}$ & $\begin{array}{c}16 \\
(47,1 \% / \\
43,2 \%)\end{array}$ & $\begin{array}{c}18 \\
(52,9 \% / \\
51,4 \%)\end{array}$ & $\begin{array}{c}10 \\
(29,4 \% / \\
41,7 \%)\end{array}$ & $\begin{array}{c}4 \\
(11,8 \% / \\
30,8 \%)\end{array}$ & $\begin{array}{c}7 \\
(20,6 \% / \\
53,8 \%)\end{array}$ & $\begin{array}{c}13 \\
(38,2 \% / \\
59,1 \%)\end{array}$ \\
\hline $\begin{array}{l}\text { Buena } \\
\text { CVRS }\end{array}$ & o & $\begin{array}{c}3 \\
(100 \% / \\
6,1 \%)\end{array}$ & $\begin{array}{c}2 \\
(66,7 \% / \\
5,4 \%)\end{array}$ & $\begin{array}{c}1 \\
(33,3 \% / \\
2,9 \%)\end{array}$ & $\begin{array}{c}1 \\
(33,3 \% / \\
4,2 \%)\end{array}$ & $\begin{array}{c}2 \\
(66,7 \% / \\
15,4 \%)\end{array}$ & o & 0 \\
\hline
\end{tabular}

Tabla 9.

Puntuaciones globales CAVIPRES en relación con el estado civil, tratamiento urológico y tiempo en VA. ${ }^{* *}$ El primer porcentaje hace referencia al porcentaje de la fila y el segundo al de la columna

\begin{tabular}{|c|c|c|c|c|c|c|c|c|}
\hline & \multicolumn{2}{|c|}{ Pareja } & \multicolumn{2}{|c|}{$\begin{array}{c}\text { Tratamiento } \\
\text { farmacológico } \\
\end{array}$} & \multicolumn{4}{|c|}{ Tiempo en VA } \\
\hline & NO & SI & NO & SI & Basal & $\begin{array}{c}6-12 \\
\text { meses }\end{array}$ & $\begin{array}{c}12-18 \\
\text { meses }\end{array}$ & $\begin{array}{c}\text { Más } \\
\text { de } 18 \\
\text { meses }\end{array}$ \\
\hline $\begin{array}{c}\text { Muy } \\
\text { mala } \\
\text { CVRS }\end{array}$ & $\begin{array}{c}1 \\
(33,3 \% / \\
4,3 \%)\end{array}$ & $\begin{array}{c}2 \\
(66,7 \% / \\
4,1 \%)\end{array}$ & $\begin{array}{c}3 \\
(100 \% / \\
81 \%)\end{array}$ & o & $\begin{array}{c}1 \\
(33,3 \% / \\
4,2 \%)\end{array}$ & o & $\begin{array}{c}1 \\
(33,3 \% / \\
7,7 \%)\end{array}$ & $\begin{array}{c}1 \\
(33, \% / \\
4,5 \%)\end{array}$ \\
\hline $\begin{array}{l}\text { Mala } \\
\text { CVRS }\end{array}$ & $\begin{array}{c}6 \\
(42,9 \% / \\
26,1 \%)\end{array}$ & $\begin{array}{c}8 \\
(57,1 \% / \\
16,3 \%)\end{array}$ & $\begin{array}{c}7 \\
(50 \% / \\
18,9 \%)\end{array}$ & $\begin{array}{c}7 \\
(50 \% / \\
20 \%)\end{array}$ & $\begin{array}{c}6 \\
(42,9 \% / \\
25 \%)\end{array}$ & $\begin{array}{c}4 \\
(28,6 \% / \\
30,8 \%)\end{array}$ & $\begin{array}{c}1 \\
(7,1 \% / \\
7,7 \%)\end{array}$ & $\begin{array}{c}3 \\
(21,4 \% / \\
13,6 \%)\end{array}$ \\
\hline $\begin{array}{l}\text { Regular } \\
\text { CVRS }\end{array}$ & $\begin{array}{c}7 \\
(17,5 \% / \\
30,4 \%)\end{array}$ & $\begin{array}{c}33 \\
(82,5 \% / \\
67,3 \%)\end{array}$ & $\begin{array}{c}18 \\
(45 \% / \\
48,6 \%)\end{array}$ & $\begin{array}{c}22 \\
(55 \% / \\
62,9 \%)\end{array}$ & $\begin{array}{c}13 \\
(32,5 \% / \\
54,2 \%)\end{array}$ & $\begin{array}{c}6 \\
(15 \% / \\
46,2 \%)\end{array}$ & $\begin{array}{c}8 \\
(20 \% / \\
61,5 \%)\end{array}$ & $\begin{array}{c}13 \\
(32,5 / \\
59,1 \%)\end{array}$ \\
\hline $\begin{array}{l}\text { Buena } \\
\text { CVRS }\end{array}$ & $\begin{array}{c}9 \\
(60 \% / \\
39,1 \%)\end{array}$ & $\begin{array}{c}6 \\
(40 \% / \\
12,2 \%)\end{array}$ & $\begin{array}{c}9 \\
(60 \% / \\
24,3 \%)\end{array}$ & $\begin{array}{c}6 \\
(40 \% / \\
17,1 \%)\end{array}$ & $\begin{array}{c}4 \\
(16,7 \% / \\
16,7 \%)\end{array}$ & $\begin{array}{c}3 \\
(20 \% / \\
23,1 \%)\end{array}$ & $\begin{array}{c}3 \\
(20 \% / \\
23,1 \%)\end{array}$ & $\begin{array}{c}5 \\
(33,3 \% / \\
22,7 \%)\end{array}$ \\
\hline
\end{tabular}

Tabla 10.

Puntuaciones apartado psicológico CAVIPRES en relación con el estado civil, tratamiento urológico y tiempo en VA. ${ }^{* *}$ El primer porcentaje hace referencia al porcentaje de la fila y el segundo al de la columna 


\begin{tabular}{|c|c|c|c|c|c|c|c|c|}
\hline & \multicolumn{2}{|c|}{ Pareja } & \multicolumn{2}{|c|}{$\begin{array}{c}\text { Tratamiento } \\
\text { farmacológico } \\
\end{array}$} & \multicolumn{4}{|c|}{ Tiempo en VA } \\
\hline & NO & SI & NO & SI & Basal & $\begin{array}{c}\text { 6-12 } \\
\text { meses }\end{array}$ & $\begin{array}{c}12-18 \\
\text { meses }\end{array}$ & $\begin{array}{c}\text { Más } \\
\text { de } 18 \\
\text { meses }\end{array}$ \\
\hline $\begin{array}{l}\text { Muy } \\
\text { mala } \\
\text { CVRS }\end{array}$ & $\begin{array}{c}1 \\
(50 \% / \\
4,3 \%)\end{array}$ & $\begin{array}{c}1 \\
(50 \% / \\
2 \%)\end{array}$ & $\begin{array}{c}2 \\
(100 \% / \\
5,4 \%)\end{array}$ & o & o & $\begin{array}{c}1 \\
(50 \% / \\
7,7 \%)\end{array}$ & 0 & $\begin{array}{c}1 \\
(50 \% / \\
4,5 \%)\end{array}$ \\
\hline $\begin{array}{l}\text { Mala } \\
\text { CVRS }\end{array}$ & $\begin{array}{c}2 \\
(66,7 \% / \\
8,7 \%)\end{array}$ & $\begin{array}{c}3 \\
(33,3 \% / \\
2 \%)\end{array}$ & $\begin{array}{c}1 \\
(33,3 \% / \\
2,7 \%)\end{array}$ & $\begin{array}{c}2 \\
(66,7 \% / \\
5,7 \%)\end{array}$ & o & $\begin{array}{c}1 \\
(33,3 \% / \\
7,7 \%)\end{array}$ & o & $\begin{array}{c}2 \\
(66,75 / \\
9,1 \%)\end{array}$ \\
\hline $\begin{array}{l}\text { Regular } \\
\text { CVRS }\end{array}$ & $\begin{array}{c}2 \\
(40 \% / \\
8,7 \%)\end{array}$ & $\begin{array}{c}3 \\
(60 \% / \\
6,1 \%)\end{array}$ & $\begin{array}{c}4 \\
(80 \% / \\
10,8 \%)\end{array}$ & $\begin{array}{c}1 \\
(20 \% / \\
2,9 \%)\end{array}$ & $\begin{array}{c}3 \\
(60 \% / \\
12,5 \%)\end{array}$ & $\begin{array}{c}1 \\
(20 \% / \\
7,7 \%)\end{array}$ & 0 & $\begin{array}{c}1 \\
(20 \% / \\
4,5 \%)\end{array}$ \\
\hline $\begin{array}{l}\text { Buena } \\
\text { CVRS }\end{array}$ & $\begin{array}{c}18 \\
(29 \% / \\
78,3 \%)\end{array}$ & $\begin{array}{c}44 \\
(71 \% / \\
89,8 \%)\end{array}$ & $\begin{array}{c}30 \\
(48,4 \% / \\
81,1 \%)\end{array}$ & $\begin{array}{c}32 \\
(51,6 \% / \\
91,4 \%)\end{array}$ & $\begin{array}{c}21 \\
(33,9 \% / \\
87,5 \%)\end{array}$ & $\begin{array}{c}10 \\
(16,1 \% / \\
76,9 \%)\end{array}$ & $\begin{array}{c}13 \\
(21 \% / \\
100 \%)\end{array}$ & $\begin{array}{c}18 \\
(29 \% / \\
81,8 \%)\end{array}$ \\
\hline
\end{tabular}

\begin{tabular}{|c|c|c|c|c|c|c|c|c|}
\hline & \multicolumn{2}{|c|}{ Pareja } & \multicolumn{2}{|c|}{$\begin{array}{l}\text { Tratamiento } \\
\text { farmacologico }\end{array}$} & \multicolumn{4}{|c|}{ Tiempo en VA } \\
\hline & NO & SI & NO & SI & Basal & $\begin{array}{c}\text { 6-12 } \\
\text { meses }\end{array}$ & $\begin{array}{c}12-18 \\
\text { meses }\end{array}$ & $\begin{array}{c}\text { Más } \\
\text { de } 18 \\
\text { meses }\end{array}$ \\
\hline $\begin{array}{l}\text { Muy } \\
\text { mala } \\
\text { CVRS }\end{array}$ & 0 & $\begin{array}{c}2 \\
(100 \% / \\
4,1 \%)\end{array}$ & $\begin{array}{c}2 \\
(100 \% / \\
5,4 \%)\end{array}$ & 0 & 0 & $\begin{array}{c}2 \\
(100 \% / \\
15,4 \%)\end{array}$ & 0 & 0 \\
\hline $\begin{array}{l}\text { Mala } \\
\text { CVRS }\end{array}$ & $\begin{array}{c}2 \\
(100 \% / \\
4,3 \%)\end{array}$ & 0 & 0 & $\begin{array}{c}2 \\
(100 \% / \\
5,7 \%)\end{array}$ & $\begin{array}{c}1 \\
(50 \% / \\
4,2 \%)\end{array}$ & $\begin{array}{c}1 \\
(50 \% / \\
7,7 \%)\end{array}$ & 0 & 0 \\
\hline $\begin{array}{l}\text { Regular } \\
\text { CVRS }\end{array}$ & $\begin{array}{c}1 \\
(10 \% / \\
4,3 \%)\end{array}$ & $\begin{array}{c}9 \\
(90 \% / \\
18,4 \%)\end{array}$ & $\begin{array}{c}5 \\
(50 \% / \\
13,5 \%)\end{array}$ & $\begin{array}{c}5 \\
(50 \% / \\
14,3 \%)\end{array}$ & $\begin{array}{c}5 \\
(50 \% / \\
20,8 \%)\end{array}$ & $\begin{array}{c}1 \\
(10 \% / \\
7,7 \%)\end{array}$ & 0 & $\begin{array}{c}4 \\
(40 \% / \\
18,2 \%)\end{array}$ \\
\hline $\begin{array}{l}\text { Buena } \\
\text { CVRS }\end{array}$ & $\begin{array}{c}20 \\
(34,5 \% / \\
87 \%)\end{array}$ & $\begin{array}{c}38 \\
(65,5 \% / \\
77,6 \%)\end{array}$ & $\begin{array}{c}30 \\
(51,7 \% / \\
81,1 \%)\end{array}$ & $\begin{array}{c}28 \\
(48,3 \% / \\
80 \%)\end{array}$ & $\begin{array}{c}18 \\
(31 \% / \\
75 \%)\end{array}$ & $\begin{array}{c}9 \\
(15,5 \% / \\
69,2 \%)\end{array}$ & $\begin{array}{c}13 \\
(22,4 \% / \\
100 \%)\end{array}$ & $\begin{array}{c}18 \\
(31 \% / \\
81,8 \%)\end{array}$ \\
\hline
\end{tabular}

Tabla 11.

Puntuaciones apartado futuro CAVIPRES en relación con el estado civil, tratamiento urológico y tiempo en VA.

**El primer porcentaje hace referencia al porcentaje de la fila y el segundo al de la columna

\begin{tabular}{|c|c|c|c|c|c|c|c|c|}
\hline & \multicolumn{2}{|c|}{ Pareja } & \multicolumn{2}{|c|}{$\begin{array}{l}\text { Tratamiento } \\
\text { farmacologico }\end{array}$} & \multicolumn{4}{|c|}{ Tiempo en VA } \\
\hline & NO & SI & NO & SI & Basal & $\begin{array}{c}6-12 \\
\text { meses }\end{array}$ & $\begin{array}{c}12-18 \\
\text { meses }\end{array}$ & $\begin{array}{c}\text { Más } \\
\text { de } 18 \\
\text { meses }\end{array}$ \\
\hline $\begin{array}{l}\text { Muy } \\
\text { mala } \\
\text { CVRS }\end{array}$ & $\begin{array}{c}5 \\
(25 \% / \\
21,7 \%)\end{array}$ & $\begin{array}{c}15 \\
(75 \% / \\
30,6 \%)\end{array}$ & $\begin{array}{c}10 \\
(50 \% / \\
27 \%)\end{array}$ & $\begin{array}{c}10 \\
(50 \% / \\
28,6 \%)\end{array}$ & $\begin{array}{c}4 \\
(20 \% / \\
16,7 \%)\end{array}$ & $\begin{array}{c}6 \\
(30 \% / \\
46,2 \%)\end{array}$ & $\begin{array}{c}4 \\
(20 \% / \\
30,8 \%)\end{array}$ & $\begin{array}{c}6 \\
(30 \% / \\
27,3 \%)\end{array}$ \\
\hline $\begin{array}{l}\text { Mala } \\
\text { CVRS }\end{array}$ & $\begin{array}{c}3 \\
(37,5 \% / \\
13 \%)\end{array}$ & $\begin{array}{c}5 \\
(62,5 \% / \\
10,2 \%)\end{array}$ & $\begin{array}{c}2 \\
(25 \% / \\
5,4 \%)\end{array}$ & $\begin{array}{c}6 \\
(75 \% / \\
17,1 \%)\end{array}$ & $\begin{array}{c}3 \\
(37,5 / \\
12,5 \%)\end{array}$ & $\begin{array}{c}1 \\
(12,5 \% / \\
7,7 \%)\end{array}$ & $\begin{array}{c}1 \\
(12,5 \% / \\
7,7 \%)\end{array}$ & $\begin{array}{c}3 \\
(37,5 \% / \\
13,6 \%)\end{array}$ \\
\hline $\begin{array}{l}\text { Regular } \\
\text { CVRS }\end{array}$ & $\begin{array}{c}7 \\
(36,8 \% / \\
20,4 \%)\end{array}$ & $\begin{array}{c}12 \\
(63,2 \% / \\
24,5 \%)\end{array}$ & $\begin{array}{c}11 \\
(57,9 \% / \\
29,7 \%)\end{array}$ & $\begin{array}{c}8 \\
(42,1 \% / \\
22,9 \%)\end{array}$ & $\begin{array}{c}5 \\
(26,3 \% / \\
20,8 \%)\end{array}$ & $\begin{array}{c}3 \\
(15,8 \% / \\
23,1 \%)\end{array}$ & $\begin{array}{c}4 \\
(21,1 \% / \\
30,8 \%)\end{array}$ & $\begin{array}{c}7 \\
(36,8 \% / \\
31,8 \%)\end{array}$ \\
\hline $\begin{array}{l}\text { Buena } \\
\text { CVRS }\end{array}$ & $\begin{array}{c}8 \\
(32 \% / \\
34,8 \%)\end{array}$ & $\begin{array}{c}17 \\
(68 \% / \\
34,7 \%)\end{array}$ & $\begin{array}{c}14 \\
(56 \% / \\
37,8 \%)\end{array}$ & $\begin{array}{c}11 \\
(44 \% / \\
31,4 \%)\end{array}$ & $\begin{array}{c}12 \\
(48 \% / \\
50 \%)\end{array}$ & $\begin{array}{c}3 \\
(12 \% / \\
23,1 \%)\end{array}$ & $\begin{array}{c}4 \\
(16 \% / \\
30,8 \%)\end{array}$ & $\begin{array}{c}6 \\
(24 \% / \\
27,3 \%)\end{array}$ \\
\hline
\end{tabular}

Tabla 13.

Puntuaciones apartado apoyo CAVIPRES en relación con el estado civil, tratamiento urológico y tiempo en VA. ${ }^{* *}$ El primer porcentaje hace referencia al porcentaje de la fila y el segundo al de la columna

De los 77 pacientes de los que se dispone información objetiva, 76 de ellos $(98,7 \%)$ contestaron a la EVA sobre ansiedad.

Como hemos dicho anteriormente, la puntuación mínima, correspondiente a un nivel nulo de ansiedad, que es o y la puntuación máxima, correspondiente a nivel máximo de ansiedad, que es 10. La media de nuestra muestra es de 3,38 puntos (min o máx 8).

Tras el análisis general de la EVA, se procedió a la categorización de la puntuación de la EVA en tres grupos: bajos niveles de ansiedad (0-3 puntos), nivel medio de ansiedad (4-7 puntos), altos niveles de ansiedad (8-10 puntos).

El 48,1\% de los pacientes (37 de 76 pacientes) manifestaron un nivel de ansiedad bajo y el 49,4\% (38 de 76 pacientes) un nivel medio de ansiedad. Solamente 1 paciente $(1,3 \%)$ presentó elevados niveles de ansiedad en el momento de la recogida de los datos.

La bibliografía recoge que la ansiedad está íntimamente relacionada con el abandono del programa de VA, y por ese motivo en la tabla 9 recoge la relación de la ansiedad con el tiempo en VA que llevaban los pacientes cuando contestaron la EVA.

Puntuaciones apartado vida sexual CAVIPRES en relación con el estado civil, tratamiento urológico

$$
\text { y tiempo en } V A \text {. }
$$

**El primer porcentaje hace referencia al porcentaje de la fila y el segundo al de la columna 


\begin{tabular}{|c|c|c|c|c|}
\hline & $\begin{array}{l}\text { Momento } \\
\text { inclusión VA }\end{array}$ & $\begin{array}{l}\text { 6-12 meses tras } \\
\text { la inclusión }\end{array}$ & $\begin{array}{l}12-18 \text { meses } \\
\text { tras la } \\
\text { inclusión }\end{array}$ & $\begin{array}{c}\text { Más de } 18 \\
\text { meses tras la } \\
\text { inclusión }\end{array}$ \\
\hline $\begin{array}{l}\text { Bajo nivel } \\
\text { ansiedad }\end{array}$ & $\begin{array}{c}11 \\
(29,7 \% / 40,7 \%)\end{array}$ & $\begin{array}{c}9 \\
(24,3 \% / 69,2 \%)\end{array}$ & $\begin{array}{c}8 \\
(21,6 \% / 61,5 \%)\end{array}$ & $\begin{array}{c}9 \\
(24,3 \% / 39,1 \%)\end{array}$ \\
\hline $\begin{array}{l}\text { Nivel medio } \\
\text { ansiedad }\end{array}$ & $\begin{array}{c}15 \\
(39,5 \% / 55,6 \%)\end{array}$ & $\begin{array}{c}4 \\
(10,5 \% / 30,8 \%)\end{array}$ & $\begin{array}{c}5 \\
(13,2 \% / 38,5 \%)\end{array}$ & $\begin{array}{c}14 \\
(36,8 \% / 60,9 \%)\end{array}$ \\
\hline $\begin{array}{l}\text { Alto nivel de } \\
\text { ansiedad }\end{array}$ & $\begin{array}{c}1 \\
(100 \% / 3,7 \%)\end{array}$ & $\mathrm{O}$ & $\mathrm{O}$ & $\mathrm{O}$ \\
\hline
\end{tabular}

Tras la revisión de los cuestionarios realizados por los pacientes se realiza una comparación entre los resultados sobre CVRS según el CAVIPRES y los resultados de la EVA sobre ansiedad, que quedan reflejados en la tabla 15.

\begin{tabular}{|ccccc|} 
& Muy mala CVRS & Mala CVRS & Regular CVRS & Buena CVRS \\
\hline $\begin{array}{c}\text { Bajo nivel } \\
\text { ansiedad }\end{array}$ & 1 & 13 & 20 & 2 \\
\hline $\begin{array}{c}\text { Nivel medio } \\
\text { ansiedad }\end{array}$ & $(2,8 \% / 50 \%)$ & $(36,1 \% / 29,4 \%)$ & $(55,6 \% / 58,8 \%)$ & $(5,6 / 66,7 \%)$ \\
\hline $\begin{array}{c}\text { Alto nivel de } \\
\text { ansiedad }\end{array}$ & 0 & 19 & 14 & 1 \\
\hline
\end{tabular}

Tabla 15. Relación CVRS y ansiedad

${ }^{* *}$ El primer porcentaje hace referencia al porcentaje de la fila y el segundo al de la columna

De igual manera se analiza la relación de la ansiedad con el apartado psicosocial del cuestionario CAVIPRES, pues el que está relacionado con la misma, quedando reflejado en la tabla 16.

\begin{tabular}{|c|c|c|c|c|}
\hline & Muy mala CVRS & Mala CVRS & Regular CVRS & Buena CVRS \\
\hline $\begin{array}{l}\text { Bajo nivel } \\
\text { ansiedad }\end{array}$ & $\begin{array}{c}1 \\
(2,8 \% / 33, \%)\end{array}$ & $\begin{array}{c}3 \\
(8,3 \% / 21,4 \%)\end{array}$ & $\begin{array}{c}19 \\
(52,8 \% / 47,5 \%)\end{array}$ & $\begin{array}{c}13 \\
(36,1 / 86,7 \%)\end{array}$ \\
\hline $\begin{array}{l}\text { Nivel medio } \\
\text { ansiedad }\end{array}$ & $\begin{array}{c}2 \\
(5,7 \% / 66,7 \%)\end{array}$ & $\begin{array}{c}10 \\
(28,6 \% / 71,4 \%)\end{array}$ & $\begin{array}{c}21 \\
(60 \% / 53,5 \%)\end{array}$ & $\begin{array}{c}2 \\
(5,7 \% / 13,3 \%)\end{array}$ \\
\hline $\begin{array}{l}\text { Alto nivel de } \\
\text { ansiedad }\end{array}$ & o & $\begin{array}{c}1 \\
(100 \% / 7,1 \%)\end{array}$ & o & o \\
\hline
\end{tabular}

Tabla 16. Relación CVRS aspecto psicosocial con la ansiedad.

${ }^{*}$ El primer porcentaje hace referencia al porcentaje de la fila y el segundo al de la columna
Finalmente, comparamos los niveles de ansiedad de los pacientes respecto a la edad que tenían en el momento de completar la EVA. Dichos datos se reflejan en la tabla 17.

\begin{tabular}{|ccc|}
\hline & Menor 70 años & Mayor 70 años \\
\hline $\begin{array}{c}\text { Bajo nivel } \\
\text { ansiedad }\end{array}$ & $22(64,7 \% / 50 \%)$ & $12(35,3 \% / 41,4 \%)$ \\
\hline $\begin{array}{c}\text { Nivel medio } \\
\text { ansiedad }\end{array}$ & $21(55,3 \% / 47,7 \%)$ & $17(44,7 \% / 58,6 \%)$ \\
\hline $\begin{array}{c}\text { Alto nivel de } \\
\text { ansiedad }\end{array}$ & $1(100 \% / 2,3 \%)$ & 0 \\
\hline
\end{tabular}

Tabla 17. Relación ansiedad con la edad de los pacientes.

**El primer porcentaje hace referencia al porcentaje de la fila y el segundo al de la columna 
5. DISCUSIÓN 


\section{DISCUSIÓN}

DESCRIPTIVO DE LOS PACIENTES EN VIGILANCIA ACTIVA EN SALAMANCA: 2014-2020

La VA como tratamiento para el $\mathrm{CP}$ apareció a mediados de los 90, y a partir de ese momento han ido surgiendo numerosos programas con diferentes criterios de inclusión y exclusión. Tabla 6.

Debemos tener en cuenta que, los protocolos de VA son un proceso dinámico; y que están en constante cambio según se va investigando más acerca de esta modalidad de tratamiento.

De manera general, se considera la VA como tratamiento para pacientes con GG menor o igual a $3+3$, PSA menor o igual a $10 \mathrm{ng} / \mathrm{mL}$, TR menor o igual a cT2a y entre 2-3 cilindros afectados. [75,80]. En nuestra serie de 276 pacientes, el 59,4\% siguen estos criterios.

Sin embargo, algunos protocolos de VA permiten incluir pacientes con criterios menos restrictivos, como por ejemplo, pacientes con mas de 50\% de cilindros positivos (Royal Marsden [69]), GG 3+4 (Royal Marsden y PRIAS [69,77]) y PSA hasta 15-20 ng/mL (Sunnybrook y Estudio AEU-PIEM/2014/ooo1 [64,71]). En esta serie el 40,6\% cumplían alguno de estos criterios de VA expandida.

El protocolo de VA del CAUSA, se adhiere de manera general a los criterios PRIAS [77]. Aunque, en los 5 años de seguimiento que se estudian en esta tesis, este protocolo ha sufrido ligeras modificaciones. Sobre todo debido a las novedades introducidas en las actualizaciones de las guías clínicas. Un ejemplo de estas evoluciones es el uso de RMN para el seguimiento de estos pacientes, que se incluyó en la guía clínica de la EAU en marzo de 2019, aunque en el CAUSA, ya se venía realizando desde el 2017 debido a la disponibilidad de la técnica.

En los últimos años, se ha visto un incremento en el uso de la VA como tratamiento del CP, tal y como podemo ver en la serie de Mahal, BA et al [112] que reportaba un incremento del $14,5 \%$ en 2010 a un $42,1 \%$ en 2015, as como la serie de Ong WL et al [113], en la cual pasan de un 33\% en 2009 a un 67\% en 2016.

En nuestra serie apreciamos como desde 2014 a septiembre de 2020, cada vez un mayor número de pacientes de muy bajo y bajo riesgo son tratados mediante esta modalidad de tratamiento, pasando de un 8,8\% en 2015 a un 29,6\% en 2019 para los pacientes de LBR (según las guías de la NCCN [57]), y de un 8\% en 2014 a un 73,9\% en 2019 en los pacientes de LMBR

A partir de 2018, la VA se convirtió en nuestra serie, en el tratamiento de elección de los pacientes de LMBR, datos que se asemejan a los comunicados por la serie de Loeb et al [73]. En el caso de los pacientes de LBR según NCCN, en 2019, el 29,6\% de los mismos, fueron tratados mediante VA.

Como decíamos anteriormente, algunas series tienen criterios de inclusión menos restrictivos, pero esta expansión de los criterios de VA es un punto de discusión actualmente en la comunidad urológica internacional. En el CAUSA, hasta el 17,1\% en 2019 de los pacientes de LRIF fueron tratados mediante esta estrategia, datos que se asemejaban a los comunicados por la serie de Thomsen et al [114] con un 28\% o los de la serie de Loeb et al [73] con un $17 \%$.

En este grupo de pacientes mencionado sobre estas líneas, especialmente en aquellos más jóvenes, son en los que el riesgo de reclasificación del tumor inicial en uno más agresivo puede impactar su supervivencia en mayor medida [79], y es por tanto en los que el seguimiento debe ser mas estricto si cabe.
A la hora de analizar los datos de adherencia al protocolo de VA, se ha tenido en cuenta, que en los datos revisados para dicha tesis doctoral influye el contexto de la pandemia COVID-19. Esta pandemia, supuso que algunas pruebas diagnósticas y consultas de seguimiento sufrieran retraso sobre los tiempos planificados, suponiendo por tanto una disminución en la adherencia al protocolo.

Existe una gran variedad de criterios de inclusión entre los distintos programas de VA; este hecho se reproduce en cuento a los criterios de seguimiento. Por ese motivo la Asociación Europea de Urología en el año 2018 realizó un consenso y posicionamiento sobre el seguimiento de estos pacientes al cual el CAUSA se adhiere [75]

El mayor debate se encuentra en los intervalos de tiempo entre las distintas visitas de seguimiento, así como las pruebas a realizar en el mismo. Dentro de este debate, Kalapara et al [76] comunican una adherencia a los criterios de seguimiento variable a lo largo del tiempo, disminuyendo esta, cuanto más tiempo llevan los pacientes en el protocolo.

En los datos revisados para la presente tesis doctoral, la adherencia al criterio de realización de re-biopsia dentro del primer año de inclusión es del 6o,6\% lo cual menor a lo recogido Kalapara et al [76], para los pacientes que siguen criterios de inclusión PRIAS. En este punto, hay que destacar el impacto ocasionado por la pandemia causada por la COVID-19; esta supuso la suspensión de la práctica totalidad de la actividad quirúrgica no urgente durante los meses de marzo a mayo de 2020. Por ese motivo, aunque la realización de dichas biopsias es necesaria para el seguimiento de los pacientes en VA, no eran urgentes en el contexto de la emergencia sanitaria ocasionada por el SARS-COV2. Además los pacientes se encontraban estables y controlados mediante los marcadores analíticos; y el riesgo-beneficio de acudir al hospital a realizar las biopsias se consideró, muy elevado.

En el caso de las re-biopsias no realizadas, debemos tener en cuenta como solamente el 16\% de las mismas, se deben a un fallo en el protocolo y que el $30 \%$ de ellas, se deben a una decisión del paciente. Es decir, o bien el paciente sale del programa antes del año y por tanto no debe de realizar dicha re-biopsia, o bien se le propone la realización de la re-biopsia y la deniega, o posterga, siendo realizada fuera de los tiempos establecidos en el protocolo.

Otro de los puntos de debate es el papel de la RMN el cual aún no está completamente definido. Las guías NICE introducen su posible uso en 2014 [80], siendo sugerido en el documento de consenso de 2018 de la Asociación Europea de Urología [75]. En esta línea, el estudio ASIST [81] pone de manifiesto que la RMN más biopsia dirigida a la lesión aumenta el valor de la RMN en el manejo de los pacientes en VA. No obstante es necesaria una exigente curva de aprendizaje en la realización de ambas técnicas [82]. En el caso que nos ocupa, el 72,5\% de los pacientes han realizado la RMN dentro del primer año de seguimiento, tal y como se indica en el protocolo.

En el caso de las RMN no realizadas, hay que tener en cuenta que la RMN es una prueba muy dependiente de la disponibilidad, pues el mismo aparato de RMN se utiliza para el resto de los servicios hospitalarios. Por tanto en el $37 \%$ comunicado como fallo del protocolo hay que añadir la dificultad en la gestión de recursos en el hospital, lo que conlleva a una selección de aquellos pacientes más jóvenes y por tanto, en los que el impacto en supervivencia puede tener mayor relevancia. Como decíamos anteriormente, el impacto de la pandemia COVID-19 también ha tenido influencia en la realización de dicha prueba ya que durante los primeros meses de la pandemia se suspendió la realización de todas las pruebas diagnósticas no urgentes. 
SALIDA DEL PROTOCOLO, MOTIVOS SALIDA, PROGRESION Y ESTATUS DE LOS PACIENTES.

De los pacientes analizados para la presente tesis doctoral, el 44\% de ellos había abandonado por algún motivo el programa deVA a fecha de revisión de los datos. Estos datos se asemejan a los comunicados por Thomsen et al [114], de 34,1\% de salidas en el seguimiento; o por la Universidad John Hopkins que comunican un 33,2\% de salidas de su programa de VA [64]. Por el contrario difieren de los reportados por los investigadores del estudio ProtecT, llegando en ese caso al $72 \%$ de salida en los 10 años de seguimiento [67]. Los criterios para realizar VA/ WW en el estudio citado, no se asemejan a los actuales criterios de VA, por lo tanto, la salida de los pacientes en el estudio ProtecT no es extrapolable a la práctica clínica actual.

Existen dos grandes causas para la salida del protocolo de VA. Por un lado, una decisión clínica debido una progresión de la enfermedad. Debemos tener en cuenta, como la salida del programa de VA es un evento contemplado en el protocolo, y no un fracaso del mismo. Puesto que todos los meses que el paciente permanezca en el protocolo, serán meses que el paciente no sufrirá los efectos secundarios de los tratamientos como el PR la RT, que si bien, tienen una gran efectividad para el control del tumor, también tienen un importante impacto potencial en la CVRS de los pacientes. En esa línea de pensamiento, Stacy Loeb, defiende el uso de la VA en pacientes seleccionados para reducir las alteraciones funcionales siempre que se mantenga un buen control oncológico. [115].

El 21,6\% de los pacientes abandonan el protocolo de VA, lo hacen por un motivo clínico. Dato cercano al $27 \%$ comunicado por Klot et al en su cohorte de seguimiento de paciente en VA [63]. Dentro de estos, la causa mayoritaria es un aumento en el GG, suponiendo un $57,4 \%$ de los pacientes que progresan.

Por otro lado, nos encontramos con la decisión del paciente de abandonar el protocolo. En los pacientes que salen de este, el 33,3 \% lo hacen por este motivo. Este dato, dista mucho del comunicado por Brigantti et al [75] con un 6\% de salida del protocolo por decisión del paciente, pero se asemeja a lo comunicado por Universidad John Hopkins [64], donde el 26,3\% de los pacientes que salen lo hacen sin biopsia confirmatoria.

Hay que tener en cuenta, que muchas de las grandes series (Thomsen et al [114], PURC [58], PRIAS [70], NPCR [73], Registro Victoria [113]), comunican sus datos de salida de forma global pero no indican el motivo de la misma o bien no la comunican directamente, lo cual supone una dificultad a la hora de comparar nuestros datos con los de las principales series.

Tras la salida del protocolo de VA, el paciente debe optar por alguno de los tratamientos con intención radical descritos anteriormente. En este caso, el tratamiento más utilizado para el abandono de la VA es la RT externa aunque se encuentran diferencias entre el tratamiento utilizado dependiendo del motivo de la salida de VA.

Si la salida es por un criterio clínico, el $48,9 \%$ de los pacientes (23 de 47 pacientes) reciben tratamiento con RT y el 23,4\% de los pacientes (11 de 47 pacientes) son tratados con PR. Virseda et al [116] reflejaron en su serie de 1955 PR, que no había impacto oncológico entre el tiempo desde la realización de la biopsia hasta la realización de la PR, lo cual concuerda con el uso previo de la VA en estos pacientes.

Cuando el paciente es el que decide abandonar el protocolo de VA, el tratamiento de elección es la BT (37,5\% de estos pacientes (12/32 pacientes)). Debemos tener en cuenta, que dentro de los tratamientos radicales, la BT puede considerarse como uno de los que, menores efectos secundarios de incontinencia y disfunción eréctil produce, lo cual es tenido en cuenta por los pacientes a la hora de tomar la decisión.
Finalmente, la supervivencia cáncer específica (SCE) es del 100\%. Pues aunque han fallecido 3 pacientes, ninguno lo hizo a causa de su tumor. Estos datos se asemejan a los comunicados por las grandes series, como la de Thomsen et al [114] que en 10 años de seguimiento registran una SCE del 99,6\%, o la de la serie del Memorial Sloan Kettering Cancer [117] que en 10 años de seguimiento reportaron un 98\% de SCE. Estos datos reflejan la baja mortalidad que estos tumores tienen y por tanto apoyan su manejo mediante VA pues no hay un impacto en la supervivencia y sin embargo, si que se mejora la CVRS. Los efectos secundarios de la VA son menores que los de la PR y la RT.

CALIDAD DE VIDA Y NIVELES DE ANSIEDAD DE LOS PACIENTES EN EL PROTOCOLO DE VA.

En los últimos años, en el ámbito de la oncología, el concepto de CVRS ha cobrado una mayor relevancia, debido a que el diagnóstico de algunos tipos de tumores, como pueden ser algunos tipos de Cáncer de Próstata o de Cáncer de Mama, ya no son sinónimo de muerte como ocurría hace algunas décadas. Sino que se convierten en enfermedades crónicas, en las que el impacto de los tratamientos en la CVRS de los pacientes tiene un peso mucho mayor.

En esa línea de pensamiento, la Asociación Española Contra el Cáncer (AECC), ha desarrollado numerosas iniciativas para colaborar con los hospitales con el fin de mejorar la CVRS de los pacientes oncológicos.

De igual manera, numerosos estudios, resaltan la importancia de contar con equipos multidisciplinares y dentro de los mismos, se resalta el valor del papel cardinal que despeñan las enfermeras de enlace o enfermeras gestoras de casos. Puesto que su presencia en estos equipos aporta seguridad al paciente al tener una figura de referencia durante todo el proceso que abarcan los distintos tratamientos multimodales que se le realizan a este tipo de pacientes [94, 109,111, 118]

En el caso de los pacientes con tumores prostáticos, se conocen los efectos secundarios de los tratamientos activos (PR y RT) y el impacto que tienen en la CVRS de los pacientes.

No obstante existen pocos estudios sobre la repercusión en CVRS de los pacientes en VA; y los que se han realizado comparan la PR y/o la RT frente a la VA, usando como estándar la PR o la RT; esto ha dificultado la comparación de los datos obtenidos en la presente tesis doctoral con lo comunicado por otros autores. [93, 119, 120]

Hay que tener en cuenta, que en septiembre del 2019, el panel de expertos del estudio DETECTIVE, formado por urólogos, enfermeras especialistas en urología, oncólogos radioterapeutas, oncólogos médicos, radiólogos y patólogos, en las conclusiones de dicho estudio, resaltaron la importancia de tener en cuenta la CVRS y la ansiedad en la inclusión y seguimiento de los pacientes en VA. [79]

Para la realización de dicha tesis doctoral, los datos de CVRS de los que se disponía estaban medidos mediante el cuestionario CAVIPRES. Este cuestionario está validado en castellano, lo cual facilita la comprensión de los pacientes ya que algunos otros cuestionarios, al ser traducciones del inglés conllevan algunas dificultades para extrapolar algunos conceptos. Asimismo es un cuestionario específico para CP y además no muy extenso. Sin embargo, al ser poco usado en la literatura internacional, ha resultado complicado extrapolar y comparar los datos obtenidos con otras series. [95, 121, 122]

Analizando los datos obtenido en la puntuación total del cuestionario, se observa que la CVRS de los pacientes 
en VA, es mala o regular. Estos datos, sin embargo no se correlacionan, en muchos casos, con lo trasmitido verbalmente por el paciente y que como tal, queda reflejado en la Historia Clínica.

Esta variabilidad entre lo que expresa el paciente, y lo que responde en el cuestionario podría ser multifactorial. En primer lugar, en dos de los apartados del cuestionario, una puntuación alta supone una muy buena CVRS mientras que en los otros dos apartados esa misma puntuación se traduce como una muy mala CVRS, lo cual impacta en el resultado final del cuestionario. En segundo lugar, los pacientes revisados en dicha tesis son pacientes añosos, por lo que puede conllevar a una mala interpretación de algunas preguntas del cuestionario. En tercer lugar, algunos de los pacientes pueden estar acostumbrados a presentar algunas de las complicaciones sobre las que se les pregunta en los cuestionarios, no suponiendo para ellos una incomodidad o alteración en su vida pero si que afecten el resultado del cuestionario. Y finalmente, al realizarse los cuestionarios como parte de la práctica clínica habitual, en algunas ocasiones las circunstancias en las que el paciente realiza el cuestionario no son las más idóneas (prisas para irse a casa, olvido de gafas y respuesta del cuestionario por parte de la pareja, nervios por la consulta...)

En el análisis de cada apartado del cuestionario de manera individual, en los pacientes revisados para esta tesis, el 55,6\% presentaron una buena CVRS en el ámbito psicológico. Este dato difiere de lo comunicado en la serie de van Stann et al [93] en la cual, comparaban la CVRS de los pacientes sometidos a PR y RT frente aquellos en VA y obtenían que en el aspecto emocional, los que peor CVRS presentaban eran aquellos tratados mediante VA. Sin embargo, Jeldres et al [119] en su revisión de la CVRS comparando pacientes sometidos a PR con pacientes en VA, publicaba que no existían diferencias en el aspecto psicológico.

Una de las complicaciones de los tratamientos con PR y RT, es la disfunción eréctil de los pacientes. En los pacientes del protocolo de VA del CAUSA, el 34,7\% presentaba una muy buena CVRS en este ámbito. Este dato es congruente con lo comunicado por otros autores [93, 119, 120]; este hecho defiende el uso de la VA como tratamiento en pacientes de muy bajo o bajo riesgo, con el fin de salvaguardar la salud sexual de estos pacientes. Sin embargo, el $38,9 \%$ de los pacientes prestaban una CVRS en este aspecto mala o regular; este dato pese a poder parecer elevado y contradecir el uso de la VA, es congruente con la literatura revisada en población sana. Irfa M et al [123] en la revisión sistemática sobre la epidemiología de la disfunción sexual en Asia y Europa, reportan una prevalencia de Disfunción Eréctil (DE) de entre el 8,3\%-88,8\% en personas mayores de 60 años. Esto supone que en los pacientes aquí estudiados, su problema en el ámbito sexual puede deberse a su edad, y no a la patología tumoral, y no suponerle un problema al paciente para su calidad de vida, aunque en el cuestionario se refleje con una baja puntuación.

Finalmente, la ansiedad es uno de los factores a tener en cuenta en el seguimiento de los pacientes en VA. En algunas ocasiones, un elevado nivel de ansiedad del paciente es lo que ocasiona la salida del este del protocolo de VA aun sin tener criterios clínicos para ello.

En la presente tesis doctoral, los datos objetivos de ansiedad se obtienen mediante valoración de una EVA, donde el valor mínimo de ansiedad correspondía al 1 y el nivel máximo a 10. Esta forma de medir la ansiedad es muy visual para el paciente lo cual facilita la respuesta.

De manera general, los pacientes en VA revisados para la presente tesis doctoral, presentaban unos niveles bajo o medios de ansiedad, datos que se asemejan a los comunicados por Anderson J et al y Burnet KL et al. [124 125] En cuanto a los datos reportados por el estudio ProtecT, este no encontró diferencias en la ansiedad de los pacientes entre las tres ramas del mismo (VA, RT, PR). [126] Sin embargo, Egger et al, si que comunican mayores niveles de ansiedad en los pacientes tratados con VA respecto a aquellos tratados con RT o HT. [127]
Si tenemos en cuenta los meses que llevaban los pacientes en el protocolo de VA cuando se registró el valor de la EVA, en los datos recogidos, no se aprecian diferencias entre los pacientes al momento de la inclusión frente a aquellos que llevaban más de 18 meses. Esto no se corresponde con lo reportado por Bellardita et al [84]; sin embargo es un tema sobre el cual no hay abundante bibliografía disponible y sería necesario el análisis de más series a lo largo del tiempo para comprobar dichos datos.

Finalmente, si comparamos los resultados obtenidos entre el apartado psicológico del cuestionario de CVRS y os niveles de ansiedad de los pacientes, se obtienen datos congruentes entre sí, lo cual valida a los mismos; del mismo modo resalta que los pacientes comprenden las preguntas del cuestionario de forma correcta. 


\section{LIMITACIONES DEL ESTUDIO}




\section{LIMITACIONES DEL ESTUDIO}

- Estudio unicéntrico con limitación en el tiempo de seguimiento en relación con otras series.

- Población añosa.

- Impacto del nivel sociocultural y económico de los pacientes para la comprensión de los cuestionarios y toma de decisiones.

- Impacto de organización hospitalaria y de la presión asistencial para el desarrollo del estudio, así como el impacto de la pandemia COVID-19.

\section{CONCLUSIONES}




\section{CONCLUSIONES.}

1. El CP es un tumor muy prevalente en la población masculina salmantina y el uso de la VA como alternativa terapéutica se ha incrementado en los últimos años.

2. La Vigilancia Activa es una alternativa de tratamiento segura en los pacientes con Cáncer de Próstata de muy bajo y bajo riesgo. En nuestra serie, no tiene impacto en la supervivencia de los pacientes.

3. La CVRS y la ansiedad de los pacientes de VA parece estar íntimamente relacionada con su nivel basal a diagnóstico del cáncer y no tanto con el mismo.

4. Existen muchos motivos que influyen en la comprensión de los cuestionarios de CVRS. Estos motivos, algunos intrínsecos al paciente como la edad, y otros debidos a las circunstancias en las que se realizan dichos cuestionarios, tienen influencia sobre el resultado de los mismos.

5. Los factores no derivados del paciente podrían mejorar con la implementación de la figura de una enfermera gestora de casos en las unidades uro-oncológicas. Esta figura sería la encarga de realizar los cuestionarios con los pacientes y valorar los mismos; realizaría igualmente funciones de enlace entre los pacientes y el resto del equipo multidisciplinar, mejorándose así la atención sanitaria de estos pacientes.

6. La adherencia al protocolo de VA en esta serie de cumple de manera adecuada a pesar de las circunstancias relacionadas con la pandemia COVID-19. 


\section{BIBLIOGRAFÍA}

1. Cofey, D., ¿Qué es la próstata y cual es su función? . Manual de Andrología de la Sociedad Americana de Andrología 1994.

2. Walz J, Graefen M, Huland H. Basic principles of anatomy for optimal surgical treatment of prostate cancer World J Urol. marzo de 2007;25(1):31-8.

3. Rouvière H., y Delmas A. Anatomía Humana. Descriptiva, Topográfica y Funcional. 10a edición. Masson S.A. Barcelona. 2011.

4. Wein, A., et al., Campbell-Walsh Urology, ed. A. Wein, et al. 2016, Philadelphia: Saunders.

5. Lowsley, O., The development of the human prostate gland with reference to the development of other structures at the neck of the urinary bladder. Am J Anat 1912. 13: p. 299-349.

6. Mcneal, J., Anatomy of the prostate: an historical survey of divergent reviews. Prostate 1980. 1: p. 3-13.

7. McNeal JE, Bostwick DG: Anatomy of the prostate: implications for disease. In: Bostwick DG, ed. Pathology of the Prostate. New York, Churchill Livingstone, 1990; 2 [3]

8. Schünke M, Schulte E, Schumacher U, Voll M, Wesker K. Prometheus. Madrid: Médica Panamericana; 2011.

9. Testut L. Tratado de anatomía humana. Barcelona: Salvat; 1978.

10. Atlas de Anatomía Humana de Sobota. Editorial Médica Panamericana. Madrid. 2007.

11. Moorthi, C., et al., In-vitro cell based assay: a preferred anticancer drug screening techniques for the academic researchers. J Pharmacy Res., 2011. 4(3): p. 671-675.

12. Uribe, J., Cáncer de próstata: ¿Por qué se produce el Cáncer de Próstata? . Urología Colombiana, 2005 xiv(21): p. 19-32.

13. Schalken, J. and L. van, Cellular and molecular biology of the prostate: stem cell biology Urology 2003. 62: p. 11-20.

14. Diamandis, E., Prostate specific antigen: a cancer fighter and a valuable messenger? Clin Chem, 2000. 46(7): p. 896-900.

15. Siegel RL, Miller KD, Jemal A. Cancer statistics, 2020. CA Cancer J Clin. enero de 2020;70(1):7-30

16. Miller KD, Nogueira L, Mariotto AB, Rowland JH, Yabroff KR, Alfano CM, et al. Cancer treatment and survivorship statistics, 2019. CA Cancer J Clin. 2019;69(5):363-85.

17. Informe_incidencia_REDECAN_2020.pdf [Internet]. [citado 18 de agosto de 2020]. Disponible en: https:// redecan.org/redecan.org/es/Informe_incidencia_REDECAN_2020.pdf

18. Virseda-Rodríguez AJ, Salvatierra C, García F, Sanz A, Gutiérrez E, Serrano JM, et al. Actual incidence of prostate cancer in healthcare areas of the autonomous community of Castilla-Leon during 2014. CAPCYL registry data. Actas Urol Esp. noviembre de 2018;42(9):593-9

19. Cózar JM, Miñana B, Gómez-Veiga F, Rodríguez-Antolín A, Villavicencio H, 25 Urology Units, Asociación Española de Urología, et al. Prostate cancer incidence and newly diagnosed patient profile in Spain in 2010. BJU Int. diciembre de 2012;110(11 Pt B):E701-706.

20. Cifras_del_cancer_2020.pdf [Internet]. [citado 18 de agosto de 2020]. Disponible en: https://seom.org/ seomcms/images/stories/recursos/Cifras_del_cancer_2020.pdf

21. Barrett-Connor, E., C. Garland, and J. McPhillips, A prospective population- based study of androstendione, estrogens and prostatic cancer. Cancer Res

22. Grönberg, H., Prostate cancer epidemiology. The LANCET 2003. 361: p. 859-864.

23. Jansson KF, Akre O, Garmo H, Bill-Axelson A, Adolfsson J, Stattin P, et al. Concordance of tumor differentiation among brothers with prostate cancer. Eur Urol. octubre de 2012;62(4):656-61.

24. Hemminki K. Familial risk and familial survival in prostate cancer. World J Urol. abril de 2012;30(2):143-8.

25. Randazzo M, Müller A, Carlsson S, Eberli D, Huber A, Grobholz R, et al. A positive family history as a risk factor for prostate cancer in a population-based study with organised prostate-specific antigen screening: results of the Swiss European Randomised Study of Screening for Prostate Cancer (ERSPC, Aarau). BJU Int. abril de 2016;117(4):576-83.

26. Stewart RW, Lizama S, Peairs K, Sateia HF, Choi Y. Screening for prostate cancer. Semin Oncol. febrero de 2017;44(1):47-56.

27. Tan DSW, Mok TSK, Rebbeck TR. Cancer Genomics: Diversity and Disparity Across Ethnicity and Geography. J Clin Oncol. 1 de enero de 2016;34(1):91-101.

28. Lynch HT, Kosoko-Lasaki O, Leslie SW, Rendell M, Shaw T, Snyder C, et al. Screening for familial and hereditary prostate cancer. Int J Cancer. 1 de junio de 2016;138(11):2579-91.

29. Ewing CM, Ray AM, Lange EM, Zuhlke KA, Robbins CM, Tembe WD, et al. Germline mutations in HOXB13 and prostate-cancer risk. N Engl J Med. 12 de enero de 2012;366(2):141-9.

3o. Leitzmann MF, Rohrmann S. Risk factors for the onset of prostatic cancer: age, location, and behavioral correlates. Clin Epidemiol. 2012;4:1-11.

31. EAU Guidelines. Edn. presented at the EAU Annual Congress Amsterdam 2020. ISBN 978-94-92671-07-3. EAU Guidelines Office, Arnhem, The Netherlands. http://uroweb.org/guidelines/compilations-of-all-guidelines/

32. Etzioni R, Gulati R, Cooperberg MR, Penson DM, Weiss NS, Thompson IM. Limitations of basing screening policies on screening trials: The US Preventive Services Task Force and Prostate Cancer Screening. Med Care. abril de 2013;51(4):295-300.

33. Arnsrud Godtman R, Holmberg E, Lilja H, Stranne J, Hugosson J. Opportunistic testing versus organized prostate-specific antigen screening: outcome after 18 years in the Göteborg randomized population-based prostate 
34. US Preventive Services Task Force, Grossman DC, Curry SJ, Owens DK, Bibbins-Domingo K, Caughey AB, et al. Screening for Prostate Cancer: US Preventive Services Task Force Recommendation Statement. JAMA. o8 de 2018;319(18):1901-13.

35. Catalona, W., et al., Comparison of digital rectal examination and serum prostate specific antigen in the early detection of prostate cancer: results of a multicenter clinical trial of 6,630 men. . J Urol 1994. 151(5): p. 1283-90.

36. Stamey TA, Yang N, Hay AR, McNeal JE, Freiha FS, Redwine E. Prostate-specific antigen as a serum marker for adenocarcinoma of the prostate. N Engl J Med. 8 de octubre de 1987;317(15):909-16.

37. Schmidt, J., Clinical diagnosis of prostate cancer. . Cancer, 1992: p. 221-224.

38. Semjonow, A., et al., Discordance of assay methods creates pitfalls for the interpretation of prostate-specific antigen values. . Prostate Suppl 1996. 7: p. 3-16.

39. Eastham JA, Riedel E, Scardino PT, Shike M, Fleisher M, Schatzkin A, et al. Variation of serum prostatespecific antigen levels: an evaluation of year-to-year fluctuations. JAMA. 28 de mayo de 2003;289(20):2695-700

40. Lange, D. and W. Bruce, Les éléments du diagnostic précoce et du bilan d'extension du cancer prostatique. Résultats fonctionnels de l'intervention radicale. . Ann Urol, 1990: p. 103-108.

41. Richie JP, Catalona WJ, Ahmann FR, Hudson MA, Scardino PT, Flanigan RC, et al. Effect of patient age on early detection of prostate cancer with serum prostate-specific antigen and digital rectal examination. Urology. 1993;42(4):365-74.

42. Okotie OT, Roehl KA, Han M, Loeb S, Gashti SN, Catalona WJ. Characteristics of prostate cancer detected by digital rectal examination only. Urology. diciembre de 2007;70(6):1117-20.

43. Gosselaar C, Roobol MJ, Roemeling S, Schröder FH. The role of the digital rectal examination in subsequent screening visits in the European randomized study of screening for prostate cancer (ERSPC), Rotterdam. Eur Urol. septiembre de 2008;54(3):581-8.

44. Balkissoon, R., et al., Lost in translation: unfolding medical students' misconceptions of how to perform a clinical digital rectal examination. The American Journal of Surgery, 2009. 197(4): p. 525-532.

45. Roobol MJ, Steyerberg EW, Kranse R, Wolters T, van den Bergh RCN, Bangma CH, et al. A risk-based strategy improves prostate-specific antigen-driven detection of prostate cancer. Eur Urol. enero de 2010;57(1):7985.

46. Xue J, Qin Z, Cai H, Zhang C, Li X, Xu W, et al. Comparison between transrectal and transperineal prostate biopsy for detection of prostate cancer: a meta-analysis and trial sequential analysis. Oncotarget. 4 de abril de 2017;8(14):23322-36

47. Kasivisvanathan V, Rannikko AS, Borghi M, Panebianco V, Mynderse LA, Vaarala MH, et al. MRI-Targeted or Standard Biopsy for Prostate-Cancer Diagnosis. N Engl J Med. 10 de mayo de 2018;378(19):1767-77.

48. Gleason DF, Mellinger GT. Prediction of prognosis for prostatic adenocarcinoma by combined histological grading and clinical staging. J Urol. enero de 1974;111(1):58-64.

49. Oon SF, Watson RW, O’Leary JJ, Fitzpatrick JM. Epstein criteria for insignificant prostate cancer. BJU Int. agosto de 2011;108(4):518-25.

50. Epstein JI, Allsbrook WC, Amin MB, Egevad LL, ISUP Grading Committee. The 2005 International Society of Urological Pathology (ISUP) Consensus Conference on Gleason Grading of Prostatic Carcinoma. Am J Surg Pathol. septiembre de 2005;29(9):1228-42.

51. Egevad L, Delahunt B, Srigley JR, Samaratunga H. International Society of Urological Pathology (ISUP) grading of prostate cancer - An ISUP consensus on contemporary grading. APMIS. junio de 2016;124(6):433-5.

52. Van Leenders GJLH, van der Kwast TH, Grignon DJ, Evans AJ, Kristiansen G, Kweldam CF, et al. The 2019 International Society of Urological Pathology (ISUP) Consensus Conference on Grading of Prostatic Carcinoma. The American Journal of Surgical Pathology. agosto de 2020;44(8):e87.

53. Buyyounouski MK, Choyke PL, McKenney JK, Sartor O, Sandler HM, Amin MB, et al. Prostate cancer major changes in the American Joint Committee on Cancer eighth edition cancer staging manual. CA Cancer J Clin. 06 de 2017;67(3):245-53.

54. Edge SB, American Joint Committee on Cancer, editores. AJCC cancer staging manual. 7th ed. New York: Springer; 2010. 648 p.

55. Professionals S-O. EAU History [Internet]. Uroweb. [citado 18 de agosto de 2020]. Disponible en: https:// uroweb.org/about-eau/eau-history/

56. About NCCN [Internet]. [citado 18 de agosto de 2020]. Disponible en: https://www.nccn.org/about/default. aspx

57. NCCC guidelines prostate.pdf [Internet]. [citado 18 de agosto de 2020]. Disponible en: https://www.nccn. org/professionals/physician_gls/pdf/prostate.pdf

58. Botejue M, Abbott D, Danella J, Fonshell C, Ginzburg S, Guzzo TJ, et al. Active Surveillance as Initial Management of Newly Diagnosed Prostate Cancer: Data from the PURC. J Urol. 2019;201(5):929-36

59. Hatzinger M, Hubmann R, Moll F, Sohn M. The history of prostate cancer from the beginning to DaVinci. Aktuelle Urol. julio de 2012;43(4):228-30.

6o. Podder TK, Fredman ET, Ellis RJ. Advances in Radiotherapy for Prostate Cancer Treatment. Adv Exp Med Biol. 2018;1096:31-47.

61. Johnson DC, Mueller DE, Deal AM, Dunn MW, Smith AB, Woods ME, et al. Integrating Patient Preference into Treatment Decisions for Men with Prostate Cancer at the Point of Care. J Urol. 2016;196(6):1640-4.

62. Filson CP, Marks LS, Litwin MS. Expectant management for men with early stage prostate cancer. CA Cancer J Clin. agosto de 2015;65(4):265-82

63. Klotz L, Vesprini D, Sethukavalan P, Jethava V, Zhang L, Jain S, et al. Long-term follow-up of a large active surveillance cohort of patients with prostate cancer. J Clin Oncol. 20 de enero de 2015;33(3):272-7. 
64. Tosoian JJ, Trock BJ, Landis P, Feng Z, Epstein JI, Partin AW, et al. Active surveillance program for prostate cancer: an update of the Johns Hopkins experience. J Clin Oncol. 1 de junio de 2011;29(16):2185-90

65. Wilt TJ, Jones KM, Barry MJ, Andriole GL, Culkin D, Wheeler T, et al. Follow-up of Prostatectomy versus Observation for Early Prostate Cancer. N Engl J Med. 13 de 2017;377(2):132-42.

66. Gomez-Veiga F, Pertega Diaz S, Martinez Breijo S. Prostate cancer: treat or not treat? Actas Urol Esp. agosto de 2013;37(7):451-2.

67. Hamdy FC, Donovan JL, Lane JA, Mason M, Metcalfe C, Holding P, et al. 10-Year Outcomes after Monitoring, Surgery, or Radiotherapy for Localized Prostate Cancer. N Engl J Med. 13 de 2016;375(15):1415-24.

68. Becker A, Seiler D, Kwiatkowski M, Kluth LA, Schnell D, Graefen M, et al. A comparative assessment of active surveillance for localized prostate cancer in the community versus tertiary care referral center. World $J$ Urol. agosto de 2014;32(4):891-7.

69. Selvadurai ED, Singhera M, Thomas K, Mohammed K, Woode-Amissah R, Horwich A, et al. Medium-term outcomes of active surveillance for localised prostate cancer. Eur Urol. diciembre de 2013;64(6):981-7.

70. Bul M, Zhu X, Valdagni R, Pickles T, Kakehi Y, Rannikko A, et al. Active surveillance for low-risk prostate cancer worldwide: the PRIAS study. Eur Urol. abril de 2013;63(4):597-603.

71. Rubio-Briones J, Borque A, Esteban LM, Iborra I, López PA, Gil JM, et al. Preliminary results of the Spanish Association of Urology National Registry in Active Surveillance for prostate cancer. Actas Urol Esp. febrero de 2016;40(1):3-10.

72. Adamy A, Yee DS, Matsushita K, Maschino A, Cronin A, Vickers A, et al. Role of prostate specific antigen and immediate confirmatory biopsy in predicting progression during active surveillance for low risk prostate cancer. J Urol. febrero de 2011;185(2):477-82.

73. Loeb S, Folkvaljon Y, Curnyn C, Robinson D, Bratt O, Stattin P. Uptake of Active Surveillance for Very-LowRisk Prostate Cancer in Sweden. JAMA Oncol. 1 de octubre de 2017;3(10):1393-8.

74. Marcos Asensio S, Virseda Rodríguez AJ, Martín Izquierdo MM, Herrero Polo M, Coderque Mejía MP, Rocha de Lossada et al. La vigilancia activa en pacientes con cáncer de próstata localizado. Análisis de adherencia y salida del protocolo. Arch Esp Urol. Acepted Nov 20, 2020

75. Briganti A, Fossati N, Catto JWF, Cornford P, Montorsi F, Mottet N, et al. Active Surveillance for Low-risk Prostate Cancer: The European Association of Urology Position in 2018. Eur Urol. 2018;74(3):357-68.

76. Kalapara AA, Verbeek JFM, Nieboer D, Fahey M, Gnanapragasam V, Van Hemelrijck M, et al. Adherence to Active Surveillance Protocols for Low-risk Prostate Cancer: Results of the Movember Foundation's Global Action Plan Prostate Cancer Active Surveillance Initiative. Eur Urol Oncol. febrero de 2020;3(1):80-91.

77. Soeterik TFW, van Melick HHE, Dijksman LM, Biesma DH, Witjes JA, van Basten J-PA. Active Surveillance for Prostate Cancer in a Real-life Cohort: Comparing Outcomes for PRIAS-eligible and PRIAS-ineligible Patients. Eur Urol Oncol. 2018;1(3):231-7.

78. Bruinsma SM, Zhang L, Roobol MJ, Bangma CH, Steyerberg EW, Nieboer D, et al. The Movembe
Foundation's GAP3 cohort: a profile of the largest global prostate cancer active surveillance database to date. BJU Int. 2018;121(5):737-44.

79. Lam TBL, MacLennan S, Plass K, Willemse P-PM, Mason MD, Cornford P, et al. Study Protocol for the DETECTIVE Study: An International Collaborative Study To Develop Consensus Statements for Deferred Treatment with Curative Intent for Localised Prostate Cancer. Eur Urol. 2019;75(4):699-702.

80. MerrielSWD, Hetherington L, Seggie A, Castle JT, Cross W, Roobol MJ, et al. Best practice in active surveillance for men with prostate cancer: a Prostate Cancer UK consensus statement. BJU Int. julio de 2019;124(1):47-54.

81. Klotz L, Pond G, Loblaw A, Sugar L, Moussa M, Berman D, et al. Randomized Study of Systematic Biopsy Versus Magnetic Resonance Imaging and Targeted and Systematic Biopsy in Men on Active Surveillance (ASIST): 2-year Postbiopsy Follow-up. Eur Urol. marzo de 2020;77(3):311-7.

82. Kasivisvanathan V, Giganti F, Emberton M, Moore CM. Magnetic Resonance Imaging Should Be Used in the Active Surveillance of Patients with Localised Prostate Cancer. Eur Urol. marzo de 2020;77(3):318-9

83. Bill-Axelson A, Holmberg L, Garmo H, Taari K, Busch C, Nordling S, et al. Radical Prostatectomy or Watchful Waiting in Prostate Cancer - 29-Year Follow-up. N Engl J Med. 13 de 2018;379(24):2319-29.

84. Bellardita L, Valdagni R, van den Bergh R, Randsdorp H, Repetto C, Venderbos LDF, et al. How does active surveillance for prostate cancer affect quality of life? A systematic review. Eur Urol. abril de 2015;67(4):637-45.

85. Gledhill R, Allchorne P, Green J, Cornford P. Knowledge gaps in prostate cancer treatment between physicians and clinical nurse specialists: Knowledge gaps in prostate cancer. Int J Urol Nurs. marzo de 2018;12(1):5-8.

86. The World Health Organization quality of life assessment (WHOQOL): Position paper from the World Health Organization. Social Science \& Medicine. 1 de noviembre de 1995;41(10):1403-9

87. Fernández-López JA, Fernández-Fidalgo M, Cieza A. Los conceptos de calidad de vida, salud y bienestar analizados desde la perspectiva de la Clasificación Internacional del Funcionamiento (CIF). Revista Española de Salud Pública. abril de 2010;84(2):169-84

88. Generalidades sobre los trastornos de ansiedad - Trastornos psiquiátricos [Internet]. Manual MSD versión para profesionales. [citado 24 de mayo de 2020]. Disponible en: https://www.msdmanuals.com/es/professional/ trastornos-psiqui\% $\mathrm{C}_{3} \%$ A1tricos/trastorno-de-ansiedad-y-trastornos-relacionados-con-el-estr\% $\mathrm{C}_{3} \% \mathrm{~A} 9 \mathrm{~s} /$ generalidades-sobre-los-trastornos-de-ansiedad

89. Haukland EC, von Plessen C, Nieder C, Vonen B. Adverse events in deceased hospitalised cancer patients as a measure of quality and safety in end-of-life cancer care. BMC Palliative Care [Internet]. diciembre de 2020 [citado 2 de junio de 2020];19(1). Disponible en: https://bmcpalliatcare.biomedcentral.com/articles/10.1186/ s12904-020-00579-0

90. Whiting PF, Moore THM, Jameson CM, Davies P, Rowlands M-A, Burke M, et al. Symptomatic and qualityof-life outcomes after treatment for clinically localised prostate cancer: a systematic review. BJU Int. agosto de 2016;118(2):193-204

91. M L, M L, Rc van den B, M DS, J B, T V den B, et al. Quality of Life Outcomes After Primary Treatment for Clinically Localised Prostate Cancer: A Systematic Review [Internet]. Vol. 72, European urology. Eur Urol; 2017 
92. Watts S, Leydon G, Eyles C, Moore CM, Richardson A, Birch B, et al. A quantitative analysis of the prevalence of clinical depression and anxiety in patients with prostate cancer undergoing active surveillance. BMJ Open. 22 de mayo de 2015;5(5):e0o6674-eoo6674.

93. Van Stam M-A, Aaronson NK, Bosch JLHR, Kieffer JM, van der Voort van Zyp JRN, Tillier CN, et al. Patientreported Outcomes Following Treatment of Localised Prostate Cancer and Their Association with Regret About Treatment Choices. European Urology Oncology. febrero de 2020;3(1):21-31.

94. Sebakk KS, Haug ES, Gullan D, Grov EK. Health-related quality of life in prostate cancer patients' treatment comparisons: HRQOL in prostate cancer patients. International Journal of Urological Nursing. julio de 2017;11(2):98-105.

95. Veiga FG, Olmo JMC, Günthner S, Pallas MP, Moyano AS, Ramos EB, et al. [Development and validation of the first Spanish questionnaire of quality of life in patients with prostate cancer, based on the patient's perception]. Actas Urol Esp. junio de 2009;33(6):623-34.

96. Aaronson NK, Ahmedzai S, Bergman B, Bullinger M, Cull A, Duez NJ, et al. The European Organization for Research and Treatment of Cancer QLQ-C30: a quality-of-life instrument for use in international clinical trials in oncology. J Natl Cancer Inst. 3 de marzo de 1993;85(5):365-76.

97. Van Andel G, Bottomley A, Fosså SD, Efficace F, Coens C, Guerif S, et al. An international field study of the EORTC QLQ-PR25: a questionnaire for assessing the health-related quality of life of patients with prostate cancer. Eur J Cancer. noviembre de 2008;44(16):2418-24.

98. Ware J, Kosinski M, Keller SD. A 12-Item Short-Form Health Survey: construction of scales and preliminary tests of reliability and validity. Med Care. marzo de 1996;34(3):220-33.

99. McHorney CA, Ware JE, Lu JF, Sherbourne CD. The MOS 36-item Short-Form Health Survey (SF-36): III. Tests of data quality, scaling assumptions, and reliability across diverse patient groups. Med Care. enero de 1994;32(1):40-66.

100. Litwin MS, Hays RD, Fink A, Ganz PA, Leake B, Brook RH. The UCLA Prostate Cancer Index: development, reliability, and validity of a health-related quality of life measure. Med Care. julio de 1998;36(7):1002-12.

101. Bonomi AE, Patrick DL, Bushnell DM, Martin M. Validation of the United States' version of the World Health Organization Quality of Life (WHOQOL) instrument. J Clin Epidemiol. enero de 2000;53(1):1-12.

102. Wei JT, Dunn RL, Litwin MS, Sandler HM, Sanda MG. Development and validation of the expanded prostate cancer index composite (EPIC) for comprehensive assessment of health-related quality of life in men with prostate cancer. Urology. 20 de diciembre de 2000;56(6):899-905.

103. Esper P, Mo F, Chodak G, Sinner M, Cella D, Pienta KJ. Measuring quality of life in men with prostate cance using the functional assessment of cancer therapy-prostate instrument. Urology. diciembre de 1997;50(6):920-8.

104. Nuevo Modelo de Gestion de Casos de SSPA .pdf [Internet]. [citado 4 de junio de 2020]. Disponible en: http://www.asanec.es/pdf/borrador\%20del\%20Nuevo\%20Modelo\%20de\%20Gestion\%20de\%20Casos\%20 de\%20SSPA\%20.pdf

105. Casarin SNA, Villa TCS, Cardozo Gonzáles RI, Freitas MC de, Caliri MHL, Sassaki CM. Case management: evolution of the concept in the 80's and 9o's. Revista Latino-Americana de Enfermagem. julio de 2002;10(4):472-7.

106. Morales-Asencio JM. Gestión de casos y cronicidad compleja: conceptos, modelos, evidencias e incertidumbres. Enferm Clin. 1 de enero de 2014;24(1):23-34

107. Gilbert JE, Green E, Lankshear S, Hughes E, Burkoski V, Sawka C. Nurses as patient navigators in cancer diagnosis: review, consultation and model design: Nurses as patient navigators in cancer diagnosis. European Journal of Cancer Care. marzo de 2011;20(2):228-36.

108. Joo JY, Liu MF. Effectiveness of Nurse-Led Case Management in Cancer Care: Systematic Review. Clinical Nursing Research. noviembre de 2019;28(8):968-91.

109. McGlynn B, White L, Smith K, Hollins G, Gurun M, Little B, et al. A service evaluation describing a nurseled prostate cancer service in NHS, Ayrshire and Arran. Int J Urol Nurs. noviembre de 2014;8(3):166-80.

110. Lawrence L. Nurse-Led Prostate Cancer Clinic Examines Patient Anxiety [Internet]. Cancer Network. [citado 14 de junio de 2020]. Disponible en: https://www.cancernetwork.com/view/nurse-led-prostate-cancerclinic-examines-patient-anxiety

111. Casanovas-Blanco M, Mellado B, Reig O, González N, Serrahima A, Valverde M. Implementation of a urology cancer advanced practice nurse role in a Medical Oncology Genitourinary Cancer Clinics from a tertiary metropolitan hospital in Barcelona. Int J Urol Nurs. noviembre de 2019;13(3):117-8

112. Mahal BA, Butler S, Franco I, Spratt DE, Rebbeck TR, D'Amico AV, et al. Use of Active Surveillance or Watchful Waiting for Low-Risk Prostate Cancer and Management Trends Across Risk Groups in the United States, 2010-2015. JAMA. 19 de febrero de 2019;321(7):704-6.

113. Ong WL, Evans SM, Evans M, Tacey M, Dodds L, Kearns P, et al. Trends in Conservative Management for Low-risk Prostate Cancer in a Population-based Cohort of Australian Men Diagnosed Between 2009 and 2016. Eur Urol Oncol. 6 de mayo de 2019

114. Thomsen FB, Jakobsen H, Langkilde NC, Borre M, Jakobsen EB, Frey A, et al. Active Surveillance for Localized Prostate Cancer: Nationwide Observational Study. J Urol. 2019;201(3):520-7

115. Loeb S. Active Surveillance Offers Functional Advantages Without Impacting Survival for Low-risk Prostate Cancer. European Urology. junio de 2018;73(6):868-9.

116. Virseda Rodríguez AJ, Marcos Asensio S, Herrero Polo M, Hernández Sanchez T, Sanz Ruiz A, García F, et al. The impact of time from biopsy to radical prostatectomy on Gleason score undergrading and other related factors. Actas Urol Esp. 13 de diciembre de 2019;

117. Carlsson S, Benfante N, Alvim R, Sjoberg DD, Vickers A, Reuter VE, et al. Long-Term Outcomes of Active Surveillance for Prostate Cancer: The Memorial Sloan Kettering Cancer Center Experience. J Urol. 2020;203(6):1122-7.

118. Belun-Vieira I, McInness D, Sheriff MK. In the case of prostate cancer patients, are there advantages in cancer nurse-led follow-up?: A systematic review of the evidence. Int J Urol Nurs. noviembre de 2016;10(3):154-66.

119. Jeldres C, Cullen J, Hurwitz LM, Wolff EM, Levie KE, Odem-Davis K, et al. Prospective quality-of-life 
outcomes for low-risk prostate cancer: Active surveillance versus radical prostatectomy. Cancer. 15 de julio de 2015;121(14):2465-73.

120. Moon DH, Basak RS, Usinger DS, Dickerson GA, Morris DE, Perman M, et al. Patient-reported Quality of Life Following Stereotactic Body Radiotherapy and Conventionally Fractionated External Beam Radiotherapy Compared with Active Surveillance Among Men with Localized Prostate Cancer. European Urology. septiembre de 2019;76(3):391-7.

121. Gómez-Veiga F, Cozar JM, Günthner S, Puyol-Pallas M, Silmi-Moyano A, Rebollo FJ. [CAVIPRES questionnaire as a measurement of quality of life in patients with prostate cancer in Spain: Daily clinical practice application]. Actas Urol Esp. septiembre de 2010;34(8):686-93.

122. Hamoen EHJ, De Rooij M, Witjes JA, Barentsz JO, Rovers MM. Measuring health-related quality of life in men with prostate cancer: A systematic review of the most used questionnaires and their validity. Urol Oncol. febrero de 2015;33(2):69.e19-28.

123. Irfan M, Hussain NHN, Noor NM, Mohamed M, Sidi H, Ismail SB. Epidemiology of Male Sexual Dysfunction in Asian and European Regions: A Systematic Review. Am J Mens Health. agosto de 2020;14(4):1557988320937200.

124. Anderson J, Burney S, Brooker JE, Ricciardelli LA, Fletcher JM, Satasivam P, et al. Anxiety in the management of localised prostate cancer by active surveillance. BJU Int. noviembre de 2014;114 Suppl 1:55-61.

125. Burnet KL, Parker C, Dearnaley D, Brewin CR, Watson M. Does active surveillance for men with localized prostate cancer carry psychological morbidity? BJU Int. septiembre de 2007;100(3):540-3.

126. Donovan JL, Hamdy FC, Lane JA, Mason M, Metcalfe C, Walsh E, et al. Patient-Reported Outcomes after Monitoring, Surgery, or Radiotherapy for Prostate Cancer. N Engl J Med. 13 de octubre de 2016;375(15):1425-37.

127. Egger SJ, Calopedos RJ, O’Connell DL, Chambers SK, Woo HH, Smith DP. Long-term Psychological and Quality-of-life Effects of Active Surveillance and Watchful Waiting After Diagnosis of Low-risk Localised Prostate Cancer. European Urology. junio de 2018;73(6):859-67. 


\section{ANEXOS}

\section{ANEXO 1. CUESTIONARIO CAVIPRES}
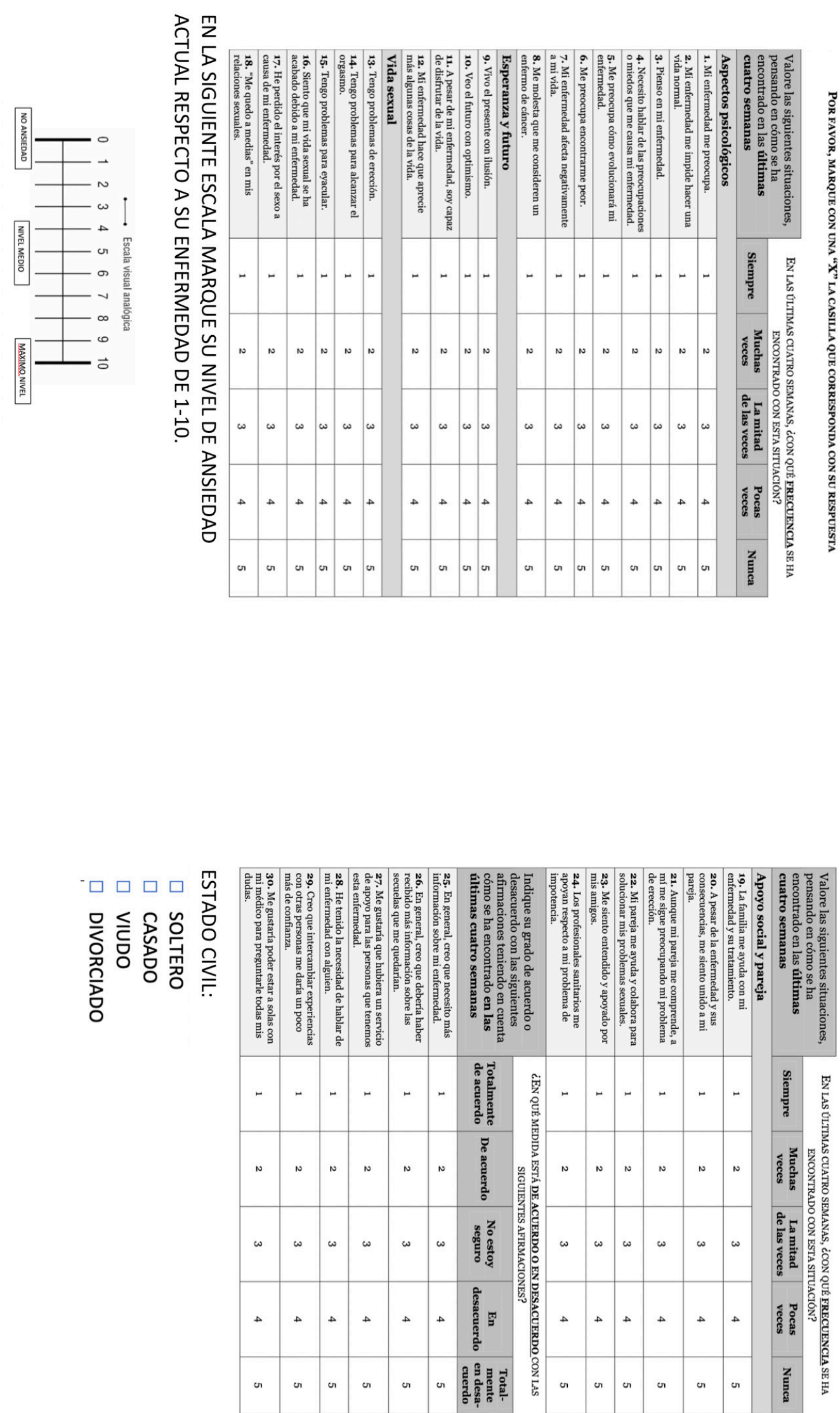

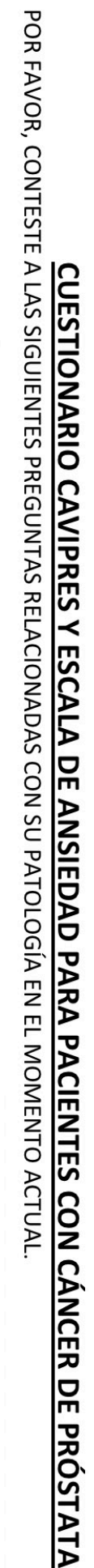

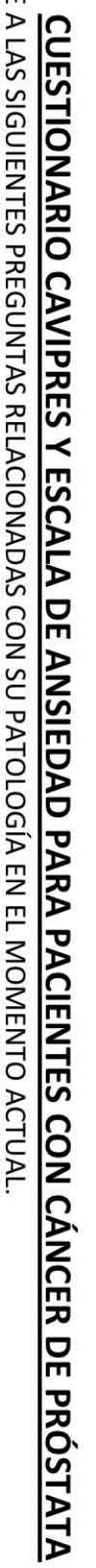

ANEXO II. APORTACIONES AL TEMA POR LA DOCTORANDA. ARTÍCULOS DE INVESTIGACIÓN EN REVISTAS.

Virseda-Rodríguez AJ, Marcos Asensio S, Núñez-Otero JJ., García F, Sanz A, Gutiérrez E, et al. [Diagnostic and therapeutic management in a series of 1156 patients with the diagnosis of prostate cancer in Castilla y Leon during 2014.]. Arch Esp Urol. junio de 2019;72(5):463-70.

Virseda Rodríguez AJ, Marcos Asensio S, Herrero Polo M, Hernández Sánchez T, Sanz Ruiz A, García F, et al. The impact of time from biopsy to radical prostatectomy on Gleason score undergrading and other related factors. Actas Urol Esp. 13 de diciembre de 2019;

Marcos Asensio S, Virseda Rodríguez AJ, Martín Izquierdo MM, Herrero Polo M, Coderque Mejía MP, Rocha de Lossada et al. La vigilancia activa en pacientes con cáncer de próstata localizado. Análisis de adherencia y salida del protocolo. Arch Esp Urol. Acepted Nov 20, 2020.

\section{COMUNICACIONES CONGRESOS}

\section{Congreso Nacional de Urología 2020}

- Análisis de factores relacionados con la progresión del grado de Gleason en la re-biopsia de una Serie de 228 pacientes incluidos en un Programa de Vigilancia Activa. Autores: Álvaro Julio Virseda Rodríguez; Sara Marcos Asensio; Alberto Rocha de Lossada; Manuel Herrero Polo; Mónica Paola Coderque Mejía; Javier García García; Teresa Hernández Sánchez; Andrea Noya Mourullo; Francisco Gómez García; Francisco Gómez Veiga.

- Análisis de la evolución de un Programa de Vigilancia Activa y de las causas de salida del mismo en los años 2014-2019 en un Hospital de cuarto nivel. Autores: Álvaro Julio Virseda Rodríguez; Sara Marcos Asensio; Manuel Herrero Polo; Alberto Rocha de Losada; Teresa Hernández Sánchez; Julio Herrera Puerto; Andrea Noya Mourullo; Francisco Gómez García; Oscar Heredero Zorzo; Javier García García; Francisco Gómez Veiga.

Simposio Proyecto Andrógeno Urología 2019

- Análisis de características diagnosticas ,tratamiento y supervivencia del cáncer de próstata avanzado en una consulta especializada de urología. Autores: Virseda Rodríguez, AJ; Marcos Asensio, S; Herrero Polo, M; Gómez Veiga, F. Premio a tercera mejor comunicación oral.

XXXVIII Congreso de la Confederación Americana de Urología (CAU) 2019

- Patrón de Discordancia Anatomopatológica y Cancer de Próstata ISUP3 o más, según los diferentes protocolos de Vigilancia Activa en una serie de 1260 prostatectomías. Autores: Virseda Rodríguez, AJ; Coderque Mejía, M.P; Hernández Sánchez, T; Rocha de Lossada, A; Noya Mourullo, A; Marcos Asensio, S; García García, J; Herrero Polo, M; Gómez Veiga, F.

Jornada Regional de Enfermería Urológica de Castillas y León 2019:

- Plan de cuidados de Enfermería para pacientes en el protocolo de Vigilancia Activa. Autores: Marcos Asensio, Sara, Hinchado Morgado, Sara; Virseda Rodríguez, A.J.; Rocha de Lossada, A; Noya Mourullo, A; Hernández 
Sánchez, T; García Gómez, F; Herrero Polo, M; Coderque Mejía, M.P; Gómez Veiga, F.

\section{Congreso Nacional de Urología 2019}

- Patrón de discordancia anatomopatológica y Cancer de Próstata Gleason 4+3 o superior según diferentes protocolos de vigilancia activa en una serie de 1260 prostatectomías. Autores: Virseda Rodríguez, A.J.; Marcos Asensio, S.; Polo López, C.; Sanz Ruiz, A.; Gala, A.; Vesga, F.; Barcina Valle, A.; Calleja Escudero, J.; López Aramburu, M.A.; Amón Sesmero, J.H.; Rodríguez, V.; Bermúdez, R.; Coderque Mejía, M.; Hernández López, T.; Valverde Martínez, S.; Gómez Veiga, F. 